November $2000 \quad$ • NREL/SR-570-28805

\title{
Biomass Energy Production in California: The Case for a Biomass Policy Initiative
}

\section{Final Report}

\author{
Gregory Morris \\ Green Power Institute \\ Berkeley, California
}

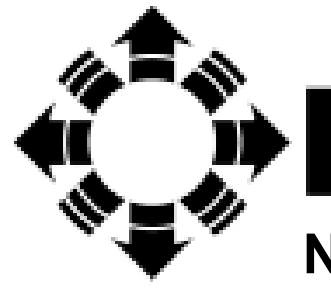

National Renewable Energy Laboratory

1617 Cole Boulevard

Golden, Colorado 80401-3393

NREL is a U.S. Department of Energy Laboratory

Operated by Midwest Research Institute • Battelle • Bechtel

Contract No. DE-AC36-99-G010337 
November $2000 \quad$ • NREL/SR-570-28805

\section{Biomass Energy Production in California: The Case for a Biomass Policy Initiative}

Final Report

Gregory Morris

Green Power Institute

Berkeley, California

NREL Technical Monitor: Richard Bain

Prepared under Subcontract No. AXE-9-18132

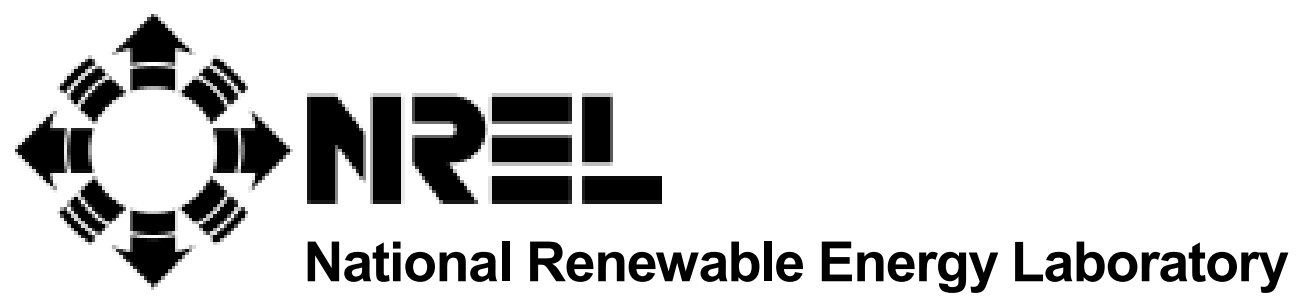

1617 Cole Boulevard

Golden, Colorado 80401-3393

NREL is a U.S. Department of Energy Laboratory

Operated by Midwest Research Institute • Battelle • Bechtel

Contract No. DE-AC36-99-G010337 


\section{NOTICE}

This report was prepared as an account of work sponsored by an agency of the United States government. Neither the United States government nor any agency thereof, nor any of their employees, makes any warranty, express or implied, or assumes any legal liability or responsibility for the accuracy, completeness, or usefulness of any information, apparatus, product, or process disclosed, or represents that its use would not infringe privately owned rights. Reference herein to any specific commercial product, process, or service by trade name, trademark, manufacturer, or otherwise does not necessarily constitute or imply its endorsement, recommendation, or favoring by the United States government or any agency thereof. The views and opinions of authors expressed herein do not necessarily state or reflect those of the United States government or any agency thereof.

Available electronically at http://www.doe.gov/bridge

Available for a processing fee to U.S. Department of Energy

and its contractors, in paper, from:

U.S. Department of Energy

Office of Scientific and Technical Information

P.O. Box 62

Oak Ridge, TN 37831-0062

phone: 865.576.8401

fax: 865.576.5728

email: reports@adonis.osti.gov

Available for sale to the public, in paper, from:

U.S. Department of Commerce

National Technical Information Service

5285 Port Royal Road

Springfield, VA 22161

phone: 800.553.6847

fax: 703.605.6900

email: orders@ntis.fedworld.gov

online ordering: http://www.ntis.gov/ordering.htm

Printed on paper containing at least $50 \%$ wastepaper, including $20 \%$ postconsumer waste 
Biomass Energy Production in California: The Case for a Biomass Policy Initiative

Page

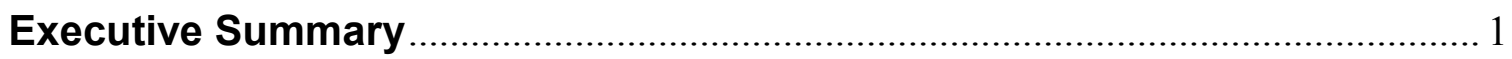

Introduction

The California Biomass Energy Industry ………........................................... 6

Development of the California Biomass Energy Industry ................................................ 6

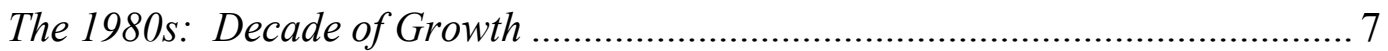

The 1990s: Maturity, Consolidation ................................................................... 10

Characteristics of California's Biomass Power Plants ......................................... 15

Fuel Use and Alternative Disposal Options for Biomass Residues in California.............. 16

Wood Processing Residues............................................................................. 17

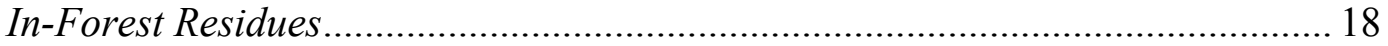

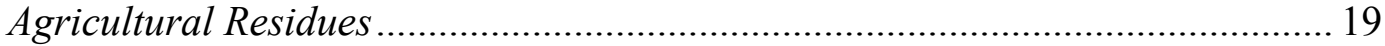

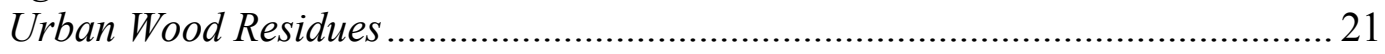

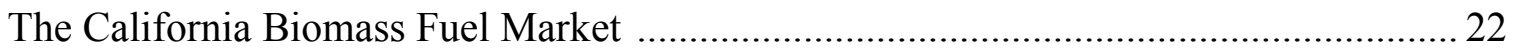

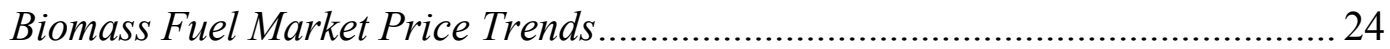

The Environmental Costs and Benefits of Biomass Energy Production ......28

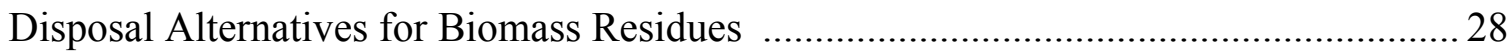

Sources of Impacts Associated with Biomass Residue Disposal...................................... 30

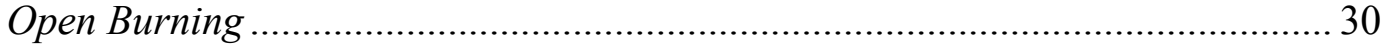

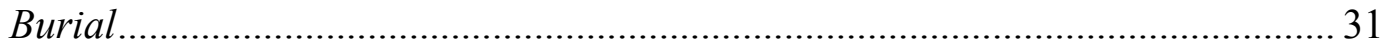

Spreading and Composting ............................................................................... 33

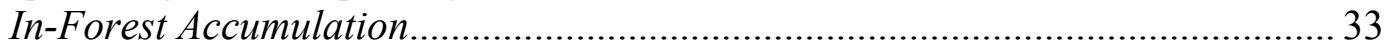

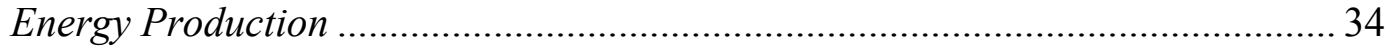


Magnitude of the Impacts of Biomass Disposal Alternatives ............................................. 35

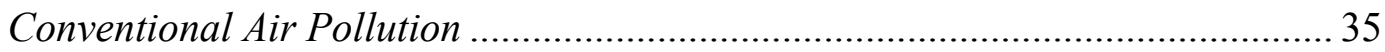

Greenhouse Gases and Climate Change.............................................................. 38

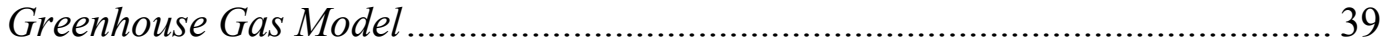

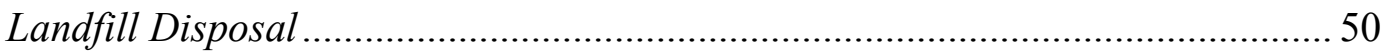

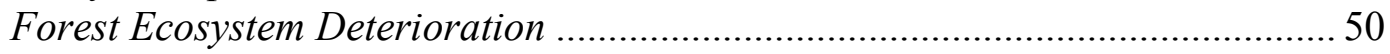

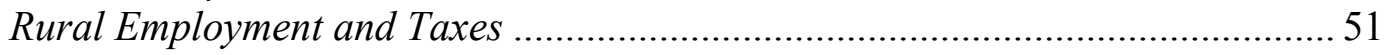

The Benefits of Energy Diversity and Domestic Supply.....................................52

The Economic Value of the Benefits of Biomass Energy Production .............................. 52

Values of Environmental Impacts .........................................................................5 53

Value of the Social Benefits of Biomass Energy Production .................................57

Net Value of the Ancillary Services of Biomass Energy Production...................... 58

\section{The Economic Predicament for Biomass Energy Production ......................... 61}

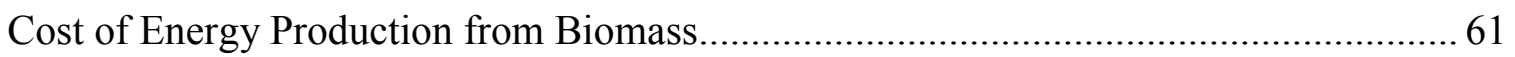

The Market for Energy Generated from Biomass Resources ........................................... 62

The Magnitude of the Need for Biomass Policy Support ................................................ 64

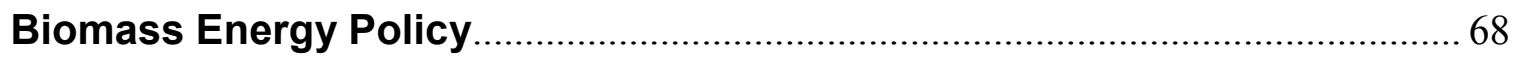

Approaches to Crafting a Biomass Energy Policy .............................................................. 68

Broad-Based Policies for Biomass ……………………....................................... 70

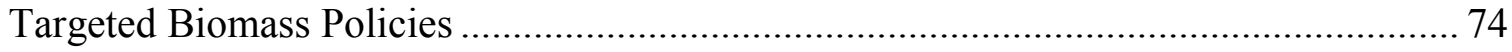

Measures Applicable to Urban Biomass Fuels .................................................. 74

Measures Applicable to Agricultural Biomass Fuels.......................................... 76

Measures Applicable to In-Forest Biomass Fuels ............................................. 78

The Costs and Benefits of Policy Support for Biomass Energy Production ...................... 80

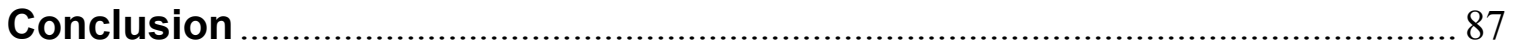

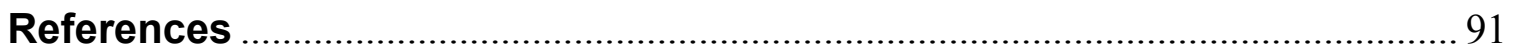


$\underline{\text { Page }}$

\section{List of Tables}

$1 \quad$ California Biomass Power Plants ................................................................. 14

$2 \quad$ Alternative Fates for Biomass Residues............................................................ 29

3 Emissions Factors for Energy Production and Biomass Disposal ........................ 37

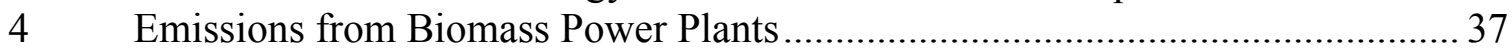

$5 \quad$ Biomass Greenhouse Gas Emissions Model ...................................................... 43

$6 \quad$ Greenhouse Gas Emissions Factors ……………............................................. 47

$7 \quad$ Values of Environmental Pollutants....................................................................5

8 Environmental Benefits of the California Biomass Energy Industry.....................58

9 Value of the Environmental Benefits of the

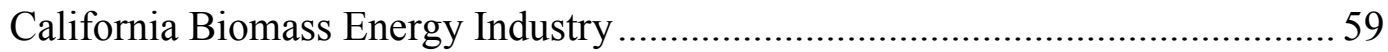

10 Average Cost of Biomass Fuel Production in California.........................................62

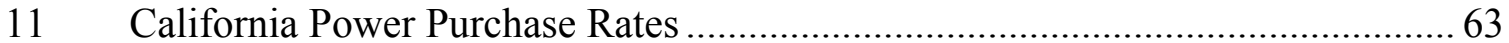

12 Cost Shifting Needs for Biomass Power Production .............................................65

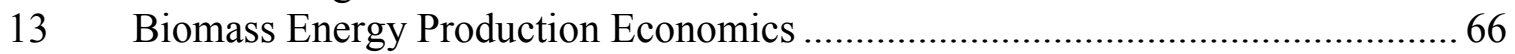

14 Biomass Energy Production Economics, Post Transition......................................67 67

15 Policy Measures for Biomass Energy Production.................................................. 69

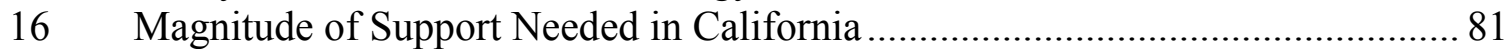

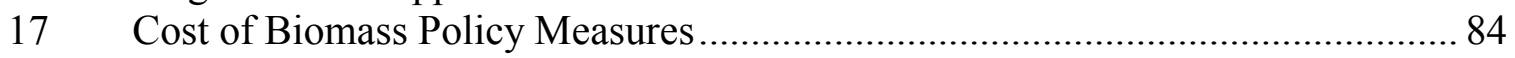

\section{List of Figures}

$1 \quad$ California Biomass Power Plants, 1985 …………….................................. 7

2 California Biomass Power Capacity ……………………………………….... 8

3 California Biomass Power Plants, 1990 ………………............................... 9

$4 \quad$ California Biomass Power Plants, 2000 ......................................................... 13

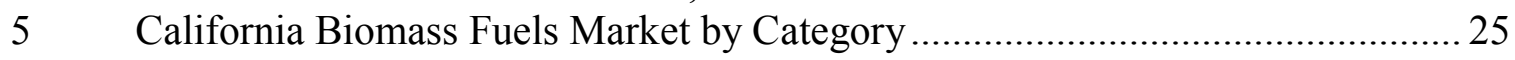

$6 \quad$ California Biomass Fuels Market....................................................................... 26

$7 \quad$ California Biomass Fuels Supply Curve, 1986-2000 ........................................ 27

$8 \quad$ Stocks and Flows in GHG Model .................................................................. 40

9 Atmospheric GHG Benefit of Biomass Energy Production................................... 42

10 GHG Burden from Biomass Disposal Options …………................................... 45

11 GHG Profile, California Biomass Fuels Used 1980 - 1999 ................................. 48

12 GHG Benefit from California Biomass Production .............................................. 49

13 Scenarios for Future Biomass Energy Production in California ........................... 88 


\section{Executive Summary}

California has a great diversity of agriculture and forestry, activities that produce large amounts of solid wastes and residues. During the 1980s California developed the largest and most diverse biomass energy industry in the world. Biomass energy production has become an important component of the state's environmental infrastructure, diverting solid wastes from open burning and disposal in landfills to a beneficial use application. The social and environmental benefits of biomass energy production are worth far more than the electricity produced, but these benefits are not compensated in the competitive marketplace. This puts them at risk, that can be legitimately addressed through public policy.

AB 1890, the 1996 landmark legislation that deregulated the electric utility industry in California, explicitly recognized the unique benefits of biomass energy production and directed that steps be taken to: “... bring about equitable and effective allocation of solidfuel biomass electricity costs that ensure the retention of the economic and environmental benefits of the biomass industry (AB 1890, Section 389)." This report provides the background information and analysis that are prerequisite to the development of effective public policy in this area, presents policy options that fulfill the intent of AB 1890 and ensure the long-term future of biomass energy production in California.

The report begins by describing the history of the biomass energy industry in California, and the current circumstances that confront the enterprise. It analyzes the contribution biomass energy production makes to the state's environmental wellbeing, and demonstrates that the cost of providing long-term stability to the industry is much smaller than the value of the social and environmental benefits that would be secured. A public policy approach is presented that would provide the incentives necessary to ensure the future of biomass energy production in California and apply to biomass energy production across the United States as well.

At its peak during the early 1990s, the California biomass industry was converting 10 million tons/year of biomass residues into $2 \%$ of the state's electricity supply. However, changing circumstances, highlighted by deregulation of the electric utility industry, led to a 35\% reduction in biomass energy production between 1994 and 1996. Biomass energy production could shrink even more when currently available renewable energy production credits, which are part of the state's electric utility deregulation plan, disappear at the end of 2001.

Biomass energy production is inherently more expensive than energy generation using fossil fuels. More than 3.5 million tons/year of biomass residues that were being used as fuel in California just a few years ago are again being landfilled, open burned, or allowed to remain as overgrowth in the state's forests. This represents a serious setback to efforts 
to comply with current and anticipated air quality standards and solid waste regulations, and to implement the preventive measures called for in the state's strategic fire plan.

California's biomass energy industry currently consists of 29 operating power plants located throughout the state, representing a total of $600 \mathrm{MW}$ of generating capacity. These facilities convert more than 6.4 million tons/year of biomass into electricity, diverting it from less desirable disposal alternatives. An additional 14 facilities, with a total generating capacity of $165 \mathrm{MW}$, are currently idle but capable of resuming operations if economic conditions warrant. The operating facilities and their fuel supply infrastructure directly employ about 2,000 people, providing valuable rural employment and economic development opportunities.

Almost half the fuel currently used by the state's biomass energy industry would be disposed of by burial in sanitary landfills if the fuel-use option were not available. California law (AB 939) mandates a reduction in landfill disposal of $50 \%$ by the end of 2000, compared to the baseline year of 1990. If the biomass energy industry were to fail, disposal of the additional wood wastes would pose a serious impediment for many counties to comply with the law. Landfill disposal of waste wood leads to a variety of adverse environmental impacts, including leachates that threaten groundwater quality, delayed stabilization of the fill, and emissions of odors, volatile organic compounds (VOCs), and greenhouse gases. The greenhouse gas burden of landfill burial of biomass exceeds that of energy production within three to four years of the disposal of the material, and grows to three times greater by the end of fifteen years, or $50 \%$ greater in the case of a gas-controlled landfill.

More than a quarter of the biomass fuel currently used in the state would be open burned in the absence of a fuel use application. Biomass residues are extensively open burned in the agricultural sector as the low-cost disposal option for these materials, and in the forestry industry as a method to reduce the forest fire risks associated with harvesting slash. Open burning is a quick but dirty way to get rid of biomass wastes. Massive amounts of smoke and other pollutants are emitted, which are major contributors to air quality degradation in many agricultural and mountain regions. Controlled combustion and emission controls in the power plants reduce the amounts of air pollution associated with the disposal of these residues by orders of magnitude.

Almost $10 \%$ of the state's biomass fuel supply is material that would add to the accumulation of fuel loading in the state's forests if the energy application were not available. Forest fuel overloading is well recognized as a major environmental problem in California. Land managers simply do not have the resources to deal meaningfully with the problem. A century's worth of success in fighting fires, combined with poor forestry practices, have led to a long-term, extensive build up of biomass in the state's forests. The overstocked biomass threatens forest health, reduces the amount and quality of water production in watersheds, and increases the risk of catastrophic wildfires that cause widespread environmental harm and property damage. 
The only methods available to reduce fuel loading in the state's forests are prescribed burning and thinning combined with fuel production. Prescribed burning causes heavy air pollution, and entails a risk of uncontrolled fire breakout. The result is that the amount of prescribed burning that can be performed in the most densely overgrown forests is very limited. Land managers in California benefit greatly by having a healthy biomass fuels market as an outlet for promoting thinning operations in the forests.

The ancillary social and environmental services provided by biomass energy generation in California include avoiding landfilling and open burning of biomass residues, improving forests and watersheds, and providing of rural development and employment opportunities. The economic value of just the quantifiable ancillary environmental benefits provided by biomass energy generation is estimated to be more than $10 \phi / \mathrm{kWh}$, which is several times greater than the value of the electricity produced. This makes the viability of biomass energy generation in California a legitimate matter of public policy concern.

Until now, the ancillary services that are provided by the biomass energy industry have been paid for by California's electricity customers. In the new era of a competitive market for power generation this may no longer be possible, as demonstrated by the loss of $35 \%$ of the benefits once provided by the biomass industry since the beginning of the deregulation process. The cost of generating energy from biomass in California is 6.0$7.5 \notin / \mathrm{kWh}$, while biomass generators with standard offer power purchase agreements earn revenues of approximately $5.0 \mathrm{k} / \mathrm{kWh}$ (energy and capacity combined). The production credits currently available through the state's renewables transition program have allowed the biomass energy industry to increase production slightly since the beginning of deregulation, but these credits are scheduled to expire at the end of 2001. No federal credits or subsidies will be available to the biomass energy industry after 2001 . In the long term the industry will have to receive some type of consideration for the environmental benefits it provides, or it will not be able to continue to operate in its present form.

A number of policies have been proposed to enhance the viability of biomass energy generation in California. Some are applicable to all types of biomass fuels; others are targeted at particular categories of residues, such as agricultural and in-forest residues. The proposed strategies include:

- Production credits and tax credits to generators and fuel suppliers

- Mandated requirements for the purchase of electricity generated from biomass

- Allocated funds for activities that produce biomass fuels (for example, for fire prevention treatments and the diversion of residues from agricultural burning)

- Liberalized diversion credit accounting rules for AB 939

The goal of the policies, in the aggregate, is to provide enough incentives to preserve (and even expand) the production of renewable biomass energy in California. The cost of measures to preserve the biomass energy industry is far less than the value of the social 
and environmental benefits that are thereby secured. These benefits, however, are public goods, which are not rewarded through the mechanism of the competitive electricity market. Thus, the preservation of these desirable benefits falls clearly within the realm of legitimate public policy actions.

An overall support program for the entire industry is necessary to preserve the viability and flexibility of biomass energy production in California. With the overall enterprise ensured, targeted measures that promote the use of particular types of residues to address specific environmental issues are entirely appropriate and productive. Targeted policies are needed in three areas in particular to promote:

- The diversion of orchard prunnings from open burning

- The diversion of urban wood waste from landfill disposal

- The pursuit of forest treatment operations to reduce the risks of wildfires and enhance watershed and ecosystem health throughout the state

Enacting a set of policies to promote biomass energy production in California will entail costs that are a small fraction of the value of the environmental services being retained. This report presents a detailed analysis of the need for a biomass energy policy initiative in California, and the social and environmental benefits it would ensure. 


\section{Introduction}

California has long been a catalyst and innovator in the development of renewable energy sources. Strong state incentives for renewable energy development were enacted during the early 1980 s to match the then recently enacted federal incentives. These incentives, combined with favorable market conditions, led to the development of more than 60 biomass energy generating facilities during an approximately 15 year period. Biomass fuels were produced from traditional sources such as residues from sawmills and food processing plants, and from new sources such as urban wood residues diverted from landfill disposal, and orchard prunings diverted from open burning. In all cases the use of these materials as fuels has helped improve environmental quality in California. However, these environmental gains are in grave risk of being lost to the emerging competitive electricity market, unless policy solutions are developed to maintain the viability of the enterprise. The cost of these solutions is only a small fraction of the benefits they would secure.

The first section of this report describes the development and maturation of the California biomass energy industry over its first two decades of operation, and the commercial environment it confronts as it enters the twenty-first century. The state's biomass fuels market, which forms the basis of the industry, is characterized and analyzed. Alternative disposal options for the residues are identified and described.

The second section describes the environmental impacts associated with biomass energy production in California. The impacts associated with energy production from biomass are balanced against those associated with the alternative disposal fates for the residues, as well as those associated with alternative production of the energy. Major impact categories associated with biomass disposal are identified and characterized, and the values of the impacts are estimated using contemporary values for environmental impact categories.

The third section describes the economics of biomass energy production in California. The costs of biomass energy production are analyzed, and the markets for biomass residues and energy products are characterized. The economic needs of the enterprise are then determined.

The final section describes the policy dilemma and options available at the state and federal levels to support the continued production of energy from biomass in California. A state biomass policy is indicated as a justifiable and beneficial means of ensuring that California is provided with the full range of services that biomass energy production offers. These services include improved air quality, reduced loading of landfills, reduced greenhouse gas emissions, and improved health and productivity and decreased wildfire risks in the state's forests. 


\section{The California Biomass Energy Industry}

California has the largest and most diverse biomass energy industry in the world. At its peak the California biomass energy industry produced almost 4.5 billion kWhs per year of electricity, and provided a beneficial use outlet for more than 10 million tons per year of the state's solid wastes. The peak, however, occurred during the early 1990s. Since that time a quarter of the biomass energy facilities have agreed to buyouts of their power sales contracts and terminated operations, while others have reduced their operations. This has occurred because of concerns about the long-term viability of these facilities in a competitive, deregulated electricity market. This uncertainty casts an ominous cloud over the future viability of biomass energy generation in California.

\section{Development of the California Biomass Energy Industry}

California has a diversity and extent of agriculture and forestry unrivaled in the world. Both activities produce large quantities of solid wastes, many of which are biomass residues that can be used as fuel. Before the federal Public Utilities Regulatory Policy Act (PURPA) was passed in 1978 only a few biomass-fired boilers were operating in California, and little electricity was being generated from biomass. Most of the state's biomass wastes were being disposed of, mainly by open burning and landfill burial. PURPA changed all that by requiring that electric utility companies buy privately produced power at their "avoided cost" of generation. PURPA created the market context that allowed for the development of the independent power industry in the United States. High avoided cost rates in many areas of the country, and favorable federal tax treatment for investments in renewable energy projects, provided the motivation for its development.

California was a leader in the development of renewable energy generating facilities. A combination of circumstances, including a high growth rate in electricity demand, oil dependence, and rising concerns about environmental deterioration led to the implementation of state energy policies that were highly conducive to the development of renewable energy sources. These policies and opportunities stimulated a major development of biomass energy generating capacity in the state. During a period of less than 15 years (roughly 1980-1993) nearly 1,000 MW of biomass generating capacity were placed into service. The biomass energy sector expanded from an outlet for a small quantity of the state's wood processing residues, to an essential component of the state's solid-waste disposal infrastructure. Today the California biomass energy industry provides a beneficial use for almost 6.5 million tons of the state's solid wastes. However, it has a highly uncertain future. The expiration of fixed-price power sales provisions for many facilities, combined with the deregulation of the electric utility industry and the current availability of cheap natural gas, threaten its long-term economic viability. 


\section{The 1980s: Decade of Growth}

The early 1980s mark the nascent period for the California biomass energy industry. During this period several pioneering biomass energy generating facilities were built and placed into service. The early facilities tended to be small, generally 2-10 MW, and most were associated with sawmills or food processing operations that were looking for beneficial use outlets for their wastes. Figure 1 shows a map of the state's operating biomass energy facilities at the end of 1985 .

Figure 1

California Biomass Power Plants, 1985

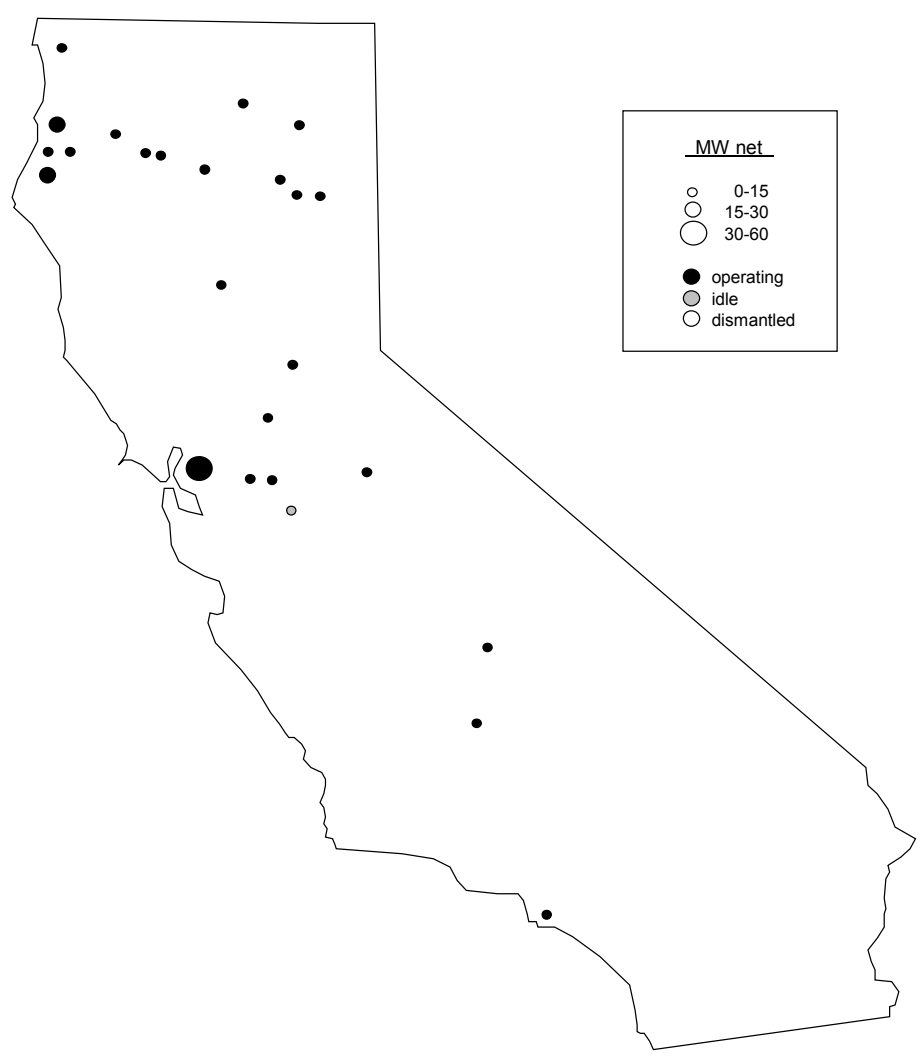

Also during the early 1980s, the California electric utility companies developed standard offer contracts for power purchases from independent generators. These contracts had particularly favorable provisions for renewable energy projects. A great deal of biomass project development activity was initiated during this period, which led to an explosion of new facility openings during the second half of the decade.

The California biomass energy industry became an important part of the state's electricity supply infrastructure, and its waste disposal infrastructures during the second half of the 1980s. The incentives for renewable energy development that were offered during the first half of the decade led to the opening of 33 new biomass generating facilities between 1985 and 1990. A few of the pioneering facilities were shut down during this period, but 
the state's total operating biomass energy capacity grew by more than $650 \mathrm{MW}$. The average size of the facilities brought on line during this period was about $17.5 \mathrm{MW}$; the largest facilities were $50 \mathrm{MW}$. The explosive growth of biomass generating capacity culminated in 1990, when 11 new facilities were commissioned in a single year, adding $232 \mathrm{MW}$ of biomass generating capacity to the state's electricity supply. Figure 2 graphically illustrates the development of the biomass energy generating industry in California from 1980 to the present. Figure 3 shows a map of the state's installed biomass power infrastructure as of the end of 1990.

Figure 2

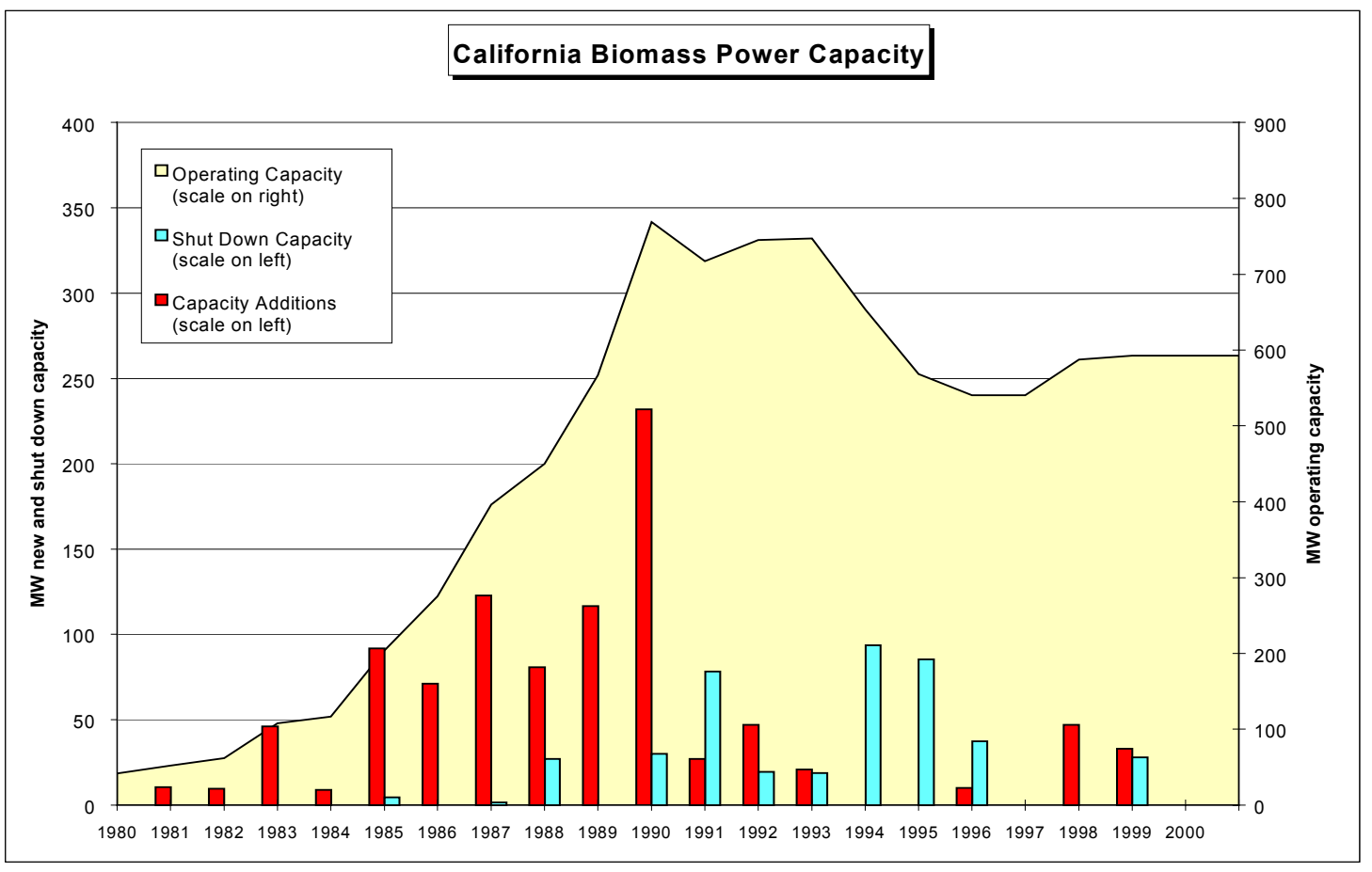

Many of the facilities that entered service during the late 1980s had Interim Standard Offer No. 4 (SO\#4) power purchase agreements (PPAs) with the state's two major electric utility companies, Pacific Gas and Electric Co. (PG\&E), and Southern California Edison (SCE) Co. The SO\#4s were the most favorable contracts available to independent project developers in California. These contracts were available for signing only during 1984 and 1985, and contract holders were given 5 years to bring their facilities into operation. The most significant feature of the SO\#4s was an option for energy sales from electricity generated from renewable resources to be based on a forecasted schedule of energy prices for the first 10 years of facility operations, rather than being subject to fluctuating, short-term prices. These schedules were based on the high avoided cost rates then in effect $(5 \phi-6 \phi / \mathrm{kWh})$, and an expectation that rates would remain high throughout the terms of the agreements. At the completion of the 10-year fixed price period generators are compensated based on the then current market price, which is called the short-run avoided cost (SRAC). 
Figure 3

California Biomass Power Plants, 1990

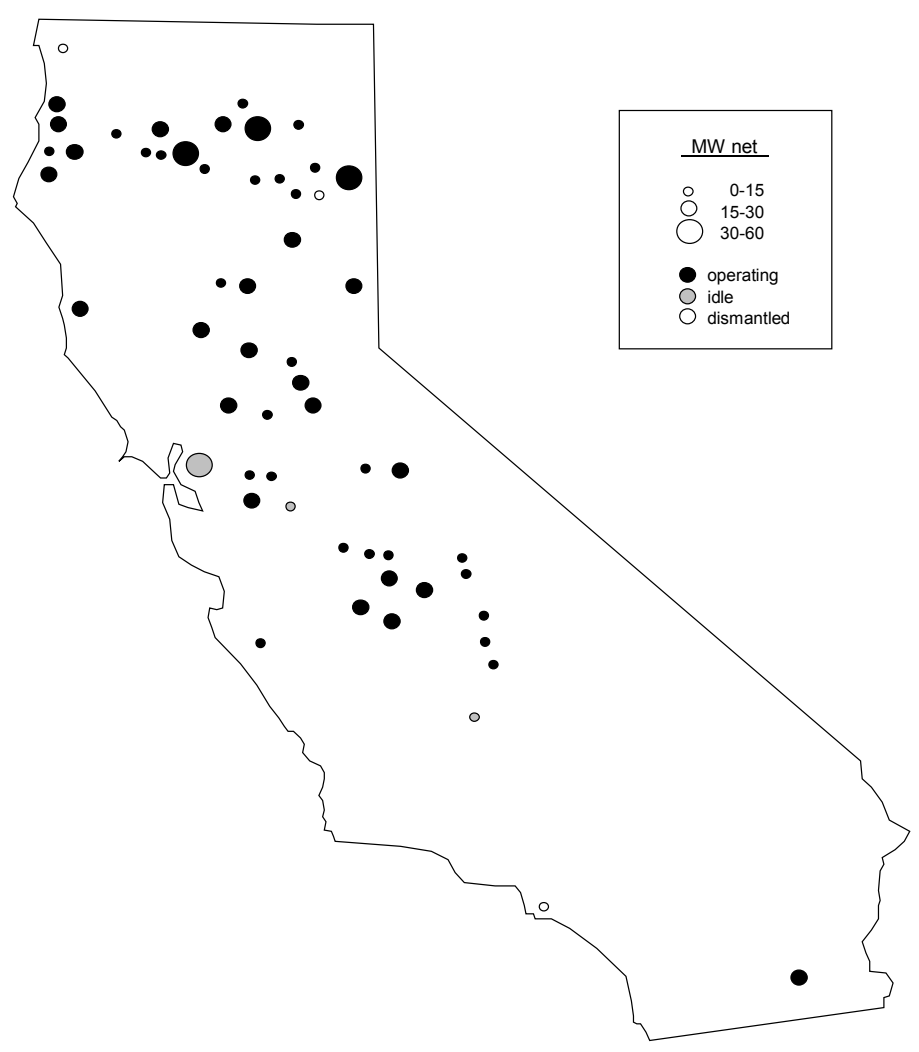

The SO\#4 power purchase provisions for biomass energy facilities were designed to encourage the development of base-load generators that would provide the power grid with dependable generating capacity during peak demand periods, which are summer weekday afternoons. Most of the contracts were written with 30-year firm capacity terms of performance, which obligate biomass facilities to generate at their contract capacity at least $80 \%$ of the time during defined peak hours of the year, for the entire term of the agreement. Payments to generators for providing firm capacity are levelized over the contract term, and confer a significant liability on generators that do not operate for the entire of the agreements.

The second half of the 1980s was also significant for a reversal in world oil markets. World oil prices, which had remained high since the price explosions of the 1970s, collapsed during the period 1985-1986. SRACs in California fell by 50\% over an 18month period. Most biomass power plants, however, were immune to the decline in SRAC rates during this period, because they received fixed-schedule rates under their contracts, based on early 1980s energy prices.

The attention of the biomass generating facilities focused instead on a looming crisis in the biomass fuels market. As the state's installed biomass generating capacity grew rapidly during the later half of the 1980s, the demand for fuel soon overwhelmed the 
readily available supply. Virtually all sawmill and food processing residues that did not have higher valued uses were being sold into the fuel market, and still there was a significant deficit between biomass supply and demand. Numerous efforts were under way to develop technologies to produce biomass fuels from new sources of supply, such as agricultural prunings, agricultural field residues, forestry residues, and urban waste wood, with rising fuel prices providing the incentive. The state's biomass fuels crisis peaked in 1990 with average prices topping \$40/bdt ${ }^{*}$ of fuel, and spot prices reaching $\$ 60 /$ bdt or higher. Moreover, several major new facilities were approaching the completion of construction, and there was a fear that biomass fuel prices might continue to rise.

\section{The 1990s: Maturity, Consolidation}

At the end of 1990 more than 770 MW of biomass energy generating capacity were operating in California, and an additional $100 \mathrm{MW}$ of capacity were in advanced stages of construction. The early years of the 1990s saw the state's biomass energy industry stabilize at a level of about $750 \mathrm{MW}$ of operating capacity. During this period the startup of the last of the SO\#4 facilities was balanced by the retirement of several pre-SO\#4 facilities, many of which had serious design flaws or operational problems. 1993 also saw the first retirement and dismantling of a facility with an SO\#4 contract. This was a facility that had been beset with technical and operational problems that prevented its profitable operation.

The California biomass fuels market also stabilized during the early 1990s, with average market prices settling at a level of about $\$ 37.50 / \mathrm{bdt}$, at an average consumption level of approximately 9 million tons per year. This stability was reached despite the beginning, in 1990, of a long-term decline in the state's wood products industry, which was caused by a combination of environmental restrictions and economic conditions. This is significant because wood processing residues are the lowest-cost biomass fuels in the state. By the end of 1993 the biomass energy industry appeared to have attained a level of maturity, and a workable equilibrium between fuel supply and fuel demand had been established. Although there were winners and losers, the California biomass energy industry as a whole successfully weathered the storm of the fuel crisis that marked the beginning of the decade.

The stability, however, was short lived. In April 1994 the California Pubic Utilities Commission (CPUC) issued its landmark Blue Book proposal for restructuring the state's regulated electric utility industry (CPUC 1994). The Blue Book proposal provided for competition among generating sources on the basis of price alone, without regard to nonmarket factors such as resource diversity and environmental impact. This represented a major threat to biomass energy generation. Because of the low density of biomass fuels

\footnotetext{
* bdt $=$ bone-dry ton equivalent, a unit of measure used for biomass fuels. A bdt refers to an amount of material that contains a ton of moisture-free biomass fiber. Generally, 1 bdt is equivalent to 1.2-2.4 actual, or green tons of biomass. In this paper the term ton used alone refers to green tons of biomass, and bdt refers to bone-dry ton equivalents of biomass.
} 
and the resultant high handling and transportation costs, the relatively small size of biomass generating facilities, and the low cost of natural gas, the cost of power production from biomass was inherently higher than the cost of power generation using natural gas. Competition based on price factors alone would not favor biomass energy generation.

The most immediate effect of the Blue Book restructuring proposal for the biomass energy industry was that it provided an incentive for the state's regulated electric utility companies to buy out the SO\#4 PPAs held by the biomass generators in their service territories. Many biomass generators were receptive to these offers because of their concern about their own long-term liabilities to the utility companies in connection with the firm-capacity obligations in their contracts. Over the next 3 years 17 biomass facilities, rated collectively at more than $215 \mathrm{MW}$, accepted buyout offers and shut down operations.* Unlike in earlier years, when only marginal facilities were closed, most of the facilities that shut down following the issuing of the Blue Book proposal were firstrate facilities that had been operating efficiently and profitably until the buyouts of their PPAs.

Annual biomass fuel use in the state shrank by $37 \%$ during the 2 years following the appearance of the Blue Book proposal. More than 3 million tons/year of biomass residues that were being used for energy production in the early 1990s were returned to open burning and landfilling for disposal. In addition, at its peak the state's biomass industry was supporting forest treatment operations on approximately 60,000 acres/year of forest land that was not otherwise being commercially harvested or treated. These treatments reduce the risk of destructive wildfires and improve the health and productivity of the thinned forest. With the retraction in the demand for biomass fuels the amount of this type of forest treatment activity has declined dramatically.

The CPUC's original restructuring proposal underwent a process of refinement that lasted for more than 2 years. By the summer of 1996 the CPUC had acknowledged the desirability of incorporating environmental factors into the choice of energy sources, and embraced the concept of a minimum purchase requirement for renewable energy sources. A working group made up of the utility companies, independent power generators, and public interest groups worked on formulating a consensus proposal to the CPUC to implement a minimum renewables purchase requirement for California's regulated electric utility sector (Morris et. al. 1996). The biomass industry, which pioneered the concept of a renewables portfolio standard (RPS), played a key role in this process.

\footnotetext{
* One of the 17 facilities was sold and restarted during this period. This facility was purchased by a buyer who intended to operate it at about one-half of its rated capacity, supplying steam and electricity to an overthe-fence industrial customer. Two other shut-down facilities, which only sold out the remaining fixedprice period of their PPAs, have since restarted. The other 14 facilities that were shut down during this period remain shut down today.
} 
In late August 1996, just before the end of the state legislative session, the California legislature formulated its own electric utility restructuring program, superseding the efforts of the CPUC. The legislation that emerged, AB 1890, included a program of short-term support for renewable energy during the 4-year transition period (1998-2001) to full implementation of restructuring. However, no long-term support program for renewables was included. AB 1890 explicitly recognized the special waste disposal benefits associated with biomass energy in California. The legislation directed the California Environmental Protection Agency (Cal/EPA) to study policies that would shift some costs of biomass energy production away from the electric ratepayer, and onto the beneficiaries of the waste disposal services it provides. Cal/EPA was directed to report to the legislature on biomass cost-shifting measures by April 1997.

Cal/EPA had difficulty coming to grips with this political football. Two of the principal agencies under the Cal/EPA umbrella, the California Air Resouces Board and the California Integrated Waste Management Board (CIWMB), had obvious interests in the outcome of the process. In addition, agencies outside Cal/EPA, such as the California Department of Forestry and Fire Prevention and the California Energy Commission, also have a strong interest in policies affecting biomass energy production. Rather than take the lead itself, Cal/EPA assigned the task to the Waste Board. CIWMB convened a series of public workshops, during which they solicited research and information about the public benefits of biomass energy production, and policy proposals to support continued biomass energy production. A great deal of public input was received, which the agency tried to distill into a report to the legislature within a very tight timeframe. At some point a decision seemed to have been made that any information that caused interagency disagreements would be removed from the report. The result was a watered-down report that provided the legislature with no basis for enacting the kinds of cost-shifting policies for biomass envisioned in $\mathrm{AB} 1890$.

The legislature made one more attempt to develop the background necessary for the developing biomass support policies in California. In 1998, AB 2273 was passed and signed into law. AB 2273 directs Cal/EPA to report annually to the legislature on progress in developing biomass cost-shifting policies in the state. CIWMB was assigned the lead role in developing the first report under this legislation. Although a report was prepared in early 1999 and sent to the Cal/EPA Board for approval, it was never released and sent to the legislature.

Despite the cloud of uncertainty over the future viability of biomass energy production in California, the state's biomass energy industry has operated with relatively stability during the latter half of the 1990s. Following the shutdowns of 1994-1996, 27 biomass facilities, representing $540 \mathrm{MW}$ of generating capacity, remained in operation. Twenty operated under intact SO\#4s. The other seven had special circumstances, such as a captive fuel supply or an ability to earn retail-offset for most or all of their electricity output, that allowed them to continue operating. The fixed-price periods in the SO\#4 PPAs came to an end at the end of the 1990s, but the renewables transition fund created 
by $\mathrm{AB} 1890$ offered biomass generators a supplement of $1.5 \mathrm{k} / \mathrm{kWh}$ for facilities that did not receive SO\#4 fixed-scheduled prices for their sales of electricity.

The operating biomass energy generating capacity in California actually increased slightly at the end of the 1990 s, to almost $600 \mathrm{MW}$. This was mainly because two 25 MW facilities that had accepted contract buyouts and shut down operations in 1994 had special provisions in their buyouts that provided for restarting the facilities at the end of their fixed-price periods. These facilities resumed operations in 1998 and 1999, respectively. Biomass fuel use increased by $15 \%$ over its low point following the 19941996 shutdowns, but was still more than 30\% lower than the peak level achieved during the early part of the decade. Table 1 shows a list of all the biomass energy generation facilities that have operated in California since 1980. Figure 4 shows a current map of the California biomass energy facilities, keyed to the list of facilities in Table 1.

Figure 4

California Biomass Power Plants, 2000

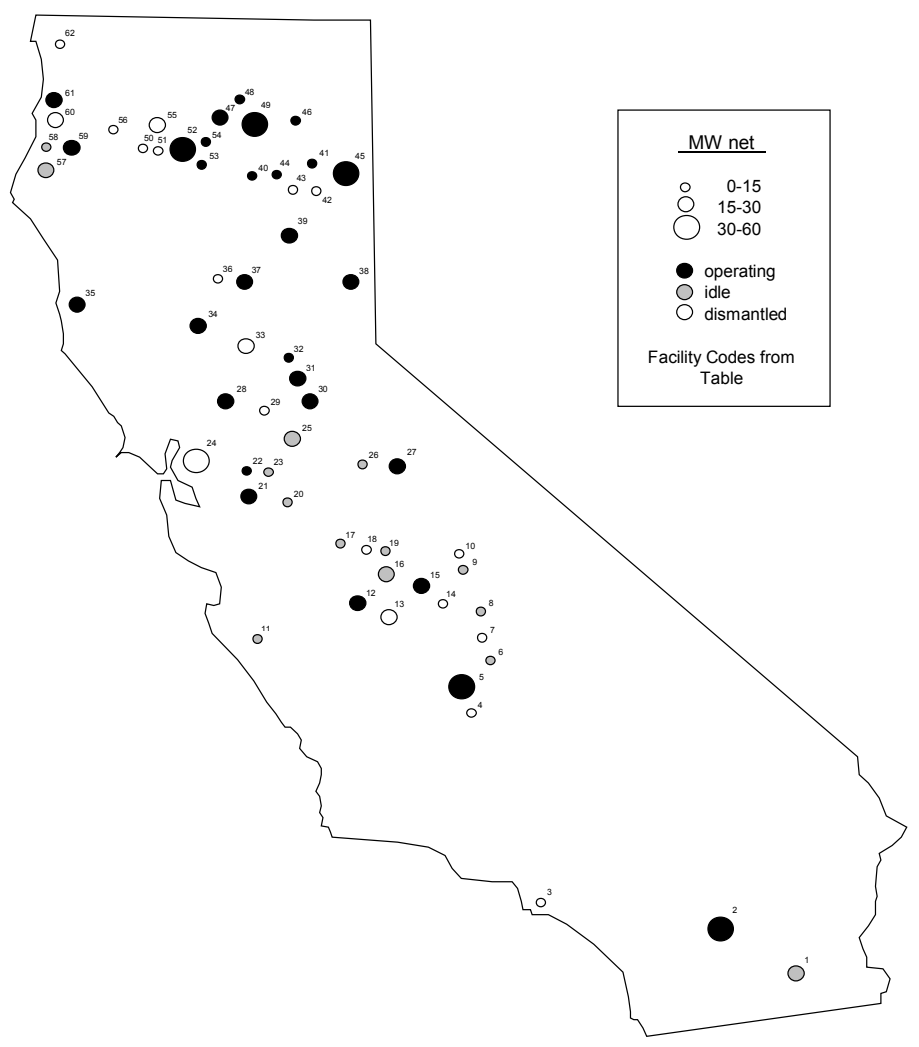

The year 1999 saw a renewal of interest in PPA buyouts. One small facility, which was already operating past its fixed-price period, accepted a buyout agreement for its remaining capacity obligation and shut down. One of the state's largest facilities accepted a buyout of its contract, and remains in operation as a merchant power facility, although its future viability is in doubt. Other possible buyouts were in various stages of discussion, and future shutdowns are possible as the new century begins. The cap on the 
renewable transition supplement paid to biomass generators decreased to $1.0 \notin / \mathrm{kWh}$ on January 1, 2000, and more than $100 \mathrm{MW}$ of capacity will see their fixed-schedule energy provisions expire during 2000. No biomass support measures have yet been enacted. The industry's future remains very much in doubt.

Table 1

\section{CALIFORNIA BIOMASS POWER PLANTS, 1980-2000}

\begin{tabular}{|c|c|c|c|c|c|c|c|c|c|c|c|c|c|}
\hline & Project & County & $\begin{array}{l}\text { Net } \\
\text { MW }\end{array}$ & $\underline{\mathrm{mBDT} / \mathrm{y}}$ & ogen & $\begin{array}{l}\text { Own } \\
\text { Fuel } \\
\end{array}$ & $\begin{array}{l}\text { Boiler } \\
\text { Type }\end{array}$ & $\underline{\text { Status }}$ & Utility & PPA & $\begin{array}{l}\text { Start } \\
\underline{\text { up }}\end{array}$ & $\begin{array}{l}\text { Shut } \\
\text { Down }\end{array}$ & $\begin{array}{l}\text { Re- } \\
\text { Start }\end{array}$ \\
\hline 1 & Western Power & Imperial & 15.0 & 122 & & & grate & Idle & SCE & SO \#4 bo & 1990 & 1996 & \\
\hline 2 & Colmac Energy & Riverside & 47.0 & 330 & & & $\mathrm{cfb}$ & Operating & SCE & SO \#4 & 1992 & & \\
\hline 3 & Proctor \& Gamble & Los Angeles & 13.5 & 98 & $x$ & & grate & Dismantled & SCE & Pre SO & 1985 & 1988 & \\
\hline 4 & Apex Orchard & Kern & 5.5 & 48 & $\mathrm{x}$ & & grate & Dismantled & PG\&E & Pre SO & 1983 & 1988 & \\
\hline 5 & Thermo Ecotek Delano & Tulare & 48.0 & 375 & & & bfb & Operating & SCE & SO \#4 & 1991 & & \\
\hline 6 & Sierra Forest Products & Tulare & 9.3 & 75 & $x$ & $x$ & grate & Idle & SCE & SO \#4 bo & 1986 & 1994 & \\
\hline 7 & Lindsay Olive & Tulare & 2.2 & 20 & $\mathrm{x}$ & $x$ & grate & Dismantled & SCE & & 1980 & 1993 & \\
\hline 8 & Dinuba Energy & Tulare & 11.5 & 97 & $x$ & $x$ & bfb & Idle & PG\&E & SO \#4 bo & 1986 & 1995 & \\
\hline 9 & Auberry & Fresno & 7.5 & 70 & $x$ & $x$ & bfb & Idle & PG\&E & SO \#4 bo & 1986 & 1994 & \\
\hline 0 & North Fork & Madera & 8.0 & 68 & $x$ & $x$ & bfb & Dismantled & PG\&E & $\mathrm{SO} \# 4$ bo & 1988 & 1994 & \\
\hline 1 & Soledad Energy & Monterey & 13.5 & 98 & & & bfb & Idle & PG\&E & $\mathrm{SO} \# 4$ bo & 1990 & 1994 & \\
\hline 2 & Thermo Ecotek Mendota & Fresno & 25.0 & 185 & & & $\mathrm{cfb}$ & Operating & PG\&E & $\mathrm{SO} \# 4$ & 1990 & & \\
\hline 3 & Agrico Cogen & Fresno & 25.0 & 198 & $x$ & & grate & Conv. to gas & PG\&E & SO \#2 & 1990 & 1991 & \\
\hline 4 & Sanger (biomass $\rightarrow$ feed) & Fresno & 0.0 & 50 & $x$ & & - & Dismantled & NA & NA & 1991 & 1991 & \\
\hline 5 & Rio Bravo Fresno & Fresno & 25.0 & 180 & & & $\mathrm{cfb}$ & Operating & $P G \& E$ & SO \#4 & 1989 & 1994 & 1998 \\
\hline 6 & SJVEP--Madera & Madera & 25.0 & 182 & & & bfb & Idle & PG\&E & SO \#4 bo & 1990 & 1995 & \\
\hline 7 & SJVEP--EI Nido & Merced & 10.2 & 88 & & & bfb & Idle & PG\&E & SO \#4 bo & 1989 & 1995 & \\
\hline 8 & SJVEP--Chowchilla I & Madera & 9.9 & 99 & & & grate & Dismantled & PG\&E & SO \#4 bo & 1988 & 1995 & \\
\hline 9 & SJVEP--Chowchilla II & Madera & 10.8 & 90 & & & bfb & Idle & PG\&E & $\mathrm{SO} \# 4$ bo & 1990 & 1995 & \\
\hline 0 & Redwood Food Pkg & Stanislaus & 4.5 & 36 & $x$ & $x$ & grate & Idle & PG\&E & SO \#1 & 1980 & 1985 & \\
\hline 1 & Tracy Biomass & San Joaquin & 19.5 & 150 & & & grate & Operating & PG\&E & SO \#4 & 1990 & & \\
\hline 2 & Diamond Walnut & San Joaquin & 4.5 & 35 & $x$ & $x$ & grate & Operating & PG\&E & Pre SO & 1981 & & \\
\hline 3 & California Cedar Products & San Joaquin & 0.8 & 11 & $x$ & $x$ & grate & Idle & PG\&E & $\mathrm{SO} \# 1$ & 1984 & 1991 & \\
\hline & Gaylord Antioch & Contra Costa & 30.0 & 225 & $x$ & & grate & Conv. to gas & PG\&E & Pre SO & 1983 & 1990 & \\
\hline 5 & Jackson Valley, Ione & Amador & 18.0 & 140 & & & & Idle & PG\&E & negotiated & 1998 & 1999 & \\
\hline 6 & Fiberboard, Standard & Tuolumne & 3.0 & 27 & $x$ & $x$ & grate & Idle & PG\&E & Pre SO & 1983 & 1996 & \\
\hline 7 & Chinese Station & Tuolumne & 22.0 & 174 & & & $\mathrm{bfb}$ & Operating & PG\&E & $\mathrm{SO} \# 4$ & 1987 & & \\
\hline 8 & Thermo Ecotek Woodland & Yolo & 25.0 & 200 & & & $\mathrm{cfb}$ & Operating & PG\&E & SO \#4 & 1990 & & \\
\hline 9 & Blue Diamond Growers & Sacramento & 9.5 & 68 & $x$ & $x$ & grate & Dismantled & PG\&E & Pre SO & 1982 & 1996 & \\
\hline & Wheelabrator Martell & Amador & 18.0 & 135 & $x$ & $x$ & grate & Operating & \multicolumn{2}{|c|}{ Industrial Cust. } & 1987 & & \\
\hline & Rio Bravo Rocklin & Placer & 25.0 & 180 & & & $\mathrm{cfb}$ & Operating & PG\&E & $\mathrm{SO} \# 4$ & 1990 & 1994 & 1999 \\
\hline 2 & Sierra Pacific Lincoln & Placer & 8.0 & 70 & $x$ & $x$ & grate & Operating & PG\&E & SO \#4 & 1985 & & \\
\hline & EF Feather River & Yuba & 16.5 & 150 & & & $\mathrm{cfb}$ & Dismantled & PG\&E & SO \#4 bo & 1987 & 1993 & \\
\hline 4 & Wadham Energy & Colusa & 26.5 & 209 & & & $\mathrm{cfb}$ & Operating & PG\&E & $\mathrm{SO} \# 4$ & 1989 & & \\
\hline & Georgia Pacific & Mendocino & 15.0 & 119 & $x$ & $x$ & grate & Operating & PG\&E & SO \#1 & 1987 & & \\
\hline 6 & Koppers & Butte & 5.5 & 110 & $x$ & $\mathrm{x}$ & grate & Dismantled & PG\&E & SO \#2 & 1984 & 1994 & \\
\hline 7 & Ogden Pacific Oroville & Butte & 18.0 & 142 & & & grate & Operating & PG\&E & $\mathrm{SO} \# 4$ & 1986 & & \\
\hline 8 & Sierra Pac. Loyalton & Sierra & 17.0 & 134 & $x$ & $x$ & grate & Operating & \multicolumn{2}{|c|}{ Sierra Pacific } & 1990 & & \\
\hline 9 & Sierra Pacific Quincy & Plumas & 25.0 & 200 & $x$ & $x$ & grate & Operating & PG\&E & $\mathrm{SO} \# 4$ & 1987 & & \\
\hline 0 & Collins Pine & Plumas & 12.0 & 90 & $x$ & $x$ & grate & Operating & PG\&E & SO \#2 & 1986 & & \\
\hline 1 & Sierra Pac. Susanville & Lassen & 13.0 & 105 & $x$ & $x$ & grate & Operating & PG\&E & $\mathrm{SO} \# 4$ & 1986 & & \\
\hline 2 & Lassen College & Lassen & 1.5 & 12 & $x$ & & grate & Dismantled & PG\&E & SO \#1 & 1985 & 1987 & \\
\hline 3 & Jeld Wen Industries & Lassen & 2.5 & 20 & $x$ & $x$ & grate & Conv. to gas & PG\&E & Pre SO & 1984 & 1992 & \\
\hline 4 & Ogden Westwood & Lassen & 11.4 & 90 & & & grate & Operating & PG\&E & $\mathrm{SO} \# 4$ & 1985 & & \\
\hline & Honey Lake Power & Lassen & 30.0 & 225 & & & grate & Operating & PG\&E & SO \#4 & 1989 & & \\
\hline 6 & Big Valley Lumber & Lassen & 7.5 & 59 & $x$ & $x$ & grate & Operating & PG\&E & Pre SO & 1983 & & \\
\hline 7 & Sierra Pacific Burney & Shasta & 17.0 & 145 & $x$ & $x$ & grate & Operating & PG\&E & SO \#4 & 1987 & & \\
\hline 8 & Ogden Burney & Shasta & 10.0 & 77 & & & grate & Operating & PG\&E & SO \#4 & 1985 & & \\
\hline & Burney Forest Products & Shasta & 31.0 & 245 & $x$ & $x$ & grate & Operating & PG\&E & $\mathrm{SO} \# 4$ & 1990 & & \\
\hline 0 & Roseburg Lumber & Shasta & 4.0 & 32 & $x$ & $x$ & grate & Dismantled & PG\&E & Pre SO & 1980 & 1992 & \\
\hline 51 & Paul Bunyan & Shasta & 3.0 & 24 & $x$ & $x$ & grate & Dismantled & PG\&E & Pre SO & 1980 & 1992 & \\
\hline
\end{tabular}




\section{Characteristics of California's Biomass Power Plants}

The author of this report has developed and maintained an extensive database on the California biomass energy industry (Morris 1997), which has been brought up to date as part of this project. The California biomass energy database contains information about every solid fuel biomass energy generating facility that has operated in California since 1980. The database includes information on an annual basis about biomass fuel use and price, and annual electricity production, for the 20-year period covered, 1980-1999, as well as projections for the current year (2000). This database is the source of many of the data used in the environmental and economic analyses in this report.

Sixty-two biomass energy generating facilities have operated in California during the past 15 years. Twenty-nine still operate. Eighteen have been dismantled or otherwise modified to render them no longer available for service as biomass energy facilities. Most of the remaining 15 facilities are currently idle and available for future operations. They are located throughout the state, as shown in Figure 4. Half obtain at least some of their fuel from captive sources, although only a few obtain all their fuel from captive sources. Thus, most have participated in the state's biomass fuels marketplace. California biomass facilities range from 1-50 MWs, with annual fuel requirements of 10,000-750,000 tons/year.

All biomass energy generation facilities in California employ conventional steam-turbine technology for converting biomass fuels to electricity. This technology has been in use for almost 100 years, and has been used extensively with a wide variety of fuels, including biomass and fossil fuels. Nevertheless, the technology continues to evolve, and has shown significant improvement as the modern biomass energy industry in California has developed. Much of the development since 1980 has been in the area of environmental performance, which includes improvements in combustion technology, and in emissions-control technology.

Most of California's biomass power plants employ conventional biomass combustion technology with fixed or traveling grate furnaces. Seventeen of the facilities were built with fluidized-bed boilers, including bubbling bed and circulating bed configurations. Fluidized-bed boilers provide for lower emissions and higher efficiency than conventional boilers, but have higher capital and operating costs. The major deployment of fluidized-bed biomass boilers has contributed valuable learning experience to the continuing technological refinement and commercial development of this promising technology.

The industry is poised to continue to contribute to technological innovation in the biomass energy arena as the twenty-first century begins. The newest biomass generating facility in the state, taking advantage of the IRS Section 29 gasification tax credit, employs a close-coupled gasifier as part of its combustion system, achieving high efficiency and low emissions. Several biomass facilities are considering the development of associated ethanol production operations as an enhancement to the overall energy 
production enterprise. It is hoped that synergies between the electricity production enterprise and the ethanol production enterprise, such as shared biomass procurement and handling facilities, and segregation of the resource into higher and lower valued outlets, will provide benefits to both. The California biomass energy industry can contribute to future biomass technology innovation only if it continues to be viable in the near-term.

\section{Fuel Use and Alternative Disposal Options for Biomass Residues in California}

The biomass energy industry in California can be thought of as much as a solid waste disposal service provider as an electricity generating enterprise. It provides for the disposal of 6.4 million tons/year of the state's solid wastes. The biomass residues used as fuel come from a variety of sources, and would be subject to a variety of alternative fates, such as open burning or landfill burial, if the biomass industry were not a disposal option. The major categories of biomass fuels used in California include:

- Wood processing residues

- In-forest residues

- Agricultural residues

- Urban wood residues

Most biomass generating facilities in California were built with an expectation of using either wood processing residues or agriculture residues as their major fuel source. The facilities designed to burn primarily agricultural residues are concentrated in the Central Valley. Those designed to burn primarily residues from the forest products industry are concentrated in the northern and eastern mountain regions. Three biomass facilities were designed to burn primarily urban wood waste. These were located close to the Los Angeles and San Francisco Bay Areas. Urban wood waste fuels, which were largely ignored during the industry's development, have become far more important than anyone originally anticipated. They are second only to sawmill residues in terms of their contribution to the California biomass fuels market.

Several California biomass facilities burn supplemental fuels in addition to solid biomass residues. Biomass energy facilities that are qualifying facilities (QFs) are allowed to obtain as much as $25 \%$ of their input heat from conventional fossil fuels. In addition, they can burn unlimited quanties of other renewable fuels or approved waste materials, such as petroleum coke and old tires. Landfill gas, ${ }^{*}$ tires, and petroleum coke are the major supplemental fuels used by the state's biomass generators. One facility uses geothermal heat to preheat boiler water.

\footnotetext{
* California has 30 power generation installations powered exclusively by landfill gas. This report is focused on the solid fuels biomass power industry, and does not cover the landfill gas facilities.
} 


\section{Wood Processing Residues}

Wood processing residues are the waste materials produced during the processing and conversion of lumber into wood products. Those residues are the most important biomass fuel source in California, consistently accounting for more than one-third of the total biomass fuel supply used. Almost half the biomass content of a typical sawlog becomes residue at a primary sawmill. A variety of secondary forestry industries have been developed to use some of this material. Active markets for wood processing residues include pulp chips, wood fiber for fiberboard and composites, animal bedding, and garden products such as decorative bark. Sawmills are used to segregating their residues into the highest-value markets available, but a substantial quantity of the residues, typically $15 \%-20 \%$ of the total biomass in a sawlog, has no useful application and must be disposed of. Wood-processing residues are produced in a variety of forms, including:

- Bark

- Round-offs

- End cuts

- Trimmings

- Sawdust

- Shavings

- Reject lumber

The traditional method of disposing of sawmill residues in California before the biomass energy industry was developed was incineration in teepee burners, a technology that produces large quantities of smoke and air pollution. Beginning in the early 1970s air pollution control efforts applied increasing pressure on sawmills to close down their teepee burners, leading them to look for new disposal alternatives. This was one important factor that led to the early development of the biomass industry in California. Virtually all the readily available wood processing residues generated that have no higher valued application are now used as power-plant fuel.

Teepee burners are no longer used to dispose of wood processing residues in California. The only readily available option for disposing of these materials, if fuel use were not a possibility, would be landfill burial - a highly undesirable alternative. Waste wood has a slower decay rate than other forms of biomass in the landfill environment, and thus is slower to stabilize. Moreover, state solid waste policy is strongly oriented to reducing the amount of material being buried in landfills, and introducting a sizable new waste stream would make compliance with recycling regulations almost impossible.

If there were no biomass energy industry in California today, some sawmill residues currently used for fuel would be used for energy production in sawmill kiln burners, an old disposal option for some of a sawmill's residues. This application would probably use one-third or more of the residues currently used for power production. A small quantity would be composted and/or spread; the rest would be landfilled. 
Wood processing residues are the cheapest of the four categories of biomass fuels to produce and deliver to the power plants. They form the backbone of the state's biomass fuel supply, and would probably be the last type of fuel to exit the system if the demand for biomass fuels state declined. The major factor that determines the quantity of mill residues used as fuel in California is the level of activity in the forest products industry. Economic factors and environmental restrictions on timber supplies have led many sawmills to shut down. This has led to a decline in the amount of wood processing residues used as power plant fuels that began during the early 1990s.

\section{In-Forest Residues}

In-forest biomass residues include two major categories: residues generated in the forest when timber is harvested for wood products, generally called slash, and material naturally occurring in forests whose removal would provide environmental benefits to the remaining forest. Harvesting residues include the tops and limbs of harvested trees, bark when debarking takes place in the forest, and cull logs* that are cut and removed during harvesting operations. The cheapest way to manage this material is to leave it in the forest as it is generated, but that is also the worst management practice from a forestry perspective, as leaving harvesting residues in the field retards regrowth of the forest and represents a substantial fire hazard. Virtually all timber harvesting contracts in California require loggers to manage the slash they generate. Slash that is generated close enough to an operating biomass energy plant can be collected and converted to fuel. The alternative is to collect the slash and burn it in piles. Open burning leads to high levels of emissions of smoke, particulates, and other air pollutants.

The other category of in-forest residue is overstocked material in vast areas of California's forests. Poor forestry practices and aggressive fire-fighting efforts during most of the past century have resulted in vast areas of the state's forests becoming overstocked with biomass. This material represents an enhanced risk of destructive wildfires, and generally degrades the functioning of the forest ecosystem. Overstocked forests benefit greatly from thinning operations. The quantity of in-forest biomass whose removal would benefit California's forests is far greater than the total amount of biomass fuel demand in the state. However, this fuel source is generally more expensive to produce than other types of biomass fuels, so less is used.

Two basic alternatives can be used to reduce the biomass overloading in standing forests: prescribed burning and mechanical thinning. The primary goal of reducing fire risks in standing forests is to protect mature trees. Most of the tonnage of forest overgrowth biomass is material on and near the forest floor, called ground fuel. Periodic fires in undisturbed California forests tended to be primarily ground fires, and control the buildup of these materials. When ground fuels are left uncontrolled for prolonged periods, such

\footnotetext{
* Cull logs are trees that are diseased, damaged, misshapen, or otherwise unsuitable for use in producing commercial wood products.
} 
as in areas where fires have been excluded for 75 years or more, some of the undergrowth begins to grow into taller poles, which become "ladder fuels." Ladder fuels provide a mechanism to transfer ground fires to the crowns of mature trees in the forest, thus greatly increasing the damage caused by the fires, in the worst cases turning benign ground fires into out-of-control, destructive wildfires. Traditional commercial harvesting operations do not affect the fuel overloading problem in the forest, because neither ground nor ladder fuels are removed. In fact, if slash is left untreated, the fire risk can be increased. Mechanical thinning and prescribed burning remove ladder and ground-based fuels.

Forestry officials would like to see large areas of California's forests thinned. An official of the U.S. Forest Service, which manages approximately one-half the state's forest land, has asserted that at least 250,000 acres per year of the land under their jurisdiction needs to be thinned to fully realize the desirable fire suppression, forest health, and watershed improvement benefits (Morris 1998a). During the peak of the California biomass fuels market in the early 1990 s only about 60,000 acres per year were being thinned statewide for fuel production. With the decline in biomass fuels demand that occurred in the middle of the decade, the level of thinning for fuels production has been cut by more than half.

The alternative to biomass fuels production for reducing overstocking in the state's forests is prescribed burning. However, environmental and safety concerns may limit the amount of prescribed burning that will be allowed in California. Prescription burning produces more pollution per ton of material consumed than open burning of biomass in piles (EPA 1995). In addition, prescribed burning in densely overstocked forest stands entails a significant risk of residual stand damage and may initiate of offsite, uncontrolled wildfires. The recent massive wildfire in Los Alamos, New Mexico, has already become a notorious example of a prescribed burn running amok, but northern California has experienced this phenomenon on a smaller scale repeatedly during the past decade. Mechanical thinning and residue removal before prescription burning reduces the pollution and risk factors associated with the treatment, and in some cases can eliminate the need to burn. Mechanical thinning, however, is expensive, and rarely performed in the absence of fuel applications for the thinned material.

\section{Agricultural Residues}

Agriculture is a multibillion-dollar enterprise in California, producing large quantities of biomass residues in the process. Approximately one-third of California's biomass energy plants were built in the state's agricultural regions in order to use these residues as fuel. Many receive emissions offsets for pollutants that are avoided when biomass residues that would otherwise be open burned are used for energy production. Agricultural fuels provide about $20 \%$ of the state's biomass fuel supply. Agricultural residues come in a wide variety of forms, some which are unsuitable for use as power plant fuel.

Agricultural residues suitable for fuel use in solid-fuel biomass energy plants include materials in the following categories: 
- Food processing residues such as pits, shells, and hulls

- Orchard and vineyard removals

- Orchard and vineyard prunings

- Field straws and stalks

Food processing residues are generated in concentrated quantities and require some form of disposal. Like wood products manufacturers, food processors have worked diligently to develop high-valued uses for these materials, such as in feed products. Nevertheless, a surplus of food processing residues is available for use as biomass fuel. In the absence of fuel markets, these materials would otherwise be buried in a landfill or open burned. Some wastes that have been used as fuels in California, such as nut hulls, shells, pits, and rice hulls, present special combustion problems that limit their application to facilities able to deal with these materials. Several pioneering biomass generating facilities were built at food processing facilities specifically to dispose of the processing residues. Although some experienced operating problems when first starting up, most were able to adapt and adjust their equipment to handle the specific fuels.

California's agriculture includes extensive plantings of orchards and vineyards, permanent woody crops that require annual pruning operations and produce large quantities of residues. Conventional agricultural practice for the disposal of these prunings is to pull them to the sides of the rows, where they are piled and burned. It has long geen recognized that agricultural burning is a major contributor to the air pollution problems in California's major agricultural regions. During the early development of the biomass energy industry there was a great deal of interest in using orchard and vineyard prunings as fuels. Combustion of this material in a power plant greatly reduces the resulting emissions of smoke and air pollutants compared with open burning. In addition to the environmental benefits anticipated, many farmers were under the impression that fuel sales would offset the cost of pruning, and even create a new profit center for their operations.

Orchard and vineyard prunings more expensive and difficult to use as fuels than was originally anticipated. This is a consequence of two factors. First, the density of the resource (tons per acre) is less than originally projected. The result of this miscalculation is that more area needs to be covered to produce a given amount of fuel, which results in concomitant increase in fuel production cost. Second, compared with other sources of biomass boiler fuels, prunings are very stick-like, which makes them more difficult to process into fuel form and creates a special hazard for fuel handling and delivery equipment at the power plant. These considerations have limited the amount of fuel produced from orchard prunings in California. It is estimated that less than $7.5 \%$ of the state's agricultural prunings are being converted to fuel in the current market environment. The remainder continues to be open burned.

In contrast to the experience with prunings, orchard and vineyard removals constitute very desirable source of biomass fuel. Orchards and vineyards are cleared periodically 
for purposes of replanting, and in response to changing land use decisions. Orchard clearing, in particular, provides a high density of material (tons per acre) that can be processed into conventional whole tree chips. In addition, this material is generally felled in the mid to late summer from plantations that have not been irrigated, the wood is often very dry compared with other sources of recently cut biomass fuels. Fuels derived from orchard clearings, and to a more limited extent from vineyard clearings, are the major agricultural residue fuels used in California.

California agriculture also produces large quantities of field residues in the forms of straws and stalks that are disposed of either by open burning, or by plowing under in the fields. These residues can be collected and processed into power plant fuels. Straw and stalk-based fuels tend to be expensive to produce, and their low bulk density $\left(\mathrm{lb} / \mathrm{ft}^{3}\right)$ presents materials handling problems and combustion difficulties. As a result, very little of this material contributes to the fuel supply, even though these materials qualify as agricultural offset fuels.

Most agricultural residues used as fuels in California are woody residues derived from extensive orchard crops. Whole-tree chips produced from orchard removals constitute a particularly successful source of biomass fuel. Even with the present level of agricultural biomass fuel use, an enormous amount of agricultural residues suitable for use as power plant fuels continues to be open burned. The alternative fate for most agricultural residues used for fuel is open burning, although a small percentage of these materials would likely be landfilled or plowed under in the absence of fuel applications.

\section{Urban Wood Residues}

Fifteen to twenty percent of the material traditionally disposed in municipal landfills is clean, separable waste wood. This material comes from a variety of sources, including:

- Waste wood from construction contractors

- Old and damaged pallets

- Waste wood from land clearing

- Waste wood from public and private tree trimmers and landscapers

- Waste wood from industrial manufacturers, including packing materials and trimmings

Urban wood residues are brought to landfills in a variety of forms, including loads of chipped wood and brush from public and private tree trimmers and land clearers, debris boxes from manufacturers of wood products and construction contractors, and mixed loads of yard debris. Some amount of demolition wood waste is also used as a biomass fuel, although many facilities have permit restrictions that prohibit the use of painted wood and/or treated wood because of emissions concerns. Transfer station and landfill operators can segregate loads containing fuel-usable materials as they enter the gate, and process the material to produce a high-quality fuel product. Urban wood residues contribute much more to California's biomass fuels mix than anyone anticipated during the early development of the industry. 
Landfill-diverted waste wood supplied about 1.5 million tons of fuel annually to the biomass energy industry during the $1990 \mathrm{~s}$, hitting a peak of 1.9 million tons in 1993. As the overall biomass fuels market declined through the decade, the percentage of landfilldiverted fuels in the state's biomass fuel mix has increased, from approximately $20 \%$ at the beginning of the decade, to $30 \%$ today. Landfill-diverted waste wood is the second cheapest source of biomass fuel to produce after sawmill residues, in large part because of the pressure to divert wastes away from landfill disposal.

The traditional disposal option for urban wood waste is burial in landfills. However, the alternative disposal options that might be available for this material in the future, should the fuels market disappear, are more complicated to project. California's solid waste diversion law, AB 939, mandates that by the end of 2000 all counties must achieve a diversion rate of $50 \%$ of their total solid waste, compared to their performance during 1990. An intermediate target of $25 \%$ diversion by 1995 was met statewide, but compliance with the year 2000 standards will be significantly more difficult to achieve. Peak urban biomass fuel use of 1.9 million tons/year represents $6.6 \%$ of the amount of solid waste that must be diverted statewide by the end of 2000 .

Solid waste managers are under pressure to develop diversion applications of all kinds. The alternatives, however, are limited, and most of the obvious markets that can accept waste wood, such as spreading as mulch or composting, are already being flooded with material. Most of the urban biomass fuels would otherwise probably be landfilled; some would be spread as mulch or composted.

\section{The California Biomass Fuels Market}

During the early development of the biomass energy industry in California, wood processing and agricultural residues provided virtually all the fuel used by the various. As the industry grew the use of these sources of fuel grew in step, and two new sources of fuel were introduced: in-forest residues and urban wood residues. Figure 5 shows the time course of the use of the four categories of biomass fuels as a function of fuel type. Wood processing residues have continued to be the primary source of supply for the biomass energy industry throughout the period covered by this study. The use of wood processing residues as fuel increased rapidly during the 1980s, peaking in 1990 at more than 5.5 million tons/year. At that point all but the most remote wood processing residues were being used as biomass fuels.

Although the demand for biomass fuels remained relatively stable during the early 1990s, the use of mill residues dropped dramatically during this period. This was a result of the fact that sawmilling activity in the state declined in response to poor economic conditions and increasing environmental restrictions on the supply of roundwood. At the same time supplies of the other types of biomass fuels became more available as high biomass fuel prices and long-term fuel supply contracts required by the financial institutions that funded the power plants stimulated a variety of new ventures in the fuel supply business. 
As the lowest-cost-to-produce fuel source, mill residues are used to the full extent they are available. The state's biomass energy industry would have to shrink to less than half its current size before significant quantities of mill residues would start to be disposed of using alternative disposal options.

The other category of biomass fuels that has been in use since the beginning of the development of the biomass energy industry is agricultural residue fuels. The first agricultural fuels to be used were food processing residues such as nut hulls and pits. Several pioneering biomass energy facilities were built at food processing facilities to provide for the disposal of these materials. Expansion of the use of agricultural fuels has been more gradual than many industry observers originally predicted, because converting of orchard and vineyard prunings to fuels was more difficult and expensive than originally projected. Agricultural fuel use increased significantly between 1988 and 1990, as the statewide biomass fuel crisis hit, and many new facilities entered operation with permit requirements to burn agricultural wastes to offset their air pollutant emissions. With the closure of many agricultural fuels-based facilities during the mid1990 s, agricultural residue fuel use declined by about $33 \%$ from its peak in the early part of the decade.

Urban waste wood began to contribute to the state's biomass fuel mix in 1983, when Gaylord Paper Corp. started up its pioneering facility in the San Francisco Bay area. This facility was designed to burn primarily urban waste wood fuel, and was a very successful venture. In 1985 a second facility designed to burn urban wood fuel, Procter \& Gamble, began operations in the Long Beach (Los Angeles) area. These two facilities, located in the two largest metropolitan areas, stimulated the development of a market for producing fuel from material that was traditionally buried in landfills.

As the technical viability of using urban waste wood fuels was proven, biomass energy facilities designed to burn primarily sawmill and agricultural residue fuels began purchasing fuels derived from urban waste wood, and the use of urban biomass fuels in California increased gradually during the mid-1980s. When the statewide biomass fuel crisis hit at the end of the decade, urban biomass fuel use doubled, reaching approximately 1.5 million tons/year in 1990. This fuel source continued to grow over the next several years, as statewide fuel demand remained stable and the availability of wood processing residues decreased. Urban biomass fuel use peaked at almost 1.9 million tons in 1993. Urban biomass fuel use contracted to below 1.2 million tons/year as overall biomass fuel demand declined with the shutdowns of the middle of the decade, then began to pick up again as the 1990s came to a close. With increasing pressure to divert material from landfill disposal to comply with AB 939, urban biomass fuel use currently exceeds 1.5 million tons/year.

In-forest residues are the most expensive of the four types of biomass fuel sources used in California. Significant in-forest fuel production did not begin until 1985, and grew gradually until the end of the decade, when the statewide fuel crisis forced fuel prices above \$40/bdt. In-forest biomass fuel use peaked in 1990-1991 at about 1.8 million tons/year, then began to fall as the market reached equilibrium, sawmilling activity 
recovered slightly, and cheaper urban and agricultural fuels outcompeted in-forest fuels. When the buyouts and closures hit the biomass energy industry in 1994-1995, in-forest biomass fuel use took the greatest hit, dropping to less than 700,000 tons/year in 1997. Since then in-forest residue fuel use has rebounded to more than 1 million tons/year.

\section{Biomass Fuel Market Price Trends}

Before the development of the modern biomass energy industry in California most agricultural and wood-processing residues, as well as a significant quantity of the forest harvesting residues, were being open burned, while urban wood residues were being buried in landfills. In addition, the amount of overstocking of fuel in the state's forests was increasing relentlessly, a process that has spanned the entire twentieth century. These disposal alternatives have economic costs as well as adverse environmental consequences. The early development of the state's biomass energy industry was spurred as much by sawmills and food processors looking for improved disposal options for their residues, as by the incentives provided by the energy sector.

During the early development of the biomass fuels market in California a surplus of residue material was available for conversion to fuel, and fuel prices were based primarily on the cost of processing the residues and transporting them to the power plants. During the early 1980s biomass fuel prices were stable, about \$15-20 per bdt. Some sawmill residues were sold to nearby generating facilities for less than $\$ 10 / \mathrm{bdt}$. Figure 6 shows the average price of biomass fuels as a function of time.

As biomass fuel demand increased during the mid to late 1980s, the average statewide price of biomass fuels began to climb upward, reaching an average value of almost $\$ 25 /$ bdt by 1988 . From 1980 to 1988 , fuel demand grew at a greater rate than the rate of increase in fuel prices. The inflation-corrected price of biomass fuel was virtually unchanged during this period. From that point forward, however, fuel demand reached a critical level, and prices shot up, reaching more than $\$ 40 /$ bdt during the early 1990s, with spot prices reportedly tipping $\$ 60 /$ bdt. The industry appeared to be in a full-blown fuel crisis, which was precipitated by the extremely rapid increase in generating capacity, and the requirements for long-term fuel supply contracts imposed by the banks on the power plants as a condition of funding.

By 1988, statewide biomass fuel demand had grown to the point that it exceeded the capacity to provide biomass fuels. The cheapest source of biomass fuels, mill residues, was completely committed to the fuels market, and additional mill residues were no longer available to satisfy new fuel demand. New sources of biomass fuels were required, and significant investments had to be made to develop the new fuel supplies. In general, the new supplies of fuel were more expensive than the fuel sources that had already been developed. These were all factors in the rapid increase in biomass fuels prices that occurred between 1988 and 1990, during which statewide average biomass fuel prices increased by approximately $60 \%$. 
By the end of 1990 the demand for biomass fuels stabilized, as did the price, which averaged about $\$ 40 /$ bdt. The fuel-supply infrastructure had a chance to catch up with the demand, and a great deal of experience was accumulating with respect to the technologies necessary to produce power plant fuels from new sources of biomass, such as urban wood residues and various types of agricultural and in-forest residues. Fuel prices might have decreased somewhat during the early 1990s as a better balance was achieved between supply and demand, except that the supply of mill residues decreased significantly because of a cutback in lumber production (see Figure 5). Thus, the pressure for fuel price decreases due to an improved supply-demand balance was countered by the loss from the market of a fraction of the wood processing residues. The loss of wood processing residues had to be made up for by sources of supply that were more expensive to produce.

Figure 5

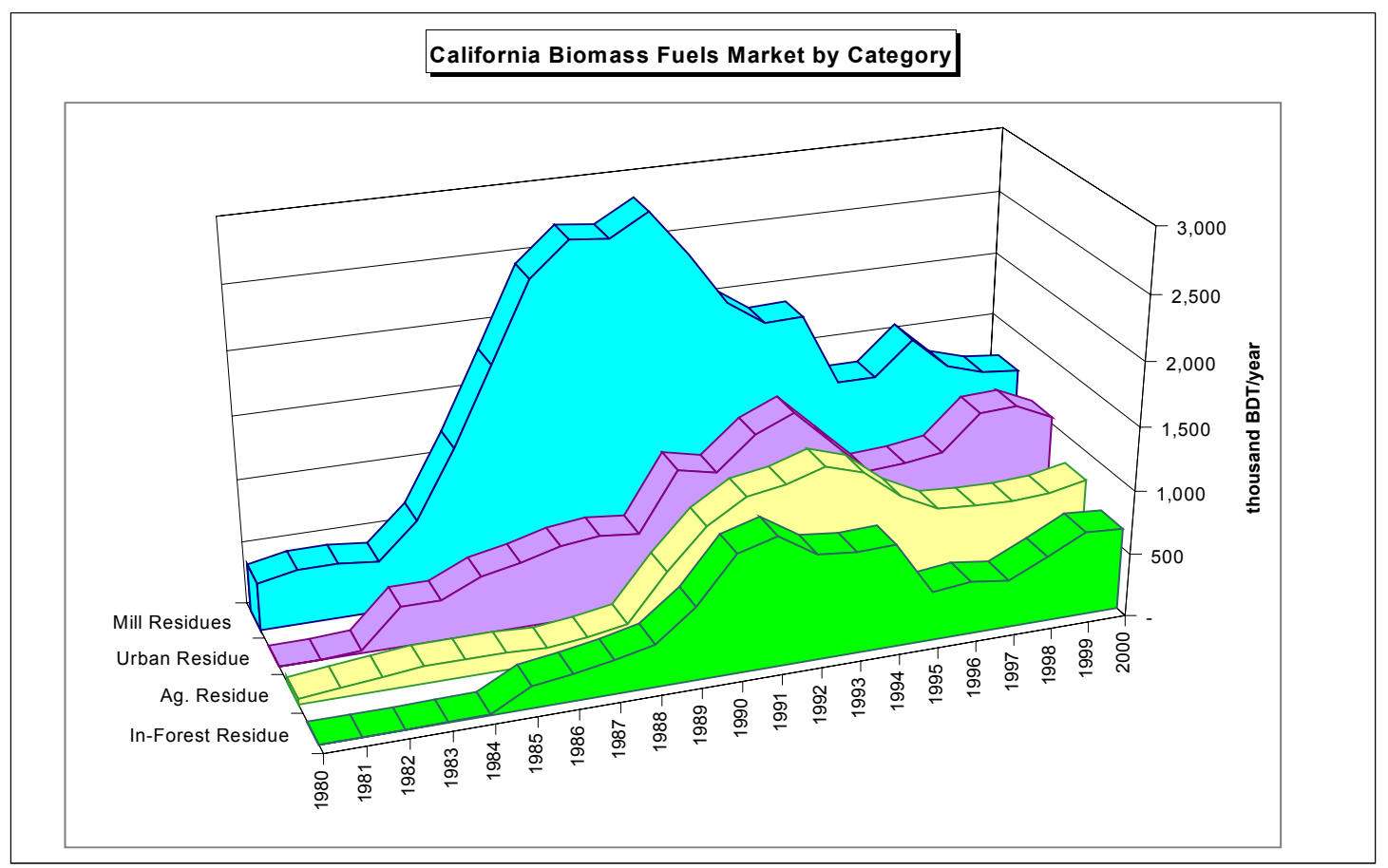

Beginning in 1994, the regulated California electric utility companies, in response to the deregulation process at the CPUC, initiated a series of buyout negotiations with many biomass generating facilities. Owners of approximately $200 \mathrm{MW}$ of capacity accepted buyouts during 1994 and 1995, shutting down 25\% of the state's operating capacity, and decreasing the demand for biomass fuels by more than one-third. Supply and demand were again out of balance, and fuel prices began a fall that brought them back to pre-1988 levels. Figure 7 shows a plot of the supply curve for biomass fuels in California. The data points represent the period 1986 to the present, showing, for each year in the range, the quantity of biomass fuel used and the average price. 
The future for biomass fuel prices in California is difficult to predict. The renewable transition fund payments to biomass generators over the past 2 years have provided sufficient incentive for generators earning SRAC rates to increase their production during off-peak hours, compared with what they were doing before the transition funds were available. This, combined with the restart of two twenty-five MW facilities, has increased total fuel use, with a concomitant rise in fuel prices. As fixed-price periods expire for more facilities, and the renewable transition fund payments are ramped down and disappear by the end of 2001, this upturn in statewide fuel demand might very well be short lived. Power plant operating economics will ultimately determine the marginal price of fuel that producers will be willing to pay.

Figure 6

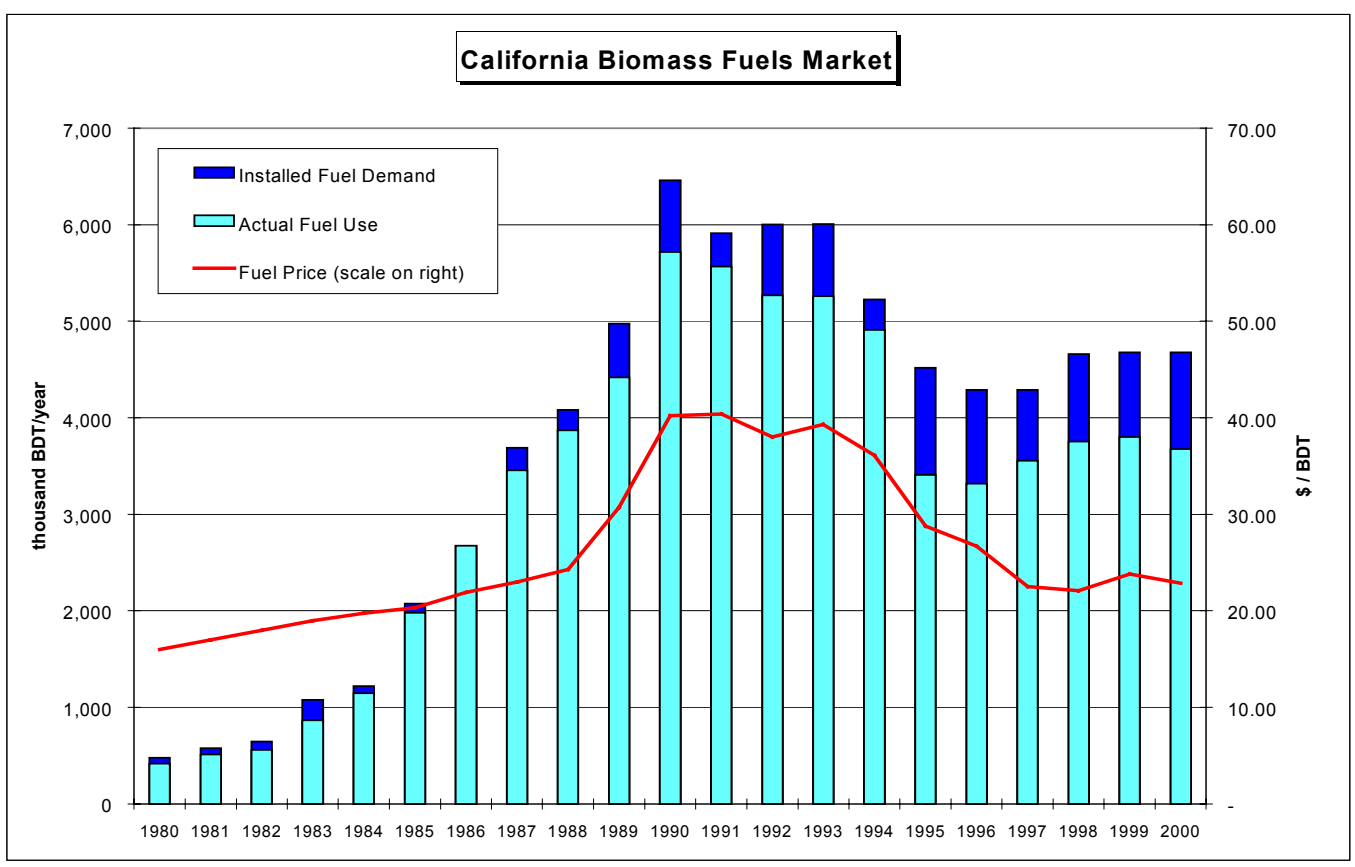


Biomass Energy Production in California: The Case for a Biomass Policy Initiative

Figure 7

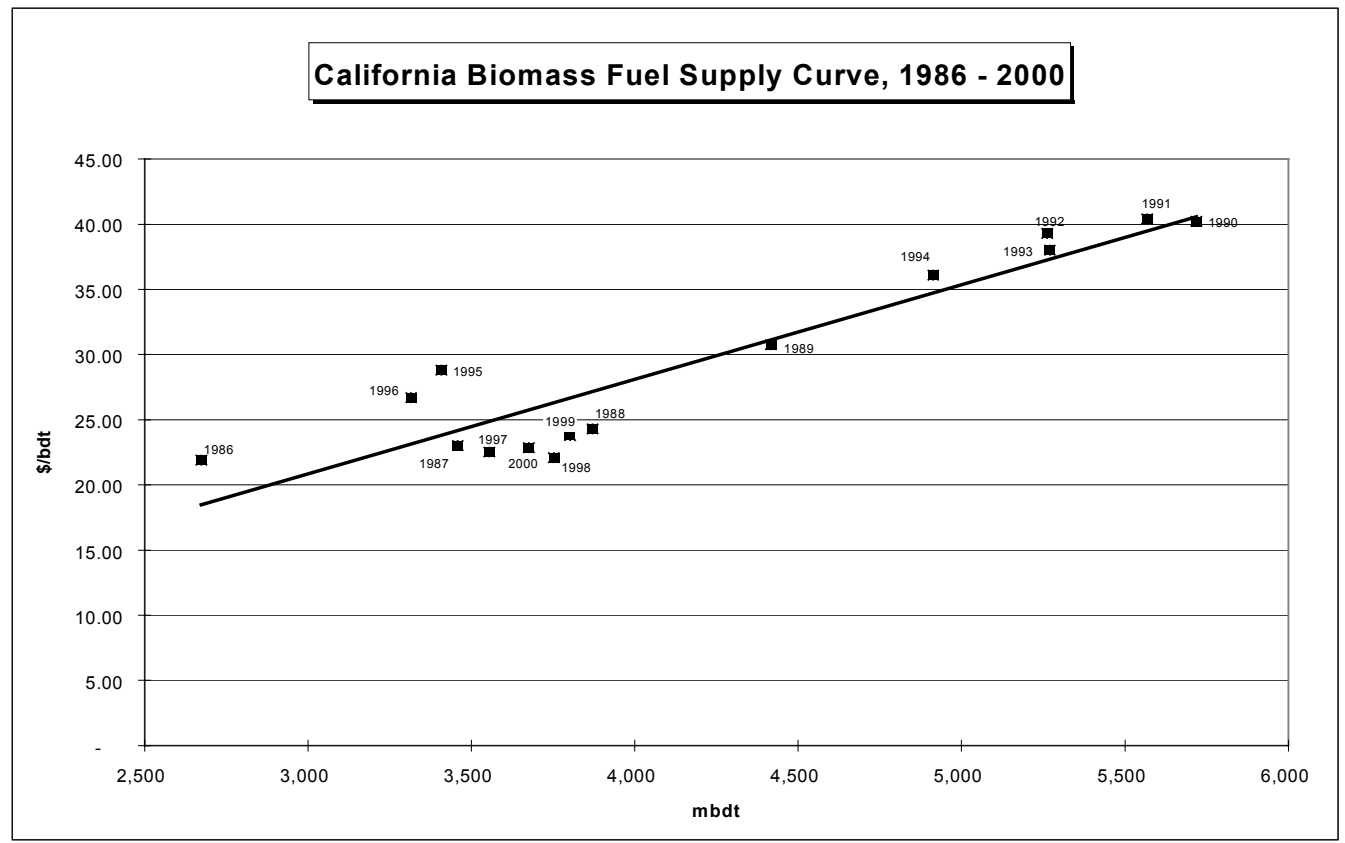




\section{The Environmental Costs and Benefits of Biomass Energy Production}

The biomass energy industry performs two distinct and important functions: energy production and waste disposal. Each has significant environmental implications. Energy production from biomass displaces the production of a like amount of energy from conventional sources. At the same time, the use of biomass fuels in energy facilities avoids the alternative disposal of these materials. While biomass energy production causes environmental impacts during fuel preparation and conversion to energy, these impacts have to be balanced against the avoidance of the impacts associated with an equivalent amount of energy generation from fossil fuels, and the avoidance of the environmental impacts that would otherwise be caused by the alternative disposal of the residues used as fuel, such as landfill burial or open burning. This avoidance is the most important source of environmental benefits associated with the production of energy from biomass resources.

The net environmental impacts of biomass energy production are defined as the impacts of the energy production pathway, less the sum of the impacts of alternative production of the same amount of energy from displaced sources and the impacts of alternate disposal of the biomass residues. To analyze the net environmental implications of using biomass for energy production, it is necessary to determine what the alternative fate of the biomass would be if it were not used as a fuel. The environmental impacts of energy production from biomass, from fossil fuels, and from all disposal alternatives for biomass residues are characterized and quantified in this section. The economic values of the impacts are then estimated, and the net benefits of biomass energy production are determined.

\section{Disposal Alternatives for Biomass Residues}

If the biomass energy industry were to collapse in California, and the state had to deal with a return to the solid-waste stream of 6.4 million tons/year of biomass currently used for energy production, it is difficult to predict what would be done with these materials. Without doubt strong efforts would be made to develop new beneficial uses for some of the residues. However, known beneficial applications for surplus biomass residues are already being flooded with material, even with the biomass energy industry in operation, so the capacity for absorbing additional large quantities of residues into already identified beneficial applications is limited.

The probable alternative fates for the various types of biomass residues used for energy production in California were discussed qualitatively in the previous chapter. Table 2 shows a quantitative breakdown of the probable alternative fates for these materials were the energy pathway not available. For purposes of analysis, most of the agricultural residues used for energy production would presumably be open burned. Even though 
state policy is oriented to reducing the amount of material disposed of in sanitary landfills, the probable alternative fate for most urban waste wood currently used for energy production is landfill disposal. A small amount of these residues would be composted or land-spread as mulch. Some sawmill residues would be used for kiln energy production if the electricity generation alternative were not available; most of the remaining residues would be destined for landfill disposal.

Table 2

Alternative Fates for Biomass Residues

\begin{tabular}{|c|c|c|c|c|c|}
\hline & Mill & Forest & $\underline{\mathrm{Ag}}$ & $\underline{\text { Urban }}$ & $\underline{\text { Total }}$ \\
\hline California Biomass Fuel Use 1999 (th.tons) & $2,5 \overline{32}$ & $\overline{1,217}$ & $1,0 \overline{8}$ & $\overline{1,604}$ & 6,412 \\
\hline $\begin{array}{l}\text { Alternative Fate (\% of category) } \\
\text { open burning } \\
\text { forest accumulation } \\
\text { controlled landfill } \\
\text { uncontrolled landfill } \\
\text { spreading } \\
\text { composting } \\
\text { kiln boiler }\end{array}$ & $\begin{array}{r}25.0 \% \\
35.0 \% \\
2.5 \% \\
2.5 \% \\
35.0 \%\end{array}$ & $\begin{array}{l}\frac{\text { Forest }}{60.0 \%} \\
40.0 \%\end{array}$ & $\begin{array}{r}\frac{\mathrm{Ag}}{90.0 \%} \\
5.0 \% \\
5.0 \%\end{array}$ & $\begin{array}{r}65.0 \% \\
20.0 \% \\
2.5 \% \\
12.5 \%\end{array}$ & \\
\hline Alternative Fate (th.tons/yr) & Mill & Forest & $\underline{\mathrm{Ag}}$ & $\underline{\text { Urban }}$ & Total \\
\hline open burning & - & 730 & 952 & - & 1,683 \\
\hline forest accumulation & - & 487 & - & - & 487 \\
\hline controlled landfill & 633 & - & 53 & 1,043 & 1,729 \\
\hline uncontrolled landfill & 886 & - & 53 & 321 & 1,260 \\
\hline spreading & 63 & - & - & 40 & 103 \\
\hline composting & 63 & - & - & 201 & 264 \\
\hline kiln boiler & 886 & - & - & - & 886 \\
\hline
\end{tabular}

In the current market for biomass fuels, the amount of in-forest residues being used for fuel has declined by approximately 50\% from the market peak of the early 1990s. The quantity of fuel produced from slash residues has shrunk as a result of the overall decline in commercial forest harvesting. However, most of the decline in the use of in-forest residues state has resulted from cutbacks in thinning operations that are not connected to commercial harvesting. The primary alternative disposal option for fuels derived from slash is open burning; the alternative for thinning residues is continued in-forest accumulation. For purposes of analysis hat most of the in-forest residues currently used for energy production would presumably be open burned; the remainder would be allowed to continue to accumulate as overstocking in the forests. If the overall demand for biomass fuels were to increase, for example to early 1990s levels, the proportion of in-forest residues whose alternative disposal would be in-forest accumulation would probably increase as well. 
Based on the alternative disposal options identified in Table 2, nearly half the biomass fuel used for power production in California would otherwise end up in landfills. Approximately 3.0 million tons/year. In addition, 1.7 million tons/year of residues would be added to the amount of biomass that is opened burned, 360,000 tons/year would be composted or spread as mulch, 490,000 million tons/year would be added to the material currently accumulating in California's forests, and 890,000 tons/ would be burned in sawmill kiln burners.

\section{Sources of Impacts Associated with Biomass Residue Disposal}

All alternatives for disposing of biomass wastes and residues, including leaving forest residues in place, entail adverse environmental impacts. Energy production from biomass residues produces air pollutants and solid waste (ash), and consumes water resources. Open burning produces smoke, air pollutants, and greenhouse gases. Burial in landfills depletes landfill space, pollutes water, and leads to greenhouse gas emissions. Spreading and composting are beneficial uses for these residues. However, these activities lead to emissions of greenhouse gases and volatile organic compounds (VOCs), and pollute water. In-forest accumulation of biomass as overgrowth material degrades forest health and increases the risks of destructive wildfires. These impacts are characterized and quantified in the following sections.

\section{Open Burning}

Open burning of in-forest biomass residues and agricultural residues is a major source of air pollution in many parts of California. Open burning produces massive amounts of visible smoke and particulates. It also produces significant quantities of emissions of other air pollutants, such as oxides of nitrogen $\left(\mathrm{NO}_{\mathrm{x}}\right)$, carbon monoxide $(\mathrm{CO})$, and hydrocarbons ( $\mathrm{HCs}$ ), which contribute to the formation of atmospheric ozone. Quantifying the emissions resulting from open burning is difficult because residues, burning practices, and environmental conditions are extremely variable. Nevertheless, using these residues as power plant fuel vastly reduces the smoke and particulate emissions associated with their disposal, and significantly reduces the amounts of $\mathrm{CO}$, $\mathrm{NO}_{\mathrm{x}}$, and HCs released to the atmosphere (Darley 1979).

Open residue burning is a particularly big problem in California's agricultural valleys, many of which are classified as nonattainment with respect to both California and federal air-quality standards for criteria air pollutants. Decreasing the amount of open burning of agricultural residues has long been an objective of air quality regulators, but the imperative for farmers to dispose of their residues cost effectively has precluded the outright banning of agricultural burning. The development of the biomass energy industry the 1980s helped mitigate the problem, but a large quantity of agricultural residues continues to be open-burned. At the peak of biomass fuel use in California from 1990 to 1993, more than 1.5 million tons/year of agricultural residues were used as fuel. The decrease in biomass fuel use since 1993 has led to a decrease in the use of 
agricultural residue fuel. As a result, 500,000 tons/year of agricultural residues that were being used as fuel as recently as 1993 are again being open burned.

The state's air quality regulatory agencies recognized the contribution the biomass energy industry could make toward eliminating of open burning of agricultural residues during the early phase of the industry's development. To give the biomass energy producers credit for the air quality benefits they provide, regulators developed the agricultural offset protocols (CARB 1984). Facilities that burn agricultural residues that would otherwise be open burned can earn an offset credit for open burning avoidance for the emissions of air pollutants at the power plant. Because emission offsets are required only for pollutants for which the receiving basin is nonattainment, most of the agricultural offset credits have been issued for emissions of $\mathrm{NO}_{\mathrm{x}}$ and particulates. For most facilities that have been permitted on the basis of the agricultural offset protocols, the permits require that one-half to two-thirds of the fuel supply be obtained from agricultural residue sources.

In addition to agricultural burning, California's air quality is affected by smoke emissions from prescription burning of brush and wood residues. Slash residues from forest harvesting operations, for example, are usually piled and burned to clean up the harvesting site and decrease the risk of wildfires. The U.S. Forest Service, which manages approximately 50\% of California's commercial forest land, has announced its intention to increase annual prescription burning by 140,000 acres/, an increase of more than 175 percent, in order to deal with the continuing buildup of overgrowth on federal forested lands (Cal/EPA 2000). While funding has not been made available for such activities, the public airing of intentions to increase burning have raised air-quality concerns at the California Air Resources Board (CARB).

In the spring of 1999, CARB initiated a proceeding to amend the state's regulations concerning open burning, which are contained in Title 17 of the California Code of Regulations. Title 17 governs all open burning activities, including agricultural burning, brush burning, and in-forest prescribed burning. Resource managers have enjoyed great freedom in the past to choose when, where, and how much prescription burning they would do. The proposed regulations would require the CARB to declare burn days and partial-burn days for each air basin, and local air pollution control districts would then allocate burn permits to keep pollution levels below target levels. The revision process stalled during 1999, then resumed earlier this year. The outcome is likely to be greater restrictions on open burning and an increased emphasis on developing alternatives.

\section{Burial}

Almost half the biomass fuel currently used in California would be buried in landfills in the absence of the energy production option (see Table 2). This material would come primarily from: urban and municipal waste wood that is now segregated and diverted from landfills, and wood processing residues. Landfill burial of wood residues entails the same kinds of environmental impacts associated with the disposal of all kinds of organic 
wastes in landfills. Woody materials degrade more slowly than other forms of organic wastes, which means that landfill stabilization is delayed when wood makes up a substantial fraction of the material buried in a landfill. Like all organic material buried in a landfill, waste wood can be a source of water-polluting leachates, and as the material degrades, it produces air emissions of VOCs and greenhouse gases.

Landfilled biomass degrades primarily under anaerobic conditions. A variety of microorganisms feed on the entombed biomass, eventually converting most of its carbon content into an approximately equal mixture of $\mathrm{CO}_{2}$ and $\mathrm{CH}_{4}$, the two principal greenhouse gases responsible for global warming. These gases percolate toward the surface, and are released to the atmosphere. This process lasts many years. Gas production from a given quantity of buried biomass occurs with a characteristic half-life, usually in the range of 10-20 years (Micales \& Skog 1996). Wood is more resistant to degradation than other forms of biomass buried in landfills, because of its dense physical structure and its high lignin content.

In addition to greenhouse gases, which are not currently regulated as pollutants, landfill gases contain a variety of VOCs and other noxious components, that are regulated pollutants. The federal Clean Air Act requires landfills with VOC emissions over threshold levels to control their emissions. This is accomplished by employing a gas collection system to collect most of the gas produced in the landfill, and combust it before releasing to the atmosphere. The gas can either be flared or burned in an engine for energy production. In either case, the effect of the treatment is to convert most of the VOCs and $\mathrm{CH}_{4}$ in the gas to $\mathrm{CO}_{2}$. Although not the aim of the emissions control requirements, this treatment significantly reduces the greenhouse gas potential of the carbon emitted from the landfill. In typical practice, a Title IV landfill gas collection system collects $70 \%$ or more of the total landfill gases, with $75 \%$ collection efficiency considered to be the upper limit (Augenstein, 1999). Gas collection starts 2-5 years after the material is placed in the ground, and typically continues for 30 years after landfill cell closure.

Accurately measuring emissions from landfill situations is difficult to predict, so predicting the proportion of the landfill-diverted biomass currently used for energy production that would otherwise be disposed in landfills with gas collection and treatment systems, and without collection systems is difficult. A higher percentage of urbanoriginated waste wood would probably be disposed in controlled landfills than would residues from the primary wood processing industries, which tend to be located in more rural locations. More remotely located regions tend to have smaller landfills, which are less likely to be subject to Title IV regulation.

Because wood waste decays slowly in the landfill environment, emissions of the bulk of the ultimate landfill gases are significantly delayed in time after the burial of the residue. This is a factor that should be taken into account in comparing the greenhouse gas implications of alternative disposal options. The initial result of diverting landfill-bound waste wood to a power plant is that virtually all the carbon content of the material is 
added to the atmospheric stock of $\mathrm{CO}_{2}$ immediately, rather than being stored underground as waste. This means that the atmospheric greenhouse gas burden associated with the biomass residue used as fuel is greater in the immediate aftermath of its combustion than if the material were buried in a landfill. Over time, however, the landfill out-gases a mixture of $\mathrm{CH}_{4}$ and $\mathrm{CO}_{2}$ to the atmosphere, and the much greater radiative effectiveness of $\mathrm{CH}_{4}$ rapidly leads to a greater greenhouse gas burden associated with the landfill-disposed biomass, which over time grows to a major liability for the landfill option. This is the case even with the use of gas control systems on landfills (see, Greenhouse Gas Analysis Model).

\section{Spreading and Composting}

An alternative disposal option to landfilling biomass wastes is surface spreading, which can be done with or without prior composting of the material. Bark and wood chips can be used directly for mulch, which usually consists of open spreading of the untreated material for landscaping purposes. Biomass can also be composted before spreading, although woody material is not ideal for composting because it breaks down slowly. Residue spreading with or without prior composting is a beneficial use for these materials. However, composting produces greenhouse gas emissions, as does subsequent degradation of spread material.

Composting of biomass accelerates the natural decomposition process. Decomposition occurs through aerobic and anaerobic pathways, producing a mixture of $\mathrm{CO}_{2}$ and $\mathrm{CH}_{4}$ emissions. In a well-managed compost operation the emissions are primarily $\mathrm{CO}_{2}$, because the material is frequently aerated. Anaerobic pockets in the compost pile, however, lead to emissions of $\mathrm{CH}_{4}$ and higher $\mathrm{HCs}$ including VOCs, some of which are malodorous or toxic compounds. The compost product, which contains approximately $50 \%$ of the original biomass carbon, is then spread, where it continues to decompose, although no longer at the accelerated pace of the compost pile.

\section{In-Forest Accumulation}

All forests are prone to periodic fires. However, the natural fire cycle has been altered in many regions of the United States by past forestry practices, by vigorous fire suppression efforts, and because populations have increasingly moved into wooded areas. The results of these phenomena have been to increase the amount of fuel loading in California's forests, and to degrade of forest health and productivity (see, for example, Cal. Dept. of Forestry 1996).

The fuel that is building up in the California's forests includes standing dead and diseased wood, downed woody material of all varieties, and an overall increase in the density of the forest's growing stock. Healthy, relatively undisturbed forest ecosystems in California that are subject to periodic low-level fires have an approximately $40 \%$ level of canopy closure, whereas many forests in the state have canopy closure levels of $60 \%$ and more. 
One category of biomass fuels used in California is in-forest residues. Some in-forest residue fuels are the result from forest thinning operations that would not be carried out in the absence of a demand for biomass fuel. Shrinkage in biomass fuel demand during the past decade has meant that fewer acres of forests are being thinned the result is that more forest acreage is in poor health, habitats and watersheds, and there is an enhanced risk of destructive wildfires than would be the case if the biomass energy industry operated at a higher level.

\section{Energy Production}

Combustion of biomass fuels in modern power plants leads to many of the same kinds of emissions as the combustion of fossil fuels in power plants. These include emissions of conventional air pollutants, greenhouse gases, and solid wastes (ash). Fuel processing, which in most cases involves some type of grinding operation, produces emissions of dust and particulates. Air emissions and solid waste (ash) production are usually the principal sources of environmental concern related to biomass facilities. Water consumption can be a concern in regions where water availability is limited.

Biomass power plants are required to achieve stringent emissions control levels for the criteria, or regulated, pollutants, including particulates, $\mathrm{NO}_{\mathrm{x}}$, oxides of sulfur $\left(\mathrm{SO}_{\mathrm{x}}\right), \mathrm{HCs}$, and $\mathrm{CO} . \mathrm{NO}_{\mathrm{x}}, \mathrm{HCs}$, and $\mathrm{CO}$ usually are controlled by using advanced combustion technologies, often including fluidized-bed combustors, staged-combustion, and/or fluegas recirculation. Some of the newest biomass energy facilities in California are required to use ammonia injection for post-combustion control of $\mathrm{NO}_{\mathrm{x}}$ emissions. $\mathrm{SO}_{\mathrm{x}}$ emissions generally are not a concern with biomass combustion because biomass residues, especially woody forms of biomass, have a very low sulfur content. Some facilities that have fluidized-bed combustors inject limestone for sulfur capture, but none are required to have post-combustion flue-gas scrubbers to control $\mathrm{SO}_{\mathrm{x}}$ emissions.

Particulates are controlled in biomass energy plants using a variety of technologies. Virtually all biomass energy plants employ cyclones to remove the bulk of the large particulates found in the flue gas. Most are equipped with electrostatic precipitators for final particulate removal; some use baghouses. Most modern biomass energy plants are required to achieve zero visible emissions to meet environmental permit conditions. Their emissions of total and sub-micron sized particulates are also regulated and controlled to stringent levels, comparable to or lower than the emissions levels achieved by the large fossil fuel power plants operated by the electric utility companies.

The production of electricity in biomass power plants helps reduce air pollution by displacing the production of power using conventional sources. The marginal generating source displaced by biomass energy generation in most cases is natural gas fired power generation, using steam-turbine technology, and/or gas-turbine technology. The full net emissions reductions associated with biomass energy generation can be calculated as the difference between the net emissions associated with the biomass power cycle alone, and the sum of the emissions that would have been produced by the avoided fossil fuel based 
generation, and the emissions associated with the displaced alternative disposal of the biomass residues.

\section{Magnitude of the Impacts of Biomass Disposal Alternatives}

All the disposal alternatives available for biomass residues in California, including leaving overgrowth biomass in place in the forest, have environmental impacts. All types of combustion of biomass and other fuels lead to emissions of air pollutants $\left(\mathrm{SO}_{\mathrm{x}}, \mathrm{NO}_{\mathrm{x}}\right.$, particulates, $\mathrm{CO}, \mathrm{HCs}$, etc.) and greenhouse gases $\left(\mathrm{CO}_{2}\right.$ and $\left.\mathrm{HCs}\right)$. Landfill disposal of biomass also leads to emissions of greenhouse gases, with approximately half the emitted carbon in the form of the more potent greenhouse gas, $\mathrm{CH}_{4}$, and the other half as $\mathrm{CO}_{2}$. Landfills also emit noxious VOCs, and landfilling of biomass depletes of landfill space and to problems of leachates and water pollution. Allowing biomass to accumulate in the forest as overgrowth material increases the risks of destructive wildfires, degrades the health and productivity of forests and watersheds, and diminishes the quality of wildlife habitat. Finally, biomass energy production, which produces air emissions and ash and consumes water resources, also delivers a variety of desirable rural development and social benefits, such as increased rural employment opportunities, local tax revenues for rural communities, and increased diversity of energy sources for all the state's residents.

\section{Conventional Air Pollution}

Biomass combustion, like the combustion of fossil fuels, produces emissions of a range of conventional air pollutants that are the subject of ongoing concern. California's unique combination of geography, climate, and economic activity cause particular concern about air pollution. The state's multibillion-dollar agricultural industry produces millions of tons of biomass residues that are open burned every year as a regular part of the productive operations. Agricultural burning is a major source of smoke and other pollutants in California's San Joaquin and Sacramento Valleys, which have trouble complying with state and federal ambient air quality standards.

California's forests and woodlands are also sources of major quantities of emissions of smoke and air pollution caused by open burning from prescription burns and uncontrolled wildfires. Prescription burning in many cases is designed to reduce the risks of wildfires, which are exacerbated by biomass in excess of natural conditions in many regions. The major tools for reducing forest fire risks in overgrown forests and woodlands are prescription burning and removal of biomass for use as fuel. California has a huge inventory of forested acreage that would benefit from fire-risk reduction treatments, but very little is actually being done. Nevertheless, in recognition of the potential for increased prescription burning, CARB has initiated a process of revamping the state code regulating the open burning of agricultural residues and prescription burning of wood residues. 
Landfilling biomass avoids combustion of the material, and the subsequent emissions of conventional air pollutants. Landfills, however, are not free from air pollution concerns. Degradation of biomass in landfills produces a complex mixture of gaseous products that percolate through the fill and are emitted to the atmosphere. The major air pollution problem associated with landfills is emissions of VOCs, which are toxic chemicals and contribute to smog formation. Title IV of the federal code requires landfills with VOC emissions over a given threshold to employ gas collection and combustion systems to reduce them. The gas can either be flared or conditioned and combusted in an engine for power production.

Biomass energy plants are regulated with respect to the amounts of air pollutants such as $\mathrm{SO}_{\mathrm{x}}, \mathrm{NO}_{\mathrm{x}}$, particulates, $\mathrm{CO}$, and $\mathrm{HCs}$ they can emit. The power plants employ combustion controls and post-combustion cleanup technologies to limit their emissions of air pollutants. Open combustion of biomass produces much higher levels of air pollutants than controlled combustion of the same material in power plant boilers. In particular, open burning produces massive emissions of smoke and particulates, and much higher emissions of $\mathrm{CO}$ and $\mathrm{HCs}$, in comparison with biomass combustion in controlled boilers. $\mathrm{NO}_{\mathrm{x}}$ emissions are also elevated under uncontrolled combustion conditions. As a rule, the higher the temperatures in the combustion zone, the lower the emissions of pollutants. Typical kiln boilers, which tend to employ fairly rudimentary combustors, produce emissions that are higher than those produced in power plant boilers equipped with emissions control technologies, but much lower than those associated with uncontrolled open burning.

AP-42 is the EPA's comprehensive publication on emissions factors for a wide variety of human activities (EPA 1995). AP-42 has emissions factors for many combustion processes, including controlled combustion of biomass and fossil fuels in boilers, open burning of biomass, and disposal of biomass in landfills. AP-42 is the major source of air pollution emissions data for this report. These data are supplemented by other relevant sources.

Table 3 shows average emissions levels of the criteria air pollutants for biomass energy generation. The data are based on information supplied by 34 California biomass facilities, and show permitted emissions levels and actual source test data. The data are further differentiated by combustor type. Eleven of the 34 facilities included in the survey have fluidized-bed combustors; 23 have grate-type burners of various designs. The fluidized-bed combustors achieve lower emissions levels for all criteria pollutants of concern for biomass power plants, compared with the grate burners. The most dramatic difference is in $\mathrm{CO}$ emissions, for which the fluidized-bed combustors are more than an order of magnitude better than the grate burners. As the table demonstrates, the fluidized-bed combustors achieve emissions rates of half or less as compared with the grate burners for all pollutants shown. 
Table 3

Emissions Factors for Energy Production and Biomass Disposal

\begin{tabular}{|c|c|c|c|c|c|c|c|c|}
\hline & $\begin{array}{c}\text { SOx } \\
\text { lb/th.bdt }\end{array}$ & $\begin{array}{c}\text { NOx } \\
\text { lb/th.bdt }\end{array}$ & $\begin{array}{l}\text { particulate } \\
\text { lb/th.bdt }\end{array}$ & $\begin{array}{c}\text { CO } \\
\mathrm{lb} / \mathrm{th} \cdot \mathrm{bdt}\end{array}$ & $\begin{array}{l}\mathrm{nmHCs} \\
\mathrm{lb} / \mathrm{th} \cdot \mathrm{bdt}\end{array}$ & $\begin{array}{c}\text { GHGs } \\
\text { ton/th.bdt }\end{array}$ & $\begin{array}{c}\text { landfill } \\
\text { m3/th.bdt }\end{array}$ & $\begin{array}{c}\text { thinned } \\
\text { acres/th.bdt }\end{array}$ \\
\hline biomass energy * & 150 & 2,500 & 450 & 7,500 & 25 & 1,763 & 24 & \\
\hline open burning & 150 & 7,000 & 15,000 & 150,000 & 24,000 & 2,061 & & \\
\hline Controlled landfill & & & & & 6,500 & 2,383 & 2,400 & \\
\hline Uncontrolled landfill & & & & & 12,300 & 4,102 & & \\
\hline forest accum. & 150 & 7,000 & 21,000 & 280,000 & 23,000 & 3,408 & & 40 \\
\hline composting & & & & & 2,900 & 2,594 & & \\
\hline spreading & & & & & 3,000 & 2,245 & & \\
\hline kiln boiler & 150 & 2,500 & 900 & 15,000 & 50 & 3,526 & 24 & \\
\hline
\end{tabular}

* Note that for biomass energy production, unit/th.bdt is approximately the same as unit/mil.kWh)

One of the largest efforts to measure the emissions of open burning of biomass was undertaken by researchers at the University of California, Riverside during the late 1970s (Darley 1979). The emission factors reported from this study were used as the basis for developing the agricultural offset protocols in California, and remain the best, albeit limited, source of data on emissions from the open burning of biomass. AP-42 uses the Darley data and other sources to characterize the emissions typical of open burning of a variety of biomass residues. Table 4 shows emissions factors for open burning of biomass residues under various conditions, as well as emissions factors for other activities that are relevant to biomass energy production and use.

Table 4

Emissions from Biomass Power Plants

(lb/bdt)

\begin{tabular}{|c|c|c|c|c|c|c|}
\hline & & mit Lev & & & red Emi & \\
\hline & All & Grates & FBs & All & Grates & FBs \\
\hline NOx & 2.6 & 3.1 & 1.5 & 2.0 & 2.5 & 1.0 \\
\hline sox & 1.2 & 0.9 & 1.7 & 0.1 & NA & 0.1 \\
\hline $\mathrm{CO}$ & 11.5 & 16.3 & 2.0 & 10.3 & 14.7 & 0.2 \\
\hline $\mathrm{HCs}$ & 1.7 & 1.8 & 1.6 & 0.5 & 0.7 & 0.1 \\
\hline Particulates & 0.8 & 1.0 & 0.6 & 0.5 & 0.6 & 0.3 \\
\hline
\end{tabular}

Data averaged for 34 California biomass facilities, 23 Grates, 11 fluidized-bed burners. 


\section{Greenhouse Gases and Climate Change}

A wide range of climate changes, known collectively as the "greenhouse effect," are expected to occur within the next several decades as concentrations of atmospheric greenhouse gases continue to rise. The principal atmospheric greenhouse gases are $\mathrm{CO}_{2}$, $\mathrm{CH}_{4}$, nitrous oxide $\left(\mathrm{N}_{2} \mathrm{O}\right)$, tropospheric ozone $\left(\mathrm{O}_{3}\right)$, and the chlorofluorocarbons $(\mathrm{CFCs})$ that are also implicated in the destruction of stratospheric ozone. These gases are transparent to incoming solar radiation, but absorb outgoing infrared radiation emitted from the Earth's surface that would otherwise be lost to space. If there were no greenhouse gases in the atmosphere, the temperature of the Earth's surface would be about $60^{\circ} \mathrm{F}$ colder than it is today. Concentrations of the natural atmospheric greenhouse gases have varied over the Earth's history. However, human activities are raising the atmospheric concentration of the greenhouse gases at an unprecedented rate, causing greater amounts of heat to be trapped and intensifying the natural greenhouse effect.

The present worldwide scientific consensus is that significant climatic changes will result from the continuing buildup in the concentration of atmospheric greenhouse gases that has been going on for more than a century (IPCC 1996). The year 2000 IPCC update, which has been released in draft form, concludes that there has already been a discernible human influence on global climate (Science 2000). Expected climate impacts include changes in precipitation patterns and water availability, higher sea levels, and more frequent and severe storms and other weather extremes. The IPCC estimates that atmospheric $\mathrm{CO}_{2}$ concentrations are currently increasing approximately $0.4 \%$ annually, and those of $\mathrm{CH}_{4}$ are increasing $0.6 \%$ annually.

Although uncertainty remains over the rate of climate change and the regional details of the impacts of such changes, the causes are well understood. The human activity most responsible for greenhouse gas emissions is the use of fossil fuels, which produces large quantities of $\mathrm{CO}_{2}$ and smaller (but still significant) quantities of $\mathrm{CH}_{4} \cdot \mathrm{CO}_{2}$ accounts for approximately $50 \%$ of the greenhouse warming in the atmosphere. Global annual emissions of $\mathrm{CO}_{2}$ are estimated to be 20 billion tons. $\mathrm{CH}_{4}$ accounts for another $20 \%$ of the present level of atmospheric greenhouse warming.

Biomass, which is approximately $50 \%$ carbon on a dry-weight basis, is an essential component of the Earth's carbon cycle. Carbon exchanges actively between the atmosphere and the Earth's biota, to the extent of almost 100 billion tons annually. Carbon is fixed into biomass via photosynthesis, and released back to the atmosphere via a variety of pathways, principally respiration, fermentation, and combustion. From a greenhouse gas perspective, atmospheric carbon has two functionally distinct forms: oxidized $\left(\mathrm{CO}_{2}\right.$ and $\left.\mathrm{CO}\right)$, and reduced $\left(\mathrm{CH}_{4}\right.$ and higher $\mathrm{HCs}$, including VOCs). The reduced forms are more potent greenhouse gases, by a factor of 25 on a per-carbon basis, than the oxidized forms (IPCC 1996). For, reduced arbon greenhouse gases are represented in this paper as $\mathrm{CH}_{4}$ equivalents, and oxidized carbon greenhouse gases are represented as $\mathrm{CO}_{2}$ equivalents. 
Assuming the agricultural and forestry enterprises from which biomass fuels are extracted are being sustainably managed, the use of biomass for energy production arguably has no net impact on the global carbon cycle. The biomass carbon released into the atmosphere by energy production is balanced by the photosynthetic production of replacement biomass in the field or forest. This is in stark contrast to the case of energy production from fossil fuels, in which carbon that is locked away in long-term geological storage is added to the stock of carbon in the atmospheric/biotic cycle as a net addition of new material, which has a very long residence time.

On the other hand, because of the very large difference in radiative effectiveness between $\mathrm{CO}_{2}$ and $\mathrm{CH}_{4}$, the form of the carbon emitted to the atmosphere during the course of the disposal of biomass wastes and residues strongly affects the greenhouse warming potential associated with the disposal process. Anaerobic decomposition of biomass, for example, which occurs in landfills and in other disposal options and produces roughly a 50-50 mixture of $\mathrm{CO}_{2}$ and $\mathrm{CH}_{4}$. Controlled combustion, in contrast, emits carbon almost exclusively in the form of $\mathrm{CO}_{2}$. For a given amount of carbon a 50-50 mixture of $\mathrm{CO}_{2}$ and $\mathrm{CH}_{4}$ has a greenhouse warming potential that is 13 times greater than that of $\mathrm{CO}_{2}$ alone, on an instantaneous basis. In the longer term $\mathrm{CH}_{4}$ in the atmosphere oxidizes to $\mathrm{CO}_{2}$ with a lifetime of approximately 12 years; $\mathrm{CO}_{2}$ has a much longer atmospheric lifetime, about 100 years. Thus, the potency of a $\mathrm{CO}_{2}$ and $\mathrm{CH}_{4}$ mixture emitted to the atmosphere at time zero declines toward that of pure $\mathrm{CO}_{2}$ over a long period of time.

One complicating factor in comparing the greenhouse gas implications of biomass energy production with disposal alternatives for the biomass is that the timing of the emissions can be very different. Energy production leads to the conversion of virtually all the carbon in the biomass to $\mathrm{CO}_{2}$, which is released immediately to the atmosphere. The various alternative disposal options produce a mixture of $\mathrm{CO}_{2}, \mathrm{CH}_{4}$, and fixed carbon, and in some cases the emissions of the greenhouse gases $\left(\mathrm{CO}_{2}\right.$ and $\left.\mathrm{CH}_{4}\right)$ are significantly delayed. For example, biomass carbon that accumulates in the forest as overstocked material may remain as intact biomass for many years before being cycled to the atmosphere via fire or decay. Lag times in emissions, as well as relative radiative effectiveness, have to be taken into account when comparing the greenhouse warming implications of alternatives for disposing of biomass residues.

\section{Greenhouse Gas Model}

A detailed dynamic atmospheric concentration model has been developed for analyzing the time-dependent greenhouse gas concentrations associated with biomass energy production. Atmospheric concentrations of the greenhouse gases associated with this pathway can be compared with alternative means of disposing of the same biomass residues, combined with alternative production of the energy using fossil fuels. The model computes the time-dependent atmospheric stocks of $\mathrm{CO}_{2}$ and $\mathrm{CH}_{4}$ associated with the biomass residues used for energy production, or subjected to alternative disposal options. Atmospheric concentrations of these greenhouse gases are followed over a 100year time period. The model can track the long-term atmospheric greenhouse gas 
concentrations resulting from a single year's worth of biomass residue use, or those associated with sustained use of biomass for energy production at current or changing levels of use.

The model is a stock and flow model that incorporates exponential decay mechanisms for all stocks of carbon. The carbon stocks analyzed in the model include the atmospheric stocks of $\mathrm{CO}_{2}$ and $\mathrm{CH}_{4}$, and various stocks of fixed carbon in storage. The storage options include carbon buried in a landfill, carbon that is land spread, and carbon that exists as overstocked biomass in the forest. For each disposal option the biomass carbon is initially partitioned among: atmospheric $\mathrm{CO}_{2}$, atmospheric $\mathrm{CH}_{4}$, and carbon in storage. The carbon in storage is then subjected to exponential decay into $\mathrm{CO}_{2}, \mathrm{CH}_{4}$, and permanent storage. The $\mathrm{CO}_{2}$ and $\mathrm{CH}_{4}$ emitted by the carbon in storage are added to the atmospheric stocks over time, in accordance with the characteristic half-life of the carbon in the storage reservoir. The atmospheric $\mathrm{CO}_{2}$ and $\mathrm{CH}_{4}$ stocks are subjected to exponential decay removal processes. The removal pathway for atmospheric $\mathrm{CH}_{4}$ is conversion via oxidation to atmospheric $\mathrm{CO}_{2}$. Figure 8 shows the stocks and flows of carbon as analyzed in the model.

Figure 8

Stocks and Flows in GHG Model
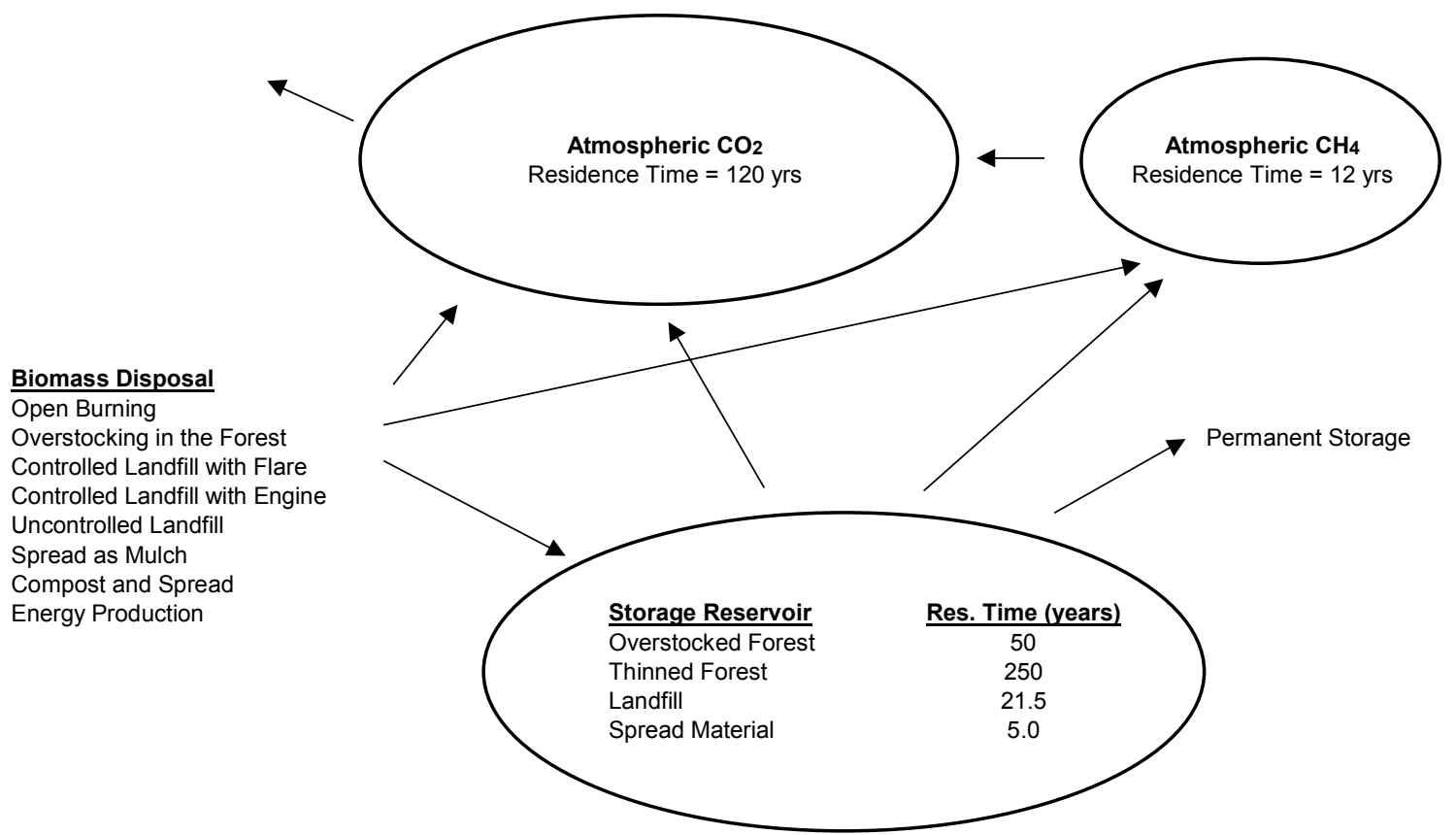

The model begins with an inventory of the types of biomass fuels used for energy production in California. Factors for partitioning each type of biomass into alternative fates (open burning, landfilling, etc.) are then entered, and the amounts of biomass that would be subject to each category of alternative fate is determined. A summary of the alternative fates of biomass residues used for energy production in California was presented in Table 2. The model follows the carbon flows for each alternative fate over a 
100-year period, and the atmospheric concentrations of $\mathrm{CO}_{2}$ and $\mathrm{CH}_{4}$ are compared for the energy production alternative, and for the alternative fates for the biomass residues, should energy production not be performed. The greenhouse gas emissions of avoided fossil fuel use can be either included or excluded from the analysis, according to the model user's preference.

Two types of landfills are included in the model: those that have gas collection systems (controlled landfills), and those that do not have gas collection systems (uncontrolled landfills). The difference between the two, as far as greenhouse gases are concerned, is the mixture of the gases emitted to the atmosphere. It is assumed that $50 \%$ of the biomass carbon converted to gas in a landfill is converted to $\mathrm{CO}_{2}$, and $50 \%$ is converted to $\mathrm{CH}_{4}$. Gas collection systems intercept a fraction of the gases generated in the landfill ( $72 \%$ in the base case), and convert all the carbon in the collected gas to $\mathrm{CO}_{2}$. This means, for example, that with the base-case gas collection system, the mixture of gases emitted to the atmosphere from a controlled landfill is $14 \% \mathrm{CH}_{4}, 86 \% \mathrm{CO}_{2}$, compared with an uncontrolled landfill, which emits carbon gases in a 50-50 mixture of $\mathrm{CH}_{4}$ and $\mathrm{CO}_{2}$.

Modern controlled landfills begin gas collection anywhere 2 to 5 years after waste is buried in the ground, and, under current regulations, continue gas collection for 30 years after cell closure. In California, approximately $60 \%$ of the biomass that would otherwise be landfilled would go to controlled landfills, and $40 \%$ would go to uncontrolled landfills, in the absence of energy production. It is likely that the proportion of waste going to controlled landfills will increase in the future. Some controlled landfills in California flare the landfill gas they collect; others burn it in engines for energy production, displacing fossil fuels and their greenhouse gas emissions in the process. The model allows the user to specify the proportion of controlled landfills that have landfill gas energy production systems.

Biomass degradation in the landfill environment is a highly variable process that depends on, among other things, evolving landfill management technology. Borings into old landfills show that the rate of biomass degradation can be radically different in different locations in the same landfill. For modeling purposes, biomass disposed in landfills is assumed to be partitioned into two distinct fractions: readily degradable carbon (cellulose and hemicellulose) and lignin. The lignin fraction is far more resistant to decomposition than the readily degradable fraction. Each carbon fraction is assigned its own characteristic half-life and percent non-degradable component in the model. The base case data set used in the analysis assumes a half-life of 15 years for readily degradable carbon and 75 years for lignin. Furthermore, it is assumed that $10 \%$ of the readily degradable carbon and $37.5 \%$ of the lignin, is not degradable. Using the base case data set, $38 \%$ of the readily degradable carbon and $87 \%$ of the lignin carbon, which together are $50 \%$ of the total biomass carbon, remain entombed in the landfill 25 years after burial. One-third of the total biomass remains entombed 50 years after burial. 
Analyzing the greenhouse gas fate of biomass left in the forest as overstocked material, rather than being thinned and used as fuel, is tricky. Left in the forest, overstocked biomass is initially treated as having entered into a long-term storage reservoir, which is the overstocked forest. The overstocked forest has a higher probability than a thinned forest of destructive wildfires. When a wildfire does occur, it consumes not only the overstocked material that would have been removed in a thinning, but also some growing stock that would have remained in the forest after a thinning. For modeling purposes, the greenhouse gas impact of leaving biomass in the forest as overstocked material is determined as the difference between the emissions of greenhouse gases from overstocked forests, and the emissions that occur from thinned forests. Biomass carbon in a thinned forest has a longer residence time than in the overstocked situation (lower annual probability of fire), and fires in thinned forests cause less extensive damage to the growing stock than fires in overstocked forests.

Table 5 shows the Model Inputs Module for the biomass greenhouse gas model. All the input data to the model are entered on this page, in the outlined cells. The data set shown in the table is the base case. Figure 9 shows the greenhouse gas burden over a 100-year time period due to the use of 6.4 million tons of biomass fuels ( 3.8 million bdt) in California during 1999 (lower of the two bold lines in the figure, labeled Biomass Energy). California's biomass power plants emitted almost 7 million tons of $\mathrm{CO}_{2}$ equivalents last year, almost all of which are $\mathrm{CO}_{2}$. The $\mathrm{CO}_{2}$ has a characteristic residence time in the atmosphere of 120 years, so 100 -years later, in the year 2100 , approximately 3 million tons of the $\mathrm{CO}_{2}$ emitted by the biomass power plants in 1999 will still be resident in the atmosphere.

Figure 9

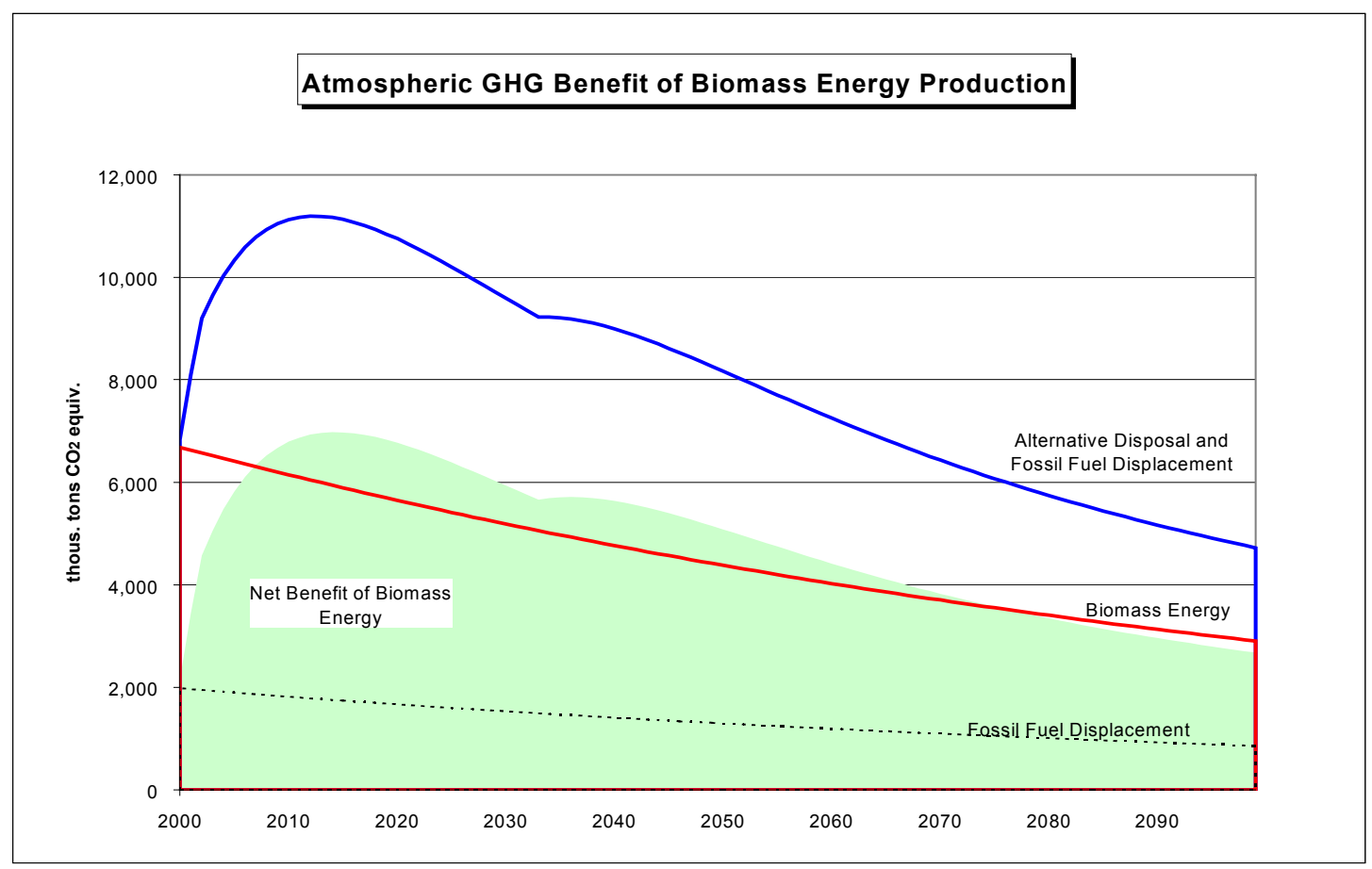


Table 5

\section{Biomass Greenhouse Gas Emissions Model}

\section{Model Inputs Module}

\begin{tabular}{|c|c|c|c|c|c|c|c|}
\hline & Mill & Forest & $\underline{\mathrm{Ag}}$ & Urban & Total & $\%$ Total & $\begin{array}{r}\text { Ann. } \\
\text { Growth }\end{array}$ \\
\hline Annual Fuel Use (th.bdt/yr) & 1,231 & 666 & 721 & 1,183 & $3 \overline{802}$ & & $0.0 \%$ \\
\hline \multicolumn{8}{|c|}{ If No Fuel Use, \% that Would Be Disposed of by } \\
\hline Open Burning & $0.0 \%$ & $60.0 \%$ & $90.0 \%$ & $0.0 \%$ & 1,049 & $28 \%$ & $0.0 \%$ \\
\hline Forest Accumulation & $0.0 \%$ & $40.0 \%$ & $0.0 \%$ & $0.0 \%$ & 267 & $7 \%$ & $0.0 \%$ \\
\hline Controlled Landfill & $25.0 \%$ & $0.0 \%$ & $5.0 \%$ & $65.0 \%$ & 1,113 & $29 \%$ & $0.0 \%$ \\
\hline Uncontrolled Landfill & $35.0 \%$ & $0.0 \%$ & $5.0 \%$ & $20.0 \%$ & 704 & $19 \%$ & $0.0 \%$ \\
\hline Spreading & $2.5 \%$ & $0.0 \%$ & $0.0 \%$ & $2.5 \%$ & 60 & $2 \%$ & $0.0 \%$ \\
\hline Composting & $2.5 \%$ & $0.0 \%$ & $0.0 \%$ & $12.5 \%$ & 179 & $5 \%$ & $0.0 \%$ \\
\hline kiln boiler & $35.0 \%$ & $0.0 \%$ & $0.0 \%$ & $0.0 \%$ & 431 & $11 \%$ & $0.0 \%$ \\
\hline
\end{tabular}

Fate of $C$ if use

Open Burning

Overstocked Forest

Thinned Forest

Controlled Landfill lignin fraction Uncontrolled Landfill lignin fraction

Spreading lignin fraction Composting lignin fraction Biomass Energy

\begin{tabular}{|c|c|c|c|}
\hline \multicolumn{3}{|c|}{ Initial Fate } & \multirow{2}{*}{$\begin{array}{l}\text { In Stora } \\
1 / 2 \text { Life }\end{array}$} \\
\hline$\underline{\mathrm{CO}_{2}}$ & $\underline{\mathrm{CH}} 4$ & Storage & \\
\hline \multirow[t]{9}{*}{$92.5 \%$} & $2.5 \%$ & $5.0 \%$ & 5.0 \\
\hline & & $100.0 \%$ & 34.7 \\
\hline & & $100.0 \%$ & 173.3 \\
\hline & & $100.0 \%$ & 15.0 \\
\hline & & & 75.0 \\
\hline & & $100.0 \%$ & 15.0 \\
\hline & & & 75.0 \\
\hline & & $100.0 \%$ & 3.5 \\
\hline & & & 25.0 \\
\hline \multirow[t]{2}{*}{$45.0 \%$} & $5.0 \%$ & $50.0 \%$ & 3.5 \\
\hline & & & 25.0 \\
\hline $99.0 \%$ & $0.1 \%$ & $1.0 \%$ & 10.0 \\
\hline
\end{tabular}

\begin{tabular}{|c|c|c|c|}
\hline$(y r)$ & Loss fro & rage & Accum. in \\
\hline s.Time & $\underline{\mathrm{CO}} 2$ & $\underline{\mathrm{CH}} 4$ & Storage \\
\hline 7.2 & $80.0 \%$ & $5.0 \%$ & $15.0 \%$ \\
\hline 50.0 & $69.0 \%$ & $6.0 \%$ & $25.0 \%$ \\
\hline 250.0 & $30.5 \%$ & $2.5 \%$ & $67.0 \%$ \\
\hline 21.6 & $77.4 \%$ & $12.6 \%$ & $10.0 \%$ \\
\hline 108.2 & $53.8 \%$ & $8.8 \%$ & $37.5 \%$ \\
\hline 21.6 & $45.0 \%$ & $45.0 \%$ & $10.0 \%$ \\
\hline 108.2 & $31.3 \%$ & $31.3 \%$ & $37.5 \%$ \\
\hline 5.0 & $85.5 \%$ & $9.5 \%$ & $5.0 \%$ \\
\hline 36.1 & $67.5 \%$ & $7.5 \%$ & $25.0 \%$ \\
\hline 5.0 & $85.5 \%$ & $9.5 \%$ & $5.0 \%$ \\
\hline 36.1 & $67.5 \%$ & $7.5 \%$ & $25.0 \%$ \\
\hline 14.4 & $60.0 \%$ & $5.0 \%$ & $35.0 \%$ \\
\hline
\end{tabular}

Avoided Fossil Fuel C

Coal

N. Gas / Steam Turb.

N. Gas / Comb. Cycle

\begin{tabular}{|c|c|}
\hline$\%$ avo & nk \\
\hline $10 \%$ & 34 \\
\hline $50 \%$ & 1,72 \\
\hline $40 \%$ & 1,38 \\
\hline
\end{tabular}

\begin{tabular}{|ccc|}
\multicolumn{1}{c}{ ton $/ \mathrm{mmkWh}$} \\
\multicolumn{1}{c}{$\underline{\mathrm{CO}_{2}}$} & $\underline{\mathrm{CH}_{4}}$ & $\underline{\text { Storage }}$ \\
\hline 1,060 & 0.15 & 3.0 \\
570 & 0.04 & \\
450 & 0.10 & \\
\hline
\end{tabular}

$\%$ avoided LF gas En.

$\begin{array}{r}\hline 10 \% \\ 50 \% \\ 40 \% \\ \hline\end{array}$

\begin{tabular}{|c|c|c|c|}
\hline Carbon in Atmosphere & $\underline{1 / 2 \text { Life }}$ & $\begin{array}{l}\text { Res. } \\
\text { Time }\end{array}$ & Rad.Eff. \\
\hline $\mathrm{CO} 2$ & 83.2 & 120.0 & 1 \\
\hline $\mathrm{CH}_{4}$ & 8.3 & 12.0 & 25 \\
\hline
\end{tabular}

First Year of Projection (1, or actual date)

One-Year Model or Continuous Input ( $1=1-\mathrm{yr}, 0=$ continous $)$ ?

No. of Years @ Growth Rate

Ave. Forest Density Before Thinning

Ave. Amount of Fuel Removed by Thinning

Time Required to Fill a Landfill Cell

Lag Before Collection Begins from a New Cell

Years Collection Maintained After Cell Closure

Proportion of Gas Collected with Controls

Proportion of Controlled LFs w/ Energy Production

LF Gas Engine Heat Rate

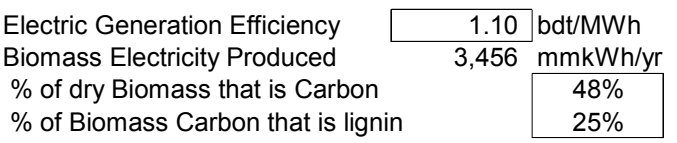

\begin{tabular}{|c|l}
\hline 2000 & \\
1 & \\
5 & \\
100 & \\
25 & bdt / ac \\
4 & bdt / ac \\
3 & years \\
30 & years \\
$72 \%$ & years \\
$50 \%$ & \\
12,000 & btu/kWh \\
\hline
\end{tabular}

Entries inside boxes are inputs to the model. 
Biomass energy production in California during 1999 avoided the production of 3,500 million $\mathrm{kWh}$ of electricity from fossil fuel sources, mostly natural gas. This translates into an avoidance of approximately 2 million tons of $\mathrm{CO}_{2}$ equivalents from fossil fuel combustion during 1999, as indicated in the dashed curve labeled Fossil Fuel Displacement in Figure 9. In addition, conversing the biomass to energy avoids alternative disposal of the residues, and their associated greenhouse gas emissions. Alternative disposal would result in the immediate emission of more than 5 million tons of $\mathrm{CO}_{2}$ equivalents during 2000, mostly from the fraction of biomass that would otherwise be open burned. Subsequent emissions of additional greenhouse gases over a long period from the burial of some residues in landfills, and the accumulation of some as overgrowth in the forests, would then ensue. The greenhouse gas levels associated with alternative disposal of the residues peaks at almost 10 million tons of $\mathrm{CO}_{2}$ equivalents in the year 2013, then begins to dissipate. A small hitch occurs in the curve in 2030, when controlled landfills terminate the gas collection process. The upper curve in the figure, labeled Alternative Disposal and Fossil Fuel Displacement, shows the atmospheric greenhouse gas profile that was avoided because of biomass energy production in California during 1999.

The net benefit of biomass energy production, defined as the difference between the emissions from energy production and those avoided because of alternative disposal of the residues and production of energy, is shown as the shaded area in the figure. The results show that the use of the 6.4 million tons ( 3.8 million bdt) of biomass fuel in California during 1999 results in a reduction in the atmospheric greenhouse gas burden of almost 2 million tons of $\mathrm{CO}_{2}$ equivalents in 2100. In 2012, when the Kyoto protocol requires that the United States reduce its greenhouse gas emissions to 7 percent below 1990 baseline levels, the use of biomass fuels during 1999 in California reduces year 2012 greenhouse gas emissions by 600,000 tons of $\mathrm{CO}_{2}$ equivalents. Moreover, atmospheric greenhouse gas levels in 2012 will be lower by more than 5 million tons of $\mathrm{CO}_{2}$ equivalents as a result of California biomass energy production during 1999.

Most greenhouse gas benefits of biomass energy production in California result from avoided alternative disposal of the biomass residues, rather than being due to the avoidance of fossil fuel use. Approximately $75 \%$ of the total greenhouse gas benefits of biomass energy production are due to the avoidance of alternative disposal of the residue materials, and $25 \%$ are due to fossil fuel avoidance, as illustrated in Figure 9.

One purpose for conducting this analysis is to determine greenhouse gas emissions factors for the activities relevant to biomass energy production, including biomass power plant emissions, avoided fossil fuel emissions, and emissions for the alternative disposal options for biomass residues. As seen in Figure 9, the atmospheric greenhouse gas profile over time is very different for the energy production activities (biomass and fossil fuel), and for the alternative disposal activities, shown collectively in the figure.

Figure 10 shows the profile over time of the greenhouse gas burdens associated with biomass energy production, avoided fossil fuel emissions, and the alternative disposal 
options included in the model, all scaled to the disposal of 1 million bdt of biomass residues. The curves for the biomass and fossil fuel energy alternatives are based on the immediate release of virtually all the fuel-bound carbon in the form of $\mathrm{CO}_{2}$, followed by its gradual clearance from the atmosphere. The conversion of 1 million bdt of biomass leads to emissions of 1.75 million tons of $\mathrm{CO}_{2}$, while avoiding emissions of 0.52 million tons of fossil fuel $\mathrm{CO}_{2}$, based on the assumed California mix of avoided fossil fuel use. Where coal makes up a greater proportion of the displaced fossil fuel use, the avoided fossil fuel emissions are greater.

Figure 10

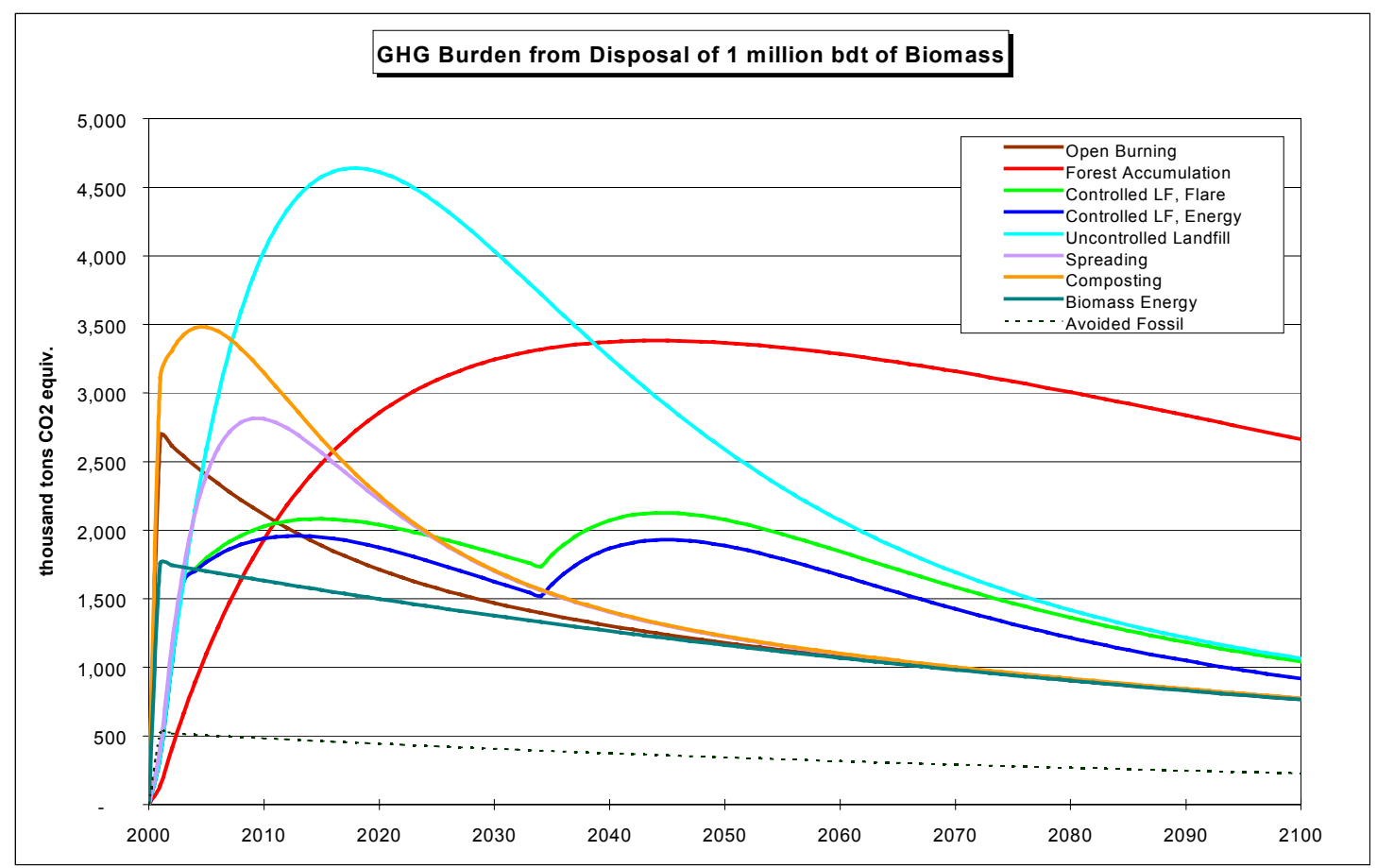

Most biomass residues used for energy production in California today would be landfilled in the absence of energy production. The immediate impact of landfilling biomass, from a greenhouse gas perspective, is to place the biomass carbon in a fixed-carbon storage reservoir, the landfill, thus keeping it from the atmosphere. The biomass carbon in the landfill, however, begins to degrade into a 50-50 mixture of $\mathrm{CH}_{4}$ and $\mathrm{CO}_{2}$, which is emitted to the atmosphere over an extended period. Because of the great imbalance in radiative effectiveness between the two forms of carbon, the greenhouse gas burden of landfill burial exceeds that of energy production within 3 to 4 years of the disposal of the material in the landfill.

For uncontrolled landfills, the greenhouse gas burden of burying 1 million bdt of biomass in 2000 increases rapidly for 15 years after the waste is buried, peaking at more than 4.6 million tons of atmospheric $\mathrm{CO}_{2}$ equivalents in 2018. After that time the rate of clearance of the accumulated $\mathrm{CH}_{4}$ in the atmosphere exceeds the rate of emissions from 
the landfill, and the total greenhouse gas burden associated with the previously buried waste decreases.

The greenhouse gas burden associated with biomass buried in controlled landfills departs from that of uncontrolled landfills as soon as the gas collection system is placed into service, which is 3 years after the waste is buried in the base-case data set. The rate of out-gassing of carbon from the landfill is the same for both types of landfills, but the ratio of $\mathrm{CH}_{4}$ to $\mathrm{CO}_{2}$ emitted to the atmosphere is very different. During the gas collection period the greenhouse gas burden remains relatively constant at approximately 2 million tons of $\mathrm{CO}_{2}$ equivalents. Following the end of gas collection the greenhouse gas burden bumps up for a couple of decades before receding. By the end of the 100 year period, the greenhouse gas burden of controlled and uncontrolled landfills is virtually the same. Producing electricity from the gas collected at a controlled landfill displaces enough fossil fuel use to reduce the greenhouse gas burden associated with the waste disposal by approximately 15 percent, based on the California mix of displaced fossil fuel use.

The delay in the onset of greenhouse gas benefits from using forest residues that would otherwise accumulate is even more pronounced than that for using landfill-diverted wood wastes. The greenhouse gas burden associated with the use of forest thinnings ${ }^{*}$ doesn't peak until almost 50 years after the forest is treated and the thinnings are used for energy production. Assuming that the treated forest continues to receive periodic treatments, the use of this type of biomass for energy production has a large positive impact much further into the future than do other categories of biomass fuels. This is mainly because thinning the forest protects the bulk of the remaining growing stock, the converse of which is that, in the absence of thinning, a wildfire, tends to release far more carbon than would have been removed by thinning and protecting the bulk of the forest biomass.

A primary alternative disposal activity employed for biomass residues in California is open burning. Open burning is similar to energy production in the sense that virtually all the residue material is converted immediately into greenhouse gases. Open burning, however, is less efficient than controlled combustion in a boiler in terms of converting carbon into $\mathrm{CO}_{2}$. The result is that open burning produces significant amounts of $\mathrm{CH}_{4}$ and otherHCs, in addition to $\mathrm{CO}_{2}$. These reduced-carbon gases in the emissions from open burning lead to an initial greenhouse gas burden of 2.7 million tons of $\mathrm{CO}_{2}$ equivalents from the disposal of 1 million bdt of residues. The $\mathrm{HCs}$ convert to $\mathrm{CO}_{2}$ with a half-life of 8.3 years, leading the greenhouse gas burden to eventually become indistinguishable from that associated with energy production from the same residues, as shown in Figure 10.

The greenhouse gas burden resulting from the open burning of 1 million bdt of biomass, which initially is 1.5 times greater than that of energy production, is the same 40 to 50 years later. The question then becomes: Is the greenhouse gas emission factor for open

\footnotetext{
* In the context of in-forest residues, net benefit is used in the sense of expected net benefits, with a probability distribution of wildfire assigned to the in-forest residue fuel that is left as overgrowth biomass in the forest.
} 
burning 1.5 times greater than that for energy production, is it the same, or is it somewhere between? Climate change is clearly a long-term, cumulative problem. Thus, judging the magnitude of the greenhouse gas implications associated with today's activities requires taking future atmospheric loadings into account. Disposal options that delay the release of the carbon associated with biomass, only to eventually cause much higher atmospheric burdens later, should be held accountable for this circumstance.

For analytical purposes, a 50-year time horizon is adopted for comparing the greenhouse gas profiles of the disposal activities considered in the model. Greenhouse gas emissions factors for each activity are calculated as the average atmospheric burden over the period. Table 6 shows the adopted base-case values for the greenhouse gas emissions factors for the biomass disposal options, as well as for energy production and avoided fossil fuel use. As shown in the table, the adopted greenhouse gas emissions factor for open burning is 1.2 times greater than that of energy production (2.06 vs 1.76$)$.

\section{Table 6 \\ Greenhouse Gas Emissions Factors}

(data are in tons $\mathrm{CO} 2$ equivalents/bdt of biomass)

$\begin{array}{lc} & \frac{\text { ton/bdt }}{1.76} \\ \text { Biomass Energy } & 2.06 \\ \text { Open Burning } & 3.35 \\ \text { Forest Accumulation } & \\ \text { Landfills } & 4.24 \\ \quad \text { Uncontrolled } & 2.37 \\ \quad \text { Gas Collection w/ Flare } & 2.18 \\ \quad \text { Gas Collection w/ Engine } & 2.27 \\ \text { Spreading } & 2.61 \\ \text { Composting } & 0.52 \\ \text { Avoided Fossil Fuel Use } & \\ \quad \text { (based on Calif. mix) } & \end{array}$

The modern California biomass energy industry has been operating for the past 20 years, growing from an outgrowth of the sawmilling industry into a crucial component of the state's solid waste disposal infrastructure. To date more than 100 million tons of biomass have been diverted from the state's landfills or from open burning, and more than 300,000 acres of forest land have been treated for wildfire risk reduction because of the operations of the industry. Figure 11 shows a graph of the long-term atmospheric greenhouse gas benefits that have already been achieved by the use of biomass for energy production over the past 20 years. The concentrations of greenhouse gases now in the atmosphere are lower by more than 100 million tons of $\mathrm{CO}_{2}$ equivalents than would have been the case had the California biomass energy industry not developed. The greenhouse 
gas benefits for the biomass fuel that has already been used will increase over the next 10 years to a level of more than 125 million tons of $\mathrm{CO}_{2}$ equivalents, then gradually decrease over time.

Figure 12 shows a plot of the greenhouse gas benefits of the same historical fuel use data for California, combined with three projections for future levels of biomass energy production. The projections are based on three scenarios, which are distinguished by the amount of policy support given to biomass energy production in the future:

Figure 11

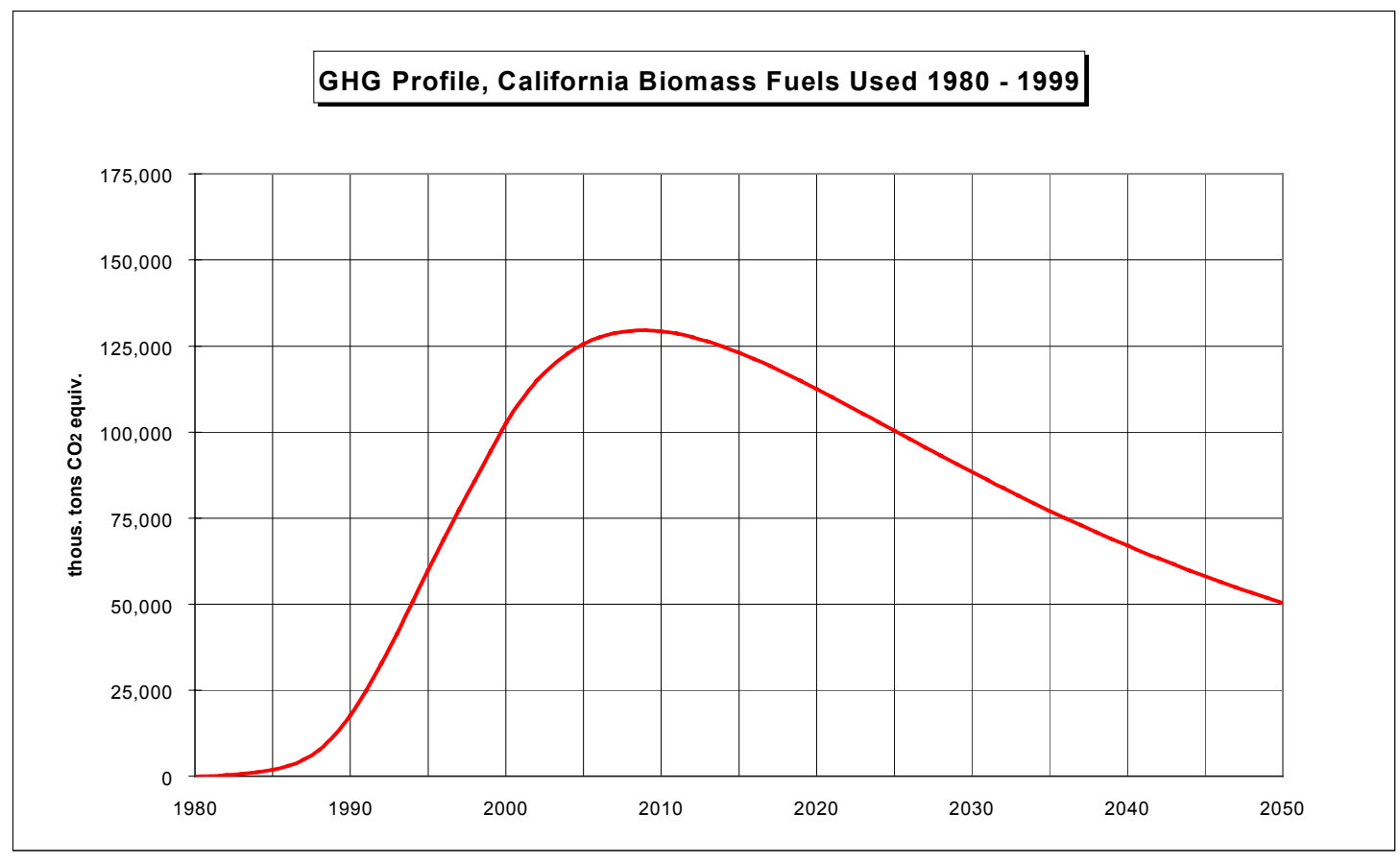


Figure 12

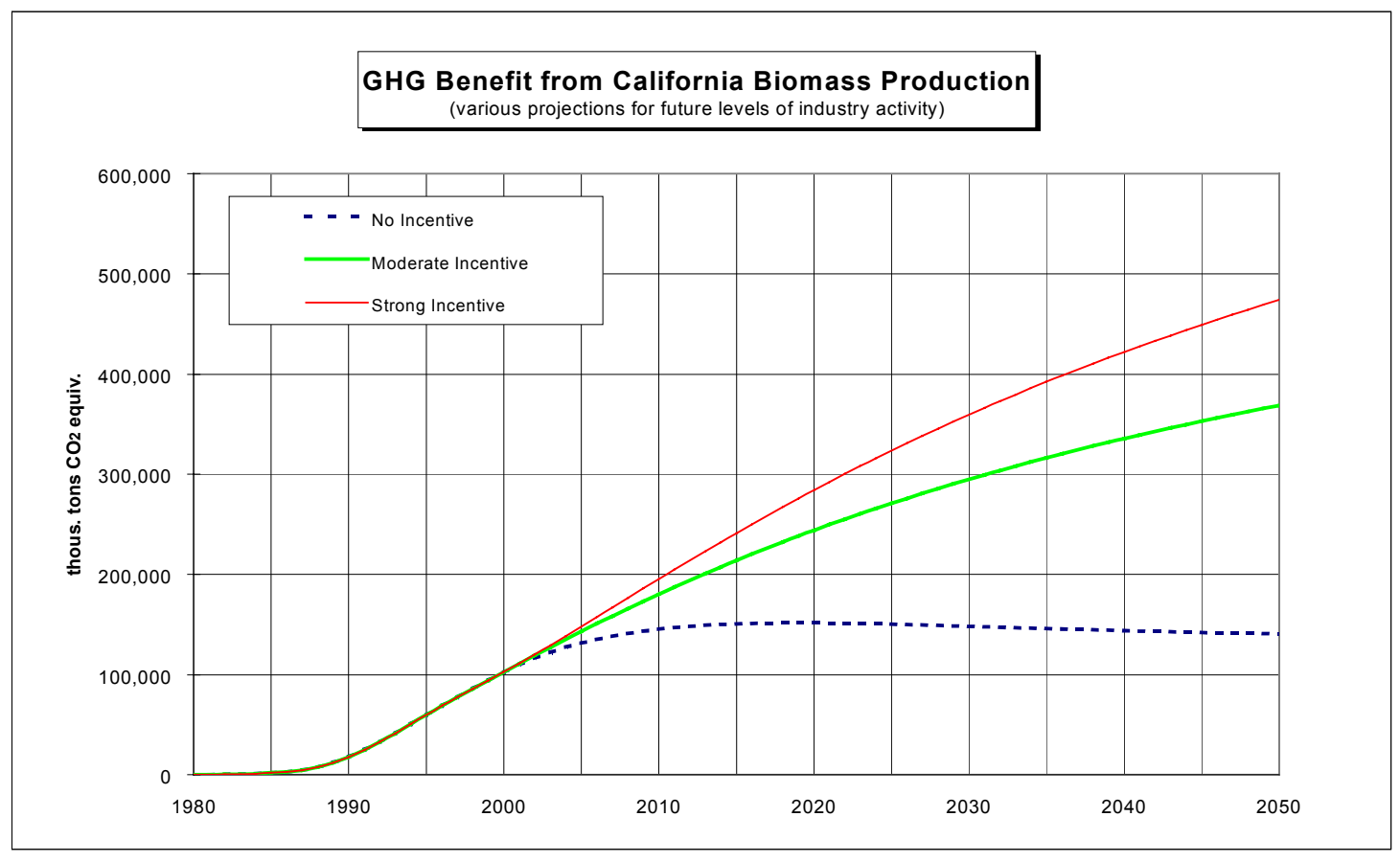

No Incentive. The no incentive scenario assumes that the currently available renewables transition credits expire as scheduled at the end of 2001, and that no new incentives are enacted for biomass energy production at the state or federal level. In this scenario most biomass facilities not associated with sawmills close down operations, leaving a residual level of biomass energy production that is approximately $25 \%$ of the 1999 level.

Moderate Incentive. The moderate incentive scenario assumes that some form of support is provided for biomass energy production in the long term that is roughly equivalent to the RTF credit that was available in California during the past 2 years $(1.5 \notin / \mathrm{kWh})$. This is equivalent to a business as usual scenario, with biomass energy production holding at current levels into the future.

Strong Incentive. The strong incentive scenario assumes that enough incentives will be available to allow most of the facilities that currently are idle but operable to restart, as well as increased operations for the facilities that currently operate. In this scenario, biomass energy production increases by $45 \%$ above the 1999 level.

In the no incentive scenario the cumulative greenhouse gas benefits of biomass energy production increase gradually over the next decade, then stabilize at a level of approximately 150 million tons of $\mathrm{CO}_{2}$ equivalents well into the future. In the moderate incentive scenario, in which biomass energy production continues at present levels, the greenhouse gas benefits increase throughout the period covered in the analysis, reaching a level of 375 million tons of $\mathrm{CO}_{2}$ equivalents by 2050 . The strong incentive scenario 
shows a similar but more rapid pattern of increase in the level of greenhouse gas benefits associated with California biomass energy production, reaching a level of 475 million tons of $\mathrm{CO}_{2}$ equivalents by 2050 .

\section{Landfill Disposal}

Solid waste disposal is an important environmental concern in California. Currently more than 37.5 million tons of solid wastes are buried in the state's landfills annually (CIWMB 2000). To reduce pressure on available landfill capacity, state law (AB 939) mandates that each county achieve a landfill diversion rate of $50 \%$ by the end of 2000 , compared to the defined baseline year of 1990. According to the CIWMB, the average statewide diversion rate as of 1999 was about 35\%, leaving it well short of the mandated level with a year before compliance requirements go into effect.

Approximately 15\%-20\% of the solid waste collected in California municipalities for disposal is woody material that can be segregated from mixed wastes and processed into high-quality biomass fuels. Urban biomass fuels account for $25 \%$ of California's biomass fuel supply. In addition, most wood processing residues that are used for energy production would be disposed in landfills if the energy production alternative were not available. Approximately 3.0 million tons/year of the fuel currently used by the California biomass energy industry would be buried in landfills if the energy production outlet were not available. This would be a disaster for many counties' efforts to comply with $\mathrm{AB} 939$ requirements.

Landfilling of biomass has a number of environmental impacts, including the comsumption of the landfill capacity. Landfills also lead to emissions of VOCs and greenhouse gases, and leachates to groundwater. Landfill technology is evolving, and modern, controlled landfills achieve much better environmental performance than landfills of the past. Nevertheless, limiting the total amount of waste in landfills is a codified goal of state environmental policy. Energy production is the only viable productive use outlet for much of the wood waste that would otherwise be buried in landfills.

\section{Forest Ecosystem Deterioration}

The ongoing deterioration of California's forests, a phenomenon that is mirrored throughout the American West, is a subject of major public policy concern. Forest deterioration is the result of long-term human intervention in native ecosystems. Poor commercial forestry practices, combined with extensive and aggressive forest firefighting efforts, have caused a long-term buildup of biomass in the state's forests compared with pre-industrial, native forest ecosystems. Forests with biomass densities (tons per acre) as much as $40 \%$ greater than the native ecosystem suffer from enhanced risks of destructive wildfires, and degraded ecosystem health and productivity. 
The accumulation in the forest of dead and diseased wood, both standing and downed, is particularly problematic from a forest fire risk perspective. This material tends to have a lower moisture content than healthy growing stock, making it easier to ignite, hotter burning, and more prone to spread wildfires. As the fuel loading in California forests continues to increase, fires that are out of control tend to be much more severe and destructive than the naturally occurring periodic fires of the pre-industrial ecosystem. Contemporary fires burn much hotter than the traditional fires, and consume much larger contiguous areas with more extensive destruction. In the most severe cases, which are becoming more common, the destruction is so extensive that the beginning of natural regeneration can be delayed by a number of years.

Fuel overloading also contributes to the degradation of the health and ecosystem functioning of forests and watersheds. The overgrowth condition in California's forests means that the amount of available rainfall that enters the evapotranspiration cycle is higher than in the native ecosystem, and less rainfall moves through the watershed as runoff and groundwater. Reduced flows of runoff and groundwater mean that less water is transferred to the meadows and lowlands, where water is stored during the rainy season and released gradually during the dry summer season.

The net result of this chain of events is that useful water production from many watersheds is lower than if the forests were in a more "native" condition. This loss of useful water production includes water for human consumption and environmental water for river and delta ecosystems. An effective, sustained thinning program in key watersheds would probably increase useful water supplies without further development of water supply infrastructures. Several experimental programs are currently under way to prove this connection, and to provide data on the amounts of water production that will result from thinning and other watershed improvement operations (Cal. Dept. of Water Resources 1994). A great deal of work remains to be done to understand the relationship between watershed improvement activities and the rate of water production from treated watersheds. Nevertheless, thinning of key watersheds would benefit state water supplies.

\section{Rural Employment and Taxes}

The specific nature of a biomass power plant's fuel supply is the primary determinant of its design and location. Since most facilities use significant components of agricultural or forestry residuals, most are located in rural areas dominated by resource-based economies. These communities often are characterized by slow economic growth and high unemployment. Biomass energy facilities have brought new jobs with good comparative wages into rural communities. Power plant employees receive attractive benefits packages, as do many support workers engaged in fuel production operations. Support jobs are generated at a ratio of almost 2:1 compared to plant employment; total employment equal 4.9 full-time jobs per megawatt of net plant generating capacity (CBEA 1996). The long-term nature of this employment provides durable improvement and added stability to the local and regional economies. 
In addition to the rural employment benefits, biomass energy plants make important contributions to the tax base of many rural communities. In many cases biomass energy plants are the largest single property taxpayers in their jurisdictions. The facilities also generate income taxes and sales taxes from their employees, and from the workers that support them in such activities as fuel production and transportation.

\section{The Benefits of Energy Diversity and Domestic Supply}

Although more than two decades have passed since the oil embargoes of the 1970 s, the United States remains in an energy deficit situation, importing nearly $60 \%$ of its petroleum. In the event of a major supply disruption, electricity generation could be severely affected,. Additionally, the concentration of large power plants at grid centers in urban areas makes power supply vulnerable to natural and human-caused disruption. The scale and dispersion of biomass energy facilities, and their renewable fuel supply in primarily rural areas, provide a low probability of grid-related or human-caused failure. Indeed, during the heat-related brownouts of 1996 in California, all biomass plants remained on-line, while many large utility plants reduced load or shut down completely.

The biomass energy industry also contributes to the potential of biomass energy use in general, in all its possible manifestations. The federal government has invested a significant amount of money and effort in developing new technologies and applications for biomass energy, including advanced electricity generating technologies and liquid fuel technologies. Many projections of future energy supplies for the United States envision an increasing role for biomass. The future of biomass energy production, whatever direction it eventually takes, will inevitably be built on the foundation of the industry that has already been created. A strong foundation provides for sound future growth. A collapsing foundation diminishes the chances for any kind of future development of biomass energy.

\section{The Economic Value of the Benefits of Biomass Energy Production}

Converting of biomass wastes and residues to energy provides great environmental benefits by reducing of air pollution, greenhouse gas emissions, and landfill use associated with their disposal, promoting healthier forests, contributing to rural economies, and displacing fossil fuels. However, placing monetary values on these environmental and social benefits is more difficult. This study uses estimates from the literature for the dollar values of environmental impact categories, and applies them to the quantifiable impacts of biomass energy production and the activities it avoids. The net value of the environmental impacts of biomass energy production is calculated as the difference between the cost of its impacts and the costs of the alternative disposal options and alternative power provision.

This analysis focuses on the value of the environmental benefits of the biomass energy industry in California. Because of uncertainties in assigning dollar values to the impact categories, ranges of values that encompass current economic thinking on the subject, 
observed and forecast market values, and the effects of current regulations and economic conditions, are presented in Table 7. Most are transaction values based on "cap and trade" systems. They represent societal values for marginal reductions in emissions, assuming that society has correctly determined an optimal "cap" for the emissions. There is evidently still substantial damage, mortality, and morbidity at the currently capped levels for most impact categories. Therefore, the market values reported in the table represent a "floor" value for the benefits of marginally reducing emissions. The real societal values may well be higher.

\section{Values of Environmental Impacts}

$\underline{\mathrm{SO}_{\mathrm{x}}}$ : The EPA Acid Rain Program has created a large and active trading market for $\mathrm{SO}_{2}$ emissions. Prices tend to be stable and uniform, signs of a maturing market. The values in Table 7 are indicative of current prices for trades. They are almost double the prices of a couple of years ago, and reflect Phase II of the Acid Rain Program. They represent good long-term societal values for analytical purposes.

$\underline{N O}_{x}$ : Cantor Fitzgerald Environmental Brokerage Services has developed an average national price index for $\mathrm{NO}_{\mathrm{x}}$. Current estimates of $\mathrm{NO}_{\mathrm{x}}$ values vary more than those for the other criteria air pollutants. Prices vary by geographic location and by time of year. These differences should be taken into account to the extent possible when determining the costs and benefits of reducing or increasing $\mathrm{NO}_{\mathrm{x}}$ emissions. $\mathrm{NO}_{\mathrm{x}}$ emissions are particularly important for California, where many air basins, including many major agricultural regions, are out of compliance with federal ambient air quality standards. California values for $\mathrm{NO}_{\mathrm{x}}$ in the San Joaquin Valley are used in the base case for this analysis.

Particulates: Most of the recent literature on particulates focuses on small particles of 10 microns or smaller. The most recent literature focuses on particles less than 2.5 microns. Open burning of biomass waste releases a broad spectrum of particle sizes; controlled burning tends to release mainly small particles, because the larger ones are more efficiently controlled. The values shown in Table 7 for particulates are based on PM-10. Rural values are for visibility degradation; urban values include visibility degradation and increases in mortality and morbidity.

Carbon monoxide: A review of the literature indicates that $\mathrm{CO}$ pollution reduction is primarily of value in a limited number of urban "hot spots," and that reductions in rural releases of $\mathrm{CO}$ by reducing open burning have little or no value to the environment. There has been a significant reduction in the ambient levels of $\mathrm{CO}$ over the past two decades, primarily through improvements in the environmental performance of automobiles. These improvements have diminished the value of further reductions in $\mathrm{CO}$ emissions from stationary sources. 
Biomass Energy Production in California: The Case for a Biomass Policy Initiative

Table 7

Values of Environmental Pollutants

\begin{tabular}{|c|c|c|c|}
\hline CATEGORY & VALUE (1999\$, $1^{\text {st }}$ quarter) & SOURCE & COMMENTS \\
\hline $\mathrm{SO}_{2}$ & $\$ 206-\$ 212 /$ ton & $\begin{array}{l}\text { Market prices for the first half of } \\
1999 \text { reported by brokerage firms } \\
\text { and the Fieldston Publications } \\
\text { market survey as reported by } \\
\text { USEPA Acid Rain Program. }\end{array}$ & $\begin{array}{l}\text { These prices are indicative } \\
\text { of current prices for trades. } \\
\text { They are almost double the } \\
\text { price a year ago and reflect } \\
\text { Phase II of the Acid Rain } \\
\text { Program. They are better } \\
\text { long-term prices than those } \\
\text { of a year ago. }\end{array}$ \\
\hline $\mathbf{N O}_{\mathbf{X}}$ & $\begin{array}{l}\text { Cantor Fitzgerald Market } \\
\text { Price: } \\
2000 \text { - } \$ 2,100 / \text { ton } \\
2000-02-\$ 2,018 / \text { ton } \\
\text { New England: } \\
\text { Ozone Season - } \$ 1000 \text { - } \\
\text { 1,050/tpy } \\
\text { Non-Ozone - } \$ 650 \text { - } 700 / \text { tpy } \\
\text { Mid Atlantic (NY, PA) } \\
\text { Severe - } \$ 5,000 / \text { tpy } \\
\text { Moderate - } \$ 2,000 / \text { tpy } \\
\text { California (ERCs): } \\
\text { San Joaquin Valley - } \\
\$ 9,733 / \text { tpy } \\
\text { Bay Area - } \$ 6,500 / \text { tpy }\end{array}$ & $\begin{array}{l}\text { Cantor Fitzgerald Environmental } \\
\text { Brokerage Services. }\end{array}$ & $\begin{array}{l}\mathrm{NO}_{\mathrm{X}} \text { prices vary quite a bit } \\
\text { regionally, by time of year. } \\
\text { Values are generally higher } \\
\text { in the California, urban } \\
\text { areas and during the } \\
\text { summer. The C-F Market } \\
\text { Price is a good compromise } \\
\text { for a single value, but } \\
\text { regional values should be } \\
\text { used, with lower values for } \\
\text { rural areas (unless rural } \\
\text { area is a non-attainment } \\
\text { area, i.e., California) }\end{array}$ \\
\hline $\mathrm{CO}_{2}$ & $\begin{array}{l}\text { Current Transactions: } \\
\$ 0.45 \text { - } \$ 1.81 / \text { ton } \mathrm{CO}_{2} \\
\text { SGM (Administration) } \\
\$ 7.74 \text { - } \$ 41.47 / \text { ton } \mathrm{CO}_{2} \\
\text { EIA/NEMS }(2010 \text { Price): } \\
\$ 18.94 \text { - } \$ 83.10 / \text { ton } \mathrm{CO}_{2} \\
\text { Markel-Macro Model }(2010 \\
\text { Price): } \\
\$ 25.01 \text { - } \$ 41.74 / \text { ton } \mathrm{CO}_{2}\end{array}$ & $\begin{array}{l}\text { Cantor Fitzgerald Environmental } \\
\text { Brokerage Services } \\
\text { Unfinished Business: The } \\
\text { Economics of the Kyoto Protocol, } \\
\text { Battelle PNL, } 7 / 98 \text { (draft) } \\
\text { Impacts of the Kyoto Protocol on } \\
\text { U.S. Energy Markets and } \\
\text { Economic Activity, EIA, 10/98 } \\
\text { Climate Change Economic } \\
\text { Analysis: Technical Annex, } \\
\text { Interagency Analytic Team, 7/97 }\end{array}$ & $\begin{array}{l}\text { Current transaction price } \\
\text { represents current trades } \\
\text { that are being undertaken } \\
\text { for risk management } \\
\text { purposes in the absence of } \\
\text { US ratification of the Kyoto } \\
\text { Protocol. } \\
\text { The model runs are for the } \\
\text { prices in } 2010 \text {. The low } \\
\text { values assume unlimited } \\
\text { international trading, the } \\
\text { hight values assume no } \\
\text { international trading. }\end{array}$ \\
\hline Methane & $\begin{array}{l}\text { Current Transactions: } \\
\$ 31 \text { - } \$ 124 / \text { ton } \mathrm{CH}_{4} \\
\text { Model Forecasts }(2010 \text { Price): } \\
\$ 532 \text { - } \$ 5,700 / \text { ton } \mathrm{CH}_{4}\end{array}$ & & $\begin{array}{l}\text { Methane values are } \mathrm{CO}_{2} \\
\text { values multiplied by } 25 \text {, the } \\
\text { instantaneous global } \\
\text { warming potential for } \\
\text { methane. }\end{array}$ \\
\hline
\end{tabular}


Biomass Energy Production in California: The Case for a Biomass Policy Initiative

\begin{tabular}{|c|c|c|c|}
\hline VOC & $\begin{array}{l}\text { California ERCs: } \\
\text { San Joaquin Valley - } \\
\$ 3,600 / \text { tpy } \\
\text { Bay Area - \$5,500/tpy } \\
\text { Maryland ERCs: } \\
\$ 2,500 / \text { tpy } \\
\text { New York/Pennsylvania } \\
\text { ERCs: } \\
\text { Severe - } \$ 2,000 / \text { tpy } \\
\text { Moderate - \$1,850/tpy } \\
\text { Massachusetts ERCs: } \\
\$ 3,000 / \text { tpy }\end{array}$ & $\begin{array}{l}\text { Cantor Fitzgerald Environmental } \\
\text { Brokerage Services }\end{array}$ & $\begin{array}{l}\text { The values for non- } \\
\text { methane hydrocarbons } \\
\text { (volatile organic } \\
\text { compounds [VOCs]) vary } \\
\text { significantly from region to } \\
\text { region. In rural areas the } \\
\text { values tend to be lower. } \\
\text { Values also tend to be } \\
\text { lower in the East than in the } \\
\text { West, and lower in the } \\
\text { Mid-Atlantic than in New } \\
\text { England. }\end{array}$ \\
\hline Particulate & $\begin{array}{l}\text { Rural: } \$ 1,050 / 1,000 \mathrm{lbs} . \\
\text { Urban: } \$ 1,506 / 1,000 \mathrm{lbs} .\end{array}$ & $\begin{array}{l}\text { Environmental Costs of Electricity, } \\
\text { Pace University Center for } \\
\text { Environmental Legal Studies, } 1990\end{array}$ & $\begin{array}{l}\text { The values are based on } \\
\text { PM-10. Rural values are } \\
\text { for visibility and the Urban } \\
\text { values include visibility } \\
\text { and mortality/morbidity. }\end{array}$ \\
\hline $\mathrm{CO}$ & $\begin{array}{l}\text { Current Transactions: } \\
\$ 0.71-2.84 / \text { ton CO } \\
\text { Model Forecasts (2010 Price): } \\
\$ 12.16-130.59 / \text { ton CO }\end{array}$ & & $\begin{array}{l}\text { The values are based on the } \\
\text { equivalent greenhouse gas } \\
\text { value on a per-carbon basis } \\
\text { to } \mathrm{CO}_{2} \text {. }\end{array}$ \\
\hline Landfill & $\$ 15.06 /$ ton $-\$ 29.94 /$ ton & $\begin{array}{l}\text { Full Cost Accounting in Action: } \\
\text { Case Studies of Six Solid Waste } \\
\text { Management Agencies, USEPA, } \\
12 / 98\end{array}$ & $\begin{array}{l}\text { Landfill costs vary by site, } \\
\text { an average of } \$ 22.00 / \text { ton. } \\
\text { Seems to be reasonable. } \\
\text { The values here are fully } \\
\text { allocated costs, including } \\
\text { capital, financing and } \\
\text { O\&M. }\end{array}$ \\
\hline $\begin{array}{c}\text { Forest } \\
\text { Productivity }\end{array}$ & $\$ 125-\$ 650 /$ acre & $\begin{array}{l}\text { Recent studies by Jolley \& } \\
\text { Carlson, and Morris (see } \\
\text { references) }\end{array}$ & \\
\hline
\end{tabular}

$\mathrm{CO}$ in the atmosphere has a greenhouse gas warming potential roughly equal to that of $\mathrm{CO}_{2}$ (see Value of Greenhouse Gas Emissions), and in fact the ultimate fate of atmospheric $\mathrm{CO}$ is oxidation to $\mathrm{CO}_{2}$. Thus, at a minimum, the value of $\mathrm{CO}$ emissions is equivalent, on a per-carbon basis, to the value assumed for $\mathrm{CO}_{2}$ emissions. This value is used in the analysis.

Non-methane hydrocarbons: The values for non-methane hydrocarbons (VOCs) vary significantly from region to region. In rural areas the values tend to be lower. Values also tend to be lower in the East than in the West, and lower in the Mid-Atlantic than in New England. California's continuing problems with ozone and smog levels cause VOC 
emissions to have a particularly high value. California values for VOCs in the San Joaquin Valley are used in the base case for this analysis.

Carbon dioxide: The current market for $\mathrm{CO}_{2}$ emissions trading is in its infancy. Trades that have been executed have been done voluntarily basis, not pushed by regulatory compliance requirements. These transactions have been conducted at very low prices, $\$ 0.45-\$ 1.81 /$ ton of $\mathrm{CO}_{2},(\$ 1.83-\$ 7.33 /$ metric ton of carbon equivalent). The current transaction price represents trades that are being undertaken for risk management purposes in the absence of U.S. ratification of the Kyoto Protocol.

If the Kyoto Protocol is ratified by the United States, prices for $\mathrm{CO}_{2}$ emissions trades are expected to increase dramatically. Price forecasts vary substantially, based mostly on the amount of trading assumed in the forecast. Prices in the literature vary from approximately $\$ 7.74 /$ ton $\mathrm{CO}_{2}$ in the Clinton Administration's analysis, which assumes widespread and unlimited international trading, to $\$ 83.10 /$ ton $\mathrm{CO}_{2}$ in the analysis done by the Energy Information Administration, U.S. Department of Energy, at the request of Congress, which assumes very little trading. An average, $\$ 45.42 /$ ton, is close to the upper end of the Interagency Analytic Team's (IAT) forecast. For analytical purposes, a value of $\$ 33 /$ ton $\mathrm{CO}_{2}$ is used for the base-case data set, which is the average of the IAT forecasts.

Methane: Methane has an instantaneous global warming potential 25 times greater than that of $\mathrm{CO}_{2}$ on a per-carbon basis (IPCC 1996). However, the residence time of $\mathrm{CH}_{4}$ in the atmosphere is much shorter that that of $\mathrm{CO}_{2}$, and oxidation to $\mathrm{CO}_{2}$ is the end product of removing atmospheric $\mathrm{CH}_{4}$. Thus, in the long term the difference in atmospheric warming potentials between the two gases decreases. The IPCC recommends using a value of 20.4 for a 20 -year time perspective, and 7.6 for a 100 -year time perspective. To avoid choosing an arbitrary time period, the greenhouse gas emissions model follows the atmospheric concentrations of $\mathrm{CO}_{2}$ and $\mathrm{CH}_{4}$ over a 100 -year period, and greenhouse gas emissions factors expressed in terms of $\mathrm{CO}_{2}$ equivalents are used in this analysis.

Value of Landfill Accumulation: The values shown in Table 7 for reductions in the amount of landfill used due to diversion of waste wood to energy production are based on the fully allocated costs of current landfills. They do not represent the cost to open a new landfill (the long-term marginal cost of waste disposal in a landfill), and thus provide a lower bound on the value of the benefits of reduced landfill use because of biomass energy production. The cost does include the cost of EPA regulations to capture and dispose of landfill methane.

Value of Forest Treatments: The literature on the value of forest treatment activities is sparse, but a recent paper (Jolley and Carlson 1999) provides a useful measure, which can be defined as the savings in ultimate cost, on a net present value (NPV) basis, of using mechanical thinning for forest treatment versus a regime of prescribed burns that must be carried out over a number of years to achieve the same degree of forest improvement. In the absence of mechanical thinning several limited burns, rather than a single more 
extensive burn, must be performed to minimize the risk of initiating an uncontrolled wildfire.

The mechanical thinning regime, followed 5 years later by a prescribed burn, has a cost (NPV) of $\$ 432$ acre. The alternative of three prescribed fire treatments over a 20 year period has a cost (NPV) of $\$ 560$ /acre, for a net saving of $\$ 128$ /acre using the mechanical thinning and fuel production alternative. This sets a lower limit on the marginal value of the mechanical thinning alternative. It does not credit the thinning alternative for its reduction in ultimate air emissions during the various burns, for its reduction in residual stand damage, or for the fact that the benefits of fuels reduction are achieved immediately with the mechanical thinning/fuel production option, while the benefits are achieved over a 20 year time period with the prescribed burning alternative.

Another recent study (Morris 1998b), which takes into account factors such as long-term timber stand values and reductions in fire-fighting costs, calculates a net benefit of mechanical thinning operations in the range of $\$ 200-\$ 650$ /acre treated. A mid-point value of $\$ 400 /$ acre is used in this analysis as the base-case value.

\section{Value of the Social Benefits of Biomass Energy Production}

The social benefits of biomass energy production, such as the generation of rural employment opportunities and economic development, and energy diversity and security, are even more difficult than the environmental benefits to quantify and value. Thus, no explicit values are included in the analysis for social benefits, although they are clearly significant and valuable. The following discussion illustrates the magnitude of the tax benefits that are provided by biomass power plants.

Based on an average annual income of $\$ 35,500$ for biomass plant operators (not including benefits or employer-paid taxes), and 4.9 workers per MW of installed capacity, biomass power plant employees and support workers generate $\$ 26,200$ in federal income taxes, and $\$ 8,700$ in state income taxes, for each MW of operating biomass electric generating capacity (CBEA 1996). Local and personal sales taxes are not included in these estimates.

Property taxes, based on a rate of $1 \%$ of assessed valuation, equate to $\$ 8,900 /$ net $\mathrm{MW}$ for power plants plus $\$ 1,400 / \mathrm{MW}$ for fuel supply infrastructure and related equipment. In addition, based on average taxable purchases of supplies, parts, and equipment of $\$ 28,000 / \mathrm{MW}$, sales tax at $7 \%$ yields an additional $\$ 2,000 / \mathrm{MW}$ annually. The total tax revenue generated from biomass energy production is approximately $\$ 47,200 /$ net MW of power produced annually. This translates into a total annual tax contribution of more than $\$ 20$ million that is attributable to the California independent biomass energy industry. 


\section{Net Value of the Ancillary Services of Biomass Energy Production}

A model has been constructed to compute the value of the identified ancillary environmental services provided by biomass energy production. The model begins with an accounting of the types and quantities of fuels used by the independent biomass energy industry in California today (Table 2). The industry provides for the disposal of more than 6.4 million tons of biomass residues annually. More than one third of the total fuel supply comprises sawmill residues; the remainder distributed among the categories of in-forest residues, agricultural residues, and urban waste wood. The first page of the model's printout, shown in Table 8, shows the amounts of biomass residues used as power-plant fuels in California in 1999. Fuel use values in the model are handled in units of bdt, not green tons.

Table 8

Environmental Benefits of the California Biomass Energy Industry

Fuel Use (th.bdt/yr)

Alternative Fate (\%)

open burning

forest accumulation

controlled landfill

uncontrolled landfill

composting

spreading

kiln boiler

Alternative Fate (th.bdt/yr) open burning

forest accumulation controlled landfill

uncontrolled landfill

composting

spreading

kiln boiler

\begin{tabular}{|rccc|}
\multicolumn{1}{r}{ Mill } & Forest & $\mathrm{Ag}$ & Urban \\
\hline 1,231 & 666 & 721 & 1,183 \\
\hline
\end{tabular}

\begin{tabular}{|rrrr|}
\hline & $60.0 \%$ & $90.0 \%$ & \\
$25.0 \%$ & $40.0 \%$ & & \\
$35.0 \%$ & & $5.0 \%$ & $65.0 \%$ \\
$2.5 \%$ & & $5.0 \%$ & $20.0 \%$ \\
$2.5 \%$ & & & $2.5 \%$ \\
$35.0 \%$ & & & $12.5 \%$ \\
\hline
\end{tabular}

$\begin{array}{rrrrrr} & & & & \text { Total } & \\ - & 400 & 649 & - & 1,049 & 28 \% \\ - & 267 & - & - & 267 & 7 \% \\ 308 & - & 36 & 769 & 1,113 & 29 \% \\ 431 & - & 36 & 237 & 704 & 19 \% \\ 31 & - & - & 30 & 60 & 2 \% \\ 31 & - & - & 148 & 179 & 5 \% \\ 431 & - & - & - & 431 & 11 \%\end{array}$

Total Fuel Use

Electric Generation Effic.

Electricity Produced

3,802 th.bdt/yr

$1.10 \mathrm{bdt} / \mathrm{MWh}$

$3,456 \mathrm{mmkWh} / \mathrm{yr}$

$\%$ of displaced electricity that would have been supplied by

Coal

Natural Gas / Steam Turbine

Natural Gas / Combined Cycle

$10 \%$

$50 \%$

$40 \%$ 
Assumptions about the alternative fates of the various residues, if they were not used as fuels, are applied to the fuel use data to determine the avoided disposal pathways provided the biomass energy industry. Almost half the residues would be landfilled in the absence of energy production, about one-quarter would be open burned, and the remainder would be composted, spread, burned in sawmill kiln boilers, or represent an accumulation of overstocked material in the forests.

Emissions factors and other environmental measures (Tables 4 and 6) are applied to the alternative disposal activities to compute the magnitude of the emissions and other impacts for biomass energy production, and for the activities it avoids. This computation is shown on the second page of the model's printout, Table 9. The magnitudes of the values are then summed across the categories, and the two alternatives, biomass energy production versus biomass residue disposal and fossil-fuel energy production, are compared.

Table 9

Value of the Environmental Benefits of the California Biomass Energy Industry

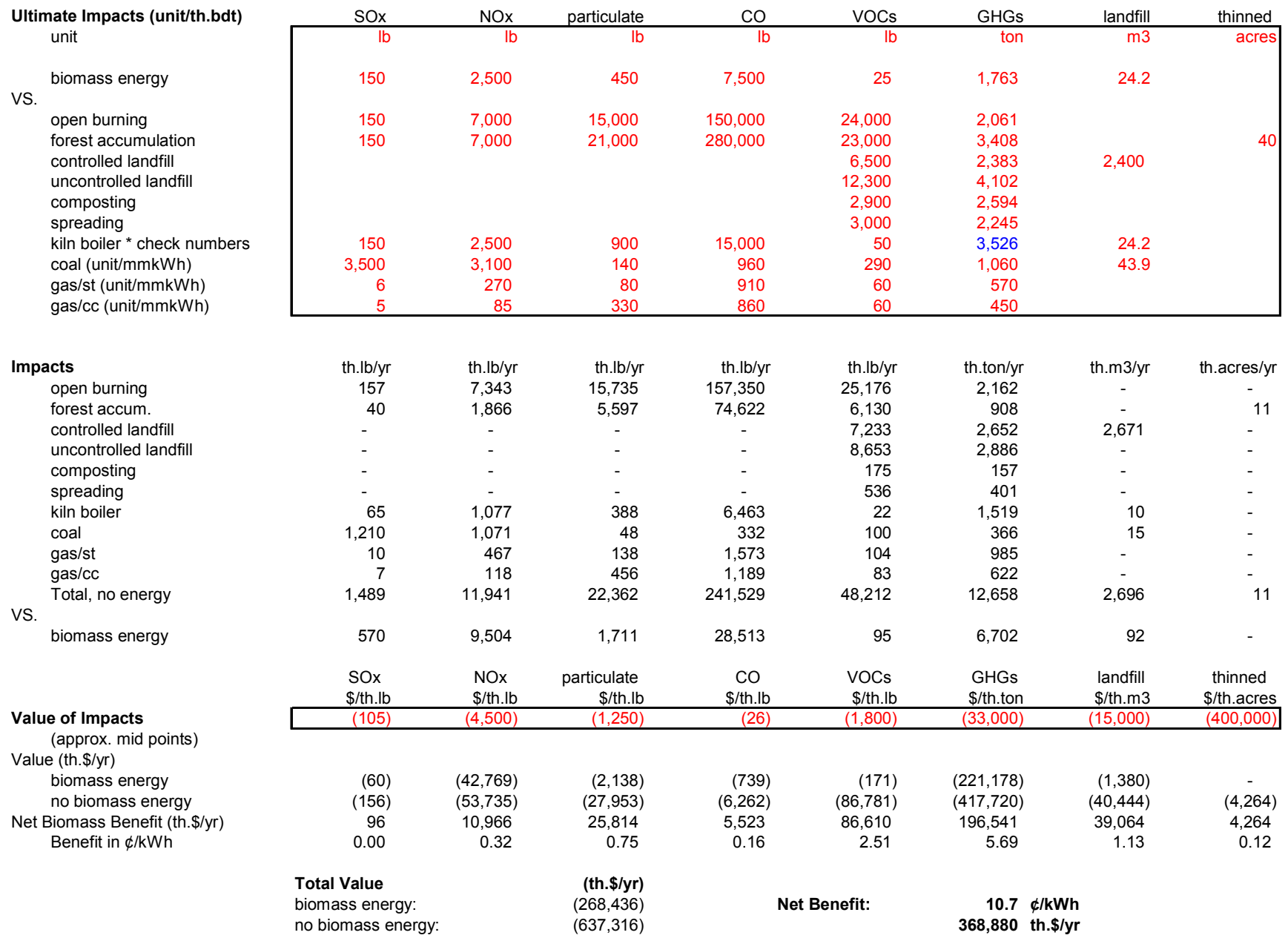


As shown in Tables 8 and 9, using conservative base-case values for all the identified impact categories, the value of the ancillary environmental benefits of biomass energy production is calculated as $\$ 370$ million/year, which is $10.7 \phi / \mathrm{kWh}$ of electricity produced from biomass. This represents an average for all biomass fuel used by the independent biomass energy industry in California. This calculated value covers only the categories of impacts included in the analysis, and none of the social benefits of biomass energy production discussed previously.

Using the base-case data set for the values of the various impact categories, the computed value of using each of the four types of biomass residues varies within the range of $8.2 \phi / \mathrm{kWh}$ (urban waste wood) to $15.6 \phi / \mathrm{kWh}$ (in-forest residues). Residues that would otherwise be open burned provide a benefit of $12.6 \phi / \mathrm{kWh}$ if used for energy production. Residues diverted from landfill disposal provide a benefit of $8.3 \phi / \mathrm{kWh}$ (controlled landfills) $-11.7 \notin / \mathrm{kWh}$ (uncontrolled landfills) when used for energy production. Residues left as overstocking in the forest provide a benefit of $20.2 \phi / \mathrm{kWh}$ if removed and used for energy production.

The dollar values for each impact category included in the model are reported in the literature as a range of values, as shown in Table 7. Values for many categories considered in this analysis have rather broad ranges of uncertainty. Running the model with minimum values for all categories produces a benefit value of $5.8 \notin / \mathrm{kWh}$ for biomass energy production. Using maximum values for all categories, the benefits are valued at $20.5 \notin / \mathrm{kWh}$.

A significant contributor to the computed value of biomass energy benefits is the value of avoided greenhouse gas emissions. Greenhouse gases are not regulated in current practice; hence, there is no established market value for them. The international Kyoto protocols, which are being ratificated by countries around the world, would require significant reductions in greenhouse gas emissions, which would establish a market and value for these materials. Assuming a zero value for greenhouse gases leaves a residual value for the other computed benefits of biomass energy production with the base-case data set of $4.8 \notin / \mathrm{kWh}$. 


\section{The Economic Predicament for Biomass Energy Production}

Generating electricity from biomass resources is inherently more expensive than generating electricity from conventional fossil fuels or hydropower. There are two major reasons for this. First, biomass fuels are bulky and expensive to collect, process, transport, and handle. Second, biomass generating facilities are smaller than power plants that burn fossil fuels, which prevents them from achieving the economies of scale typical of fossil generating facilities. Biomass facilities are smaller because of the dispersed nature of their fuel supply, which limits the amount of material that can be economically concentrated in a single place. The largest biomass energy plants in the world generate $75 \mathrm{MW}$ of power; large fossil-fuel fired facilities have generating capacities in excess of 1,000 MW.

As detailed earlier, biomass electricity generation provides a range of ancillary environmental and social services, the value of which is far greater than that of the electricity produced. However, these services are not compensated in the newly deregulated, competitive power marketplace. Because they do not receive compensation, their future provision is in doubt. California's landmark electricity deregulation legislation, AB 1890, explicitly recognizes the value of these ancillary services in a qualitative manner. To preserve these benefits, the legislation envisions the development of policies that will shift some of the costs of biomass energy generation to the beneficiaries of the ancillary benefits. The design of effective public policies in this area requires an understanding of the economic environment facing biomass energy generation, as well as the value of the benefits.

\section{Cost of Energy Production from Biomass}

The cost of biomass energy production has three major components, as follows (Morris 1998a):

\begin{tabular}{|ll|}
\hline & $\underline{£ / \mathrm{kWh}}$ \\
Capital Cost & $1.4-4.5$ \\
Fuel Cost & $1.0-3.5$ \\
Operations and Maintenance (O\&M) & $\underline{2.0-2.8}$ \\
Total & $4.4-10.8$ \\
\hline
\end{tabular}

New biomass generating facilities have total loaded capital costs of $\$ 1,600-2,300 / \mathrm{kW}$ of capacity, which constitutes a capital cost of 2.5-4.5 $\varnothing / \mathrm{kWh}$ of electricity generated. 
Facilities that have operated for at least 10 years, such as most that currently operate in California, are substantially amortized. The contribution of capital-related cost to the total cost of power generation for amortized facilities is about $1.4-2.8 \notin / \mathrm{kWh}$. Non-fuel O\&M costs for biomass generating facilities are 2.0-2.8ф/kWh (Morris 1994).

The cost of biomass fuels is the most variable factor in determining the cost of biomass energy generation. It depends on several factors, including the biomass source, the amount of processing necessary to convert it to a fuel, the distance and quality of roads, and the supply and demand for biomass fuels. As discussed previously, four categories of biomass fuels are used for energy production in California: wood processing residues, urban wood residues, agricultural residues, and in-forest residues. These are listed in increasing order of the typical cost of conversionto biomass fuels. Wood processing residues are the cheapest to provide as fuels and in-forest residues are the most expensive. Table 10 shows estimates of the typical cost of producing biomass fuels in California. The cost of producing fuel for any given application depends on the type, condition, and location of the residue source.

Table 10

Average Cost of Biomass Fuel Production in California ( $\$$ / bdt)

\begin{tabular}{|c|c|c|c|c|}
\hline & $\begin{array}{l}\text { Wood } \\
\text { Processing } \\
\text { Residues }\end{array}$ & $\begin{array}{l}\text { In-Forest } \\
\text { Residues } \\
\end{array}$ & $\begin{array}{c}\text { Agricultural } \\
\text { Residues }\end{array}$ & $\begin{array}{r}\text { Urban } \\
\text { Wood } \\
\text { Residues } \\
\end{array}$ \\
\hline \multicolumn{5}{|l|}{ Commodity Cost } \\
\hline Harvesting/Collection & 1.00 & 19.00 & 10.00 & 5.00 \\
\hline Proccessing & 5.00 & 7.50 & 6.50 & 6.00 \\
\hline Transportation & 6.00 & 9.50 & 7.25 & 9.75 \\
\hline $\begin{array}{l}\text { Total } \\
\text { Range }\end{array}$ & $\begin{array}{l}12.00 \\
7-18\end{array}$ & $\begin{array}{c}36.00 \\
25-45\end{array}$ & $\begin{array}{c}23.75 \\
16-38\end{array}$ & $\begin{array}{c}20.75 \\
13-28\end{array}$ \\
\hline Market Price (1999) & 22.66 & 32.27 & 22.46 & 20.18 \\
\hline
\end{tabular}

\section{The Market for Energy Generated from Biomass Resources}

Most biomass energy facilities operating in California today were built on the basis of the interim SO\#4 PPAs, which allowed developers to choose a fixed payment schedule for energy sales during the first 10 years of operation, and a 30 fixed payment level for capacity sales. The certainty in revenue rates was an important factor in allowing the facilities to obtain financing for their projects. The facilities with standard-offer contracts 
have now reverted to, or are about to revert to, current market price levels for their electricity sales. In the current market environment this means a drop in energy sales revenues of a factor of 4 or more.

Energy and capacity prices in California have traditionally been differentiated by seasonal and time-of-day factors. Depending on the purchasing utility company, the annual hours are divided into six or seven defined time-of-use periods, and energy and capacity revenues are determined for each period subject to CPUC oversight. In the newly deregulated marketplace, a statewide power exchange has been established that sets hourly prices, based on a bid mechanism. Biomass facilities that continue to operate under the old standard offer agreements continue to be compensated according to the old time-of-use period, CPUC regulated prices, although they will be switched over to the $\mathrm{Cal} / \mathrm{PX}$ prices when the CPUC formally determines that the competitive market is fully functional. This switch will occur by the end of the transition period to full competition, January 1, 2002, if not sooner.

Table 11 shows the CPUC-approved compensation rates SRAC in the PG\&E service territory, and average $\mathrm{Cal} / \mathrm{PX}$ prices during the same defined time-of-use periods, during the past 12-month period (April 1999-March 2000). The table also shows time-of-use period-differentiated rates for firm capacity sales. One consequence of switching from $\mathrm{SRAC}$ to $\mathrm{Cal} / \mathrm{PX}$ prices is that the differential between peak and off-peak rates is greater with $\mathrm{Cal} / \mathrm{PX}$ prices, which will make it more difficult for generators to operate in the base-load mode that most were designed for.

\section{Table 11 \\ California Power Purchase Rates}

\begin{tabular}{|c|c|c|c|}
\hline Summer & SRAC & $\mathrm{Cal} / \mathrm{PX}$ & Fixed Capacity \\
\hline Peak & 2.85 & 4.81 & 8.50 \\
\hline Part. Peak & 2.71 & 4.11 & 8.50 \\
\hline Off Peak & 2.62 & 2.82 & 0.00 \\
\hline Super Off Peak & 2.51 & 1.86 & 0.00 \\
\hline \multicolumn{4}{|l|}{ Winter } \\
\hline Part. Peak & 3.41 & 3.46 & 1.50 \\
\hline Off Peak & 3.26 & 2.94 & 0.00 \\
\hline Super Off Peak & 3.13 & 2.28 & 0.00 \\
\hline
\end{tabular}

SRAC and Cal/PX prices based on April 1999 - March 2000. Fixed Capacity price is based on a SO\#4 30-year contract.

Biomass facilities that have been bought out of their long-term standard offer power contracts are not obligated to sell through the Cal/PX. These facilities are free to enter into direct sales contracts with end users or energy services providers, or to sell through alternative exchanges, such as the independent Automated Power Exchange (APX). The APX has established a green power market for sales of electricity to marketers of green 
energy products. The consumer green energy market has been slow to develop in California, with the result that the premiums available for renewable energy sales through the APX green market have so far been modest, with green-ticket prices typically in the neighborhood of $0.3 \phi / \mathrm{kWh}$ or less. Nevertheless, if the green power market grows as many analysts expect, renewable energy producers will be able to consistently earn premium prices for their energy output, compared with prices for bulk power through the $\mathrm{Cal} / \mathrm{PX}$.

\section{The Magnitude of the Need for Biomass Policy Support}

The California market prices for the various categories of biomass fuels for 1999 are shown in the final row of Table 10. The fuel source with the lowest production cost, mill residues, has a cost that is below the current market price for these materials. Thus, producers of mill residues can earn economic profits for sales of their residues as a result of current market conditions. Most mill residues generated that do not have higher valued applications are being converted to energy, and the future supply of this source of material is tied to the activity level in the wood products sector, rather than being sensitive to shifts in the market price of biomass fuels. The other three sources of biomass fuels used in California, in-forest residues, agricultural residues, and urban residues, have market prices that are within the production-cost ranges shown, which means that the quantities used are commensurate with price, as determined by their supply curves. The potential supply of each category of biomass is expandable, if market signals are favorable. Policy measures that decrease the cost of supplying any of these sources of biomass as fuels will lead to an increase in their use.

Table 12 shows estimates of the gap between the cost of biomass energy generation, and the revenues that are available to biomass generators in California. The values shown are based on annual averages. The gap is the theoretical amount of support or compensation for environmental services provided that would be necessary to allow biomass energy generation to be economically viable in the competitive electricity market. The data in Table 12 are indicative of the revenues earned by facilities with standard-offer QF contracts that receive long-term fixed capacity payments, ${ }^{*}$ and SRAC payments for energy sales. By the end of the transition period to full restructuring of the electricity market (January 1, 2002), approximately 65\% of the state's biomass generating capacity will be compensated on that basis.

Because of differences in the cost of biomass fuels produced from the various categories of residues, the calculated cost-shifting needs for biomass energy generation are shown as a function of the type of the biomass residue used. Calculated cost shifting needs vary from about 1.2-2.4ф/kWh. The costs shown in Table 12 include a component for capital cost that is based on earning a competitive return on capital for amortized biomass facilities. In making decisions about whether to operate equipment, the capital costs can

\footnotetext{
* The exact amount of the capacity payment for any given facility depends on the start-up year for that facility. The value shown in the model is an average value.
} 
be considered sunk costs, and operations may be deemed to be reasonable as long as revenues exceed the combined costs of fuel and non-fuel O\&M. As seen from the numbers in the table, biomass energy generation today would be marginal at best, were there not some type of intervention in the marketplace. The renewables transition fund created by AB 1890 and SB 90 currently provides that intervention (Morris 1998a), and is allows biomass energy generators to continue to operate during the transition period, even at facilities that receive SRAC rates for sales of their electricity (facilities are ineligible for the transition payments while they receive SO\#4 fixed-price energy payments). That will no longer be the case when the transition funds expire at the end of 2001, unless some kind of support measures are enacted, or market conditions change dramatically.

Table 12

Cost Shifting Needs for Biomass Power Production ( $\phi / \mathrm{kWh})$

\begin{tabular}{|c|c|c|c|c|}
\hline & $\begin{array}{c}\text { Wood } \\
\text { Processing } \\
\text { Residues }\end{array}$ & $\begin{array}{l}\text { In-Forest } \\
\text { Thinning } \\
\text { Residues } \\
\end{array}$ & $\begin{array}{l}\text { Agricultural } \\
\text { Residues }\end{array}$ & $\begin{array}{r}\text { Urban } \\
\text { Wood } \\
\text { Residues } \\
\end{array}$ \\
\hline \multicolumn{5}{|l|}{ Revenues } \\
\hline SRAC & 3.0 & 3.0 & 3.0 & 3.0 \\
\hline Capacity & 2.0 & 2.0 & 2.0 & 2.0 \\
\hline Total & 5.0 & 5.0 & 5.0 & 5.0 \\
\hline \multicolumn{5}{|l|}{ Costs } \\
\hline Capital (existing facility) & 2.1 & 2.1 & 2.1 & 2.1 \\
\hline Non-Fuel O\&M & 2.3 & 2.3 & 2.3 & 2.3 \\
\hline Fuel & 2.2 & 3.0 & 2.1 & 1.8 \\
\hline Total & 6.6 & 7.4 & 6.5 & 6.2 \\
\hline Average Cost Shifting Need & 1.6 & 2.4 & 1.5 & 1.2 \\
\hline Electric Generation Efficiency (bdt/MWh) & 0.950 & 0.935 & 0.925 & 0.910 \\
\hline Average Moisture ( \% ) & $50.0 \%$ & $45.0 \%$ & $37.5 \%$ & $30.0 \%$ \\
\hline
\end{tabular}

For facilities that currently operate, decisions about how much power to generate depend on the revenues and costs in effect at any given time. Power purchase rates and capacity payments for facilities operating under SO\#4 PPAs are currently differentiated by defined time-of-use periods, as illustrated in Table 11. When the transition is made to PX prices, the power purchase rates will vary hourly. Table 13 shows estimates of the revenues and costs of operating a biomass power plant, differentiated by time-of-use period. The table does not show any component for capital costs, as those are considered sunk costs and are not relevant to decisions about whether to operate at any given time, given a decision to remain in operation at all. All fixed O\&M costs are allocated to the peak and partial peak 
periods, when capacity revenues are available to offset these costs. As shown in the table, SO\#4 facilities receiving payments from the RTF can operate with a positive cash flow during all time-of-use periods. This is confirmed by the observation that several facilities that reverted to SRAC before the RTF program, and had cut back heavily on their off-peak operations, increased their annual output after the start-up of the program. In addition, facilities that reverted to SRAC after the beginning of the RTF program did not cut their off-peak output in the way that was being done by facilities that reverted to SRAC rates before the RTF program was initiated.

Table 13

Biomass Energy Production Economics

\begin{tabular}{|c|c|c|c|c|c|c|c|c|c|}
\hline & & & Sum & & & & Winter & & \\
\hline & Schedule & peak & part & off & super & part & off & $\underline{\text { super }}$ & $\underline{\text { ave. }}$ \\
\hline Revenues & & & & & & & & & \\
\hline energy & SRAC & 2.85 & 2.71 & 2.62 & 2.51 & 3.41 & 3.26 & 3.13 & 2.96 \\
\hline capacity & firm capacity & 8.50 & 8.50 & - & - & 1.50 & - & - & 1.96 \\
\hline $\begin{array}{l}\text { RTF } \\
\text { other }\end{array}$ & RTF 2000 & 1.00 & 1.00 & 1.00 & 1.00 & 0.71 & 0.71 & 0.71 & $\begin{array}{c}0.86 \\
-\end{array}$ \\
\hline Total & & 12.35 & 12.21 & 3.62 & 3.51 & 5.61 & 3.97 & 3.83 & 5.78 \\
\hline Costs & & & & & & & & & \\
\hline fuel (1999 ave.) & & 2.20 & 2.20 & 2.20 & 2.20 & 2.20 & 2.20 & 2.20 & 2.20 \\
\hline variable O\&M & & 0.20 & 0.20 & 0.20 & 0.20 & 0.20 & 0.20 & 0.20 & 0.20 \\
\hline fixed O\&M & base & 8.61 & 8.61 & - & - & 2.17 & - & - & 2.10 \\
\hline Total & & 11.01 & 11.01 & 2.40 & 2.40 & 4.56 & 2.40 & 2.40 & 4.50 \\
\hline Net Cash & & 1.34 & 1.20 & 1.22 & 1.11 & 1.05 & 1.57 & 1.43 & 1.28 \\
\hline Inputs \& CalcL & Values & & & & & & & & \\
\hline O\&M, base-load & 2.30 & $\phi / \mathrm{kWh}$ & & & base & 7,884 & $\mathrm{kWh} / \mathrm{y} / \mathrm{kW}$ & & \\
\hline variable O\&M & 0.20 & $\phi / k W h$ & & & part & 5,432 & $\mathrm{kWh} / \mathrm{y} / \mathrm{kW}$ & & \\
\hline fixed O\&M & 166 & $\$ / k W y$ & & & $\min$ & 2,855 & $\mathrm{kWh} / \mathrm{y} / \mathrm{kW}$ & & \\
\hline LF & $90 \%$ & & & & peak/part & 2,979 & $\mathrm{kWh} / \mathrm{y} / \mathrm{kW}$ & & \\
\hline min op level & $50 \%$ & & & & sum peak/part & 1,567 & $\mathrm{kWh} / \mathrm{y} / \mathrm{kW}$ & & \\
\hline fuel price & 23.50 & $\$ / b d t$ & & & fuel price & 2.20 & $\phi / \mathrm{kWh}$ & & \\
\hline efficiency & 0.935 & $\mathrm{bdt} / \mathrm{MWh}$ & & & & & & & \\
\hline & & & & & Net & 1.28 & $\phi / \mathrm{kWh}$ & & \\
\hline
\end{tabular}

The RTF program is scheduled to expire on January 1, 2002. In addition, the methodology for calculating SRAC will convert by that date (or possibly sooner) to using the PX prices as the basis for SRAC. Under these conditions, biomass energy generation will be marginal at best. For facilities that continue to operate, many would likely cut back on off-peak operations, because of negligible or negative operating margins available during these periods. Most likely, some of the facilities would shut down, and fuel costs for those remaining would decline commensurate with the decrease in statewide biomass fuel demand (see Figure 7). Table 14 shows the economics of operating under PX prices, in the absence of RTF payments, with lower fuel prices resulting from a presumed decline in statewide fuel demand.

In addition to the operating biomass facilities, approximately $150 \mathrm{MW}$ of idle biomass generating capacity are available to resume operations in California, should conditions warrant bringing them back on line. Most of the idle facilities have sold their PPAs, and 
would receive no firm-capacity payments were they to restart. They would earn market prices for their sales of energy, which are represented by the PX prices in Table 11. Under those conditions, even the $1.5 \mathrm{k} / \mathrm{kWh}$ RTF support payment that was available in 1999 was not enough to allow the generators to cover costs, and no restarts occurred.

The environment for developing new biomass facilities in California is even more difficult than that for restarting old ones. New facilities would have to operate without standard-offer contracts, and would face much higher capital costs than those associated with already amortized facilities. A new facility would experience a deficit of $3-4 \phi / \mathrm{kWh}$, even if some form of support payment in the neighborhood of $1.5 \phi / \mathrm{kWh}$ were available. As a result, no new biomass generating capacity is expected in California in the foreseeable future.

\section{Table 14}

\section{Biomass Energy Production Economics, Post Transition}

\begin{tabular}{|c|c|c|c|c|c|c|c|c|c|}
\hline & & & Sumr & & & & Winter & & \\
\hline & Schedule & peak & part & off & super & part & off & super & ave. \\
\hline Revenues & & & & & & & & & \\
\hline energy & $P X$ & 4.81 & 4.11 & 2.82 & 1.86 & 3.46 & 2.94 & 2.28 & 2.96 \\
\hline capacity & firm capacity & 8.50 & 8.50 & - & - & 1.50 & - & - & 1.96 \\
\hline $\begin{array}{l}\text { RTF } \\
\text { other }\end{array}$ & & - & - & - & - & - & - & - & $\begin{array}{l}- \\
-\end{array}$ \\
\hline Total & & 13.31 & 12.61 & 2.82 & 1.86 & 4.96 & 2.94 & 2.28 & 4.92 \\
\hline Costs & & & & & & & & & \\
\hline fuel & & 1.87 & 1.87 & 1.87 & 1.87 & 1.87 & 1.87 & 1.87 & 1.87 \\
\hline variable $\mathrm{O} \& \mathrm{M}$ & & 0.20 & 0.20 & 0.20 & 0.20 & 0.20 & 0.20 & 0.20 & 0.20 \\
\hline fixed O\&M & base & 8.61 & 8.61 & - & - & 2.17 & - & - & 2.10 \\
\hline Total & & 10.68 & 10.68 & 2.07 & 2.07 & 4.24 & 2.07 & 2.07 & 4.17 \\
\hline Net Cash & & 2.63 & 1.92 & 0.75 & $(0.21)$ & 0.73 & 0.87 & 0.21 & 0.75 \\
\hline Inputs \& Calculated & Values & & & & & & & & \\
\hline O\&M, base-load & 2.30 & $\phi / \mathrm{kWh}$ & & & base & 7,884 & $\mathrm{kWh} / \mathrm{y} / \mathrm{kW}$ & & \\
\hline variable O\&M & 0.20 & $\phi / \mathrm{kWh}$ & & & part & 5,432 & $\mathrm{kWh} / \mathrm{y} / \mathrm{kW}$ & & \\
\hline fixed O\&M & 166 & $\$ / k W y$ & & & $\min$ & 2,855 & $\mathrm{kWh} / \mathrm{y} / \mathrm{kW}$ & & \\
\hline LF & $90 \%$ & & & & peak/part & 2,979 & $\mathrm{kWh} / \mathrm{y} / \mathrm{kW}$ & & \\
\hline min op level & $50 \%$ & & & & sum peak/part & 1,567 & $\mathrm{kWh} / \mathrm{y} / \mathrm{kW}$ & & \\
\hline fuel price & 20.00 & $\$ / b d t$ & & & fuel price & 1.87 & $\phi / \mathrm{kWh}$ & & \\
\hline efficiency & 0.935 & bdt/MWh & & & & & & & \\
\hline & & & & & Net & $\begin{array}{r}0.75 \\
59\end{array}$ & $\begin{array}{l}\phi / \mathrm{kWh} \\
\$ / \text { r per kV }\end{array}$ & acity & \\
\hline
\end{tabular}




\section{Biomass Energy Policy}

The analysis presented in this report demonstrates dramatically that biomass energy production provides valuable environmental and social benefits to society that are worth considerably more than the electricity produced. The economic analysis presented in the previous chapter shows that the quantifiable benefits are worth several times more than the cost of support necessary to preserve the viability of the biomass energy infrastructure in California. The logical conclusion is that public policy support for biomass energy production is justified and desirable. This chapter considers what a biomass energy policy might consist of, describes a variety of policy measures that could be enacted, and presents a cost-benefit analysis of developing a biomass energy policy.

\section{Approaches to Crafting a Biomass Energy Policy}

Biomass energy generation provides waste generators and society at large with a valuable package of ancillary environmental services. These services have been provided free of charge in the past, but the reality of the evolving competitive market for electricity generation brings into question the ability of biomass generators to operate without consideration for the environmental services they provide. As the analysis in the preceding section demonstrates, the ancillary environmental services are worth far more than the energy that biomass energy production provides.

In recognition of the value of these ancillary services, AB 1890 proposed shifting some of the costs of biomass energy generation away from the electric ratepayer, onto the beneficiaries of the environmental benefits. A variety of measures have been proposed to compensate biomass energy generation for its waste disposal services. Some policies would benefit biomass energy generation using any type of biomass fuel; others promote the use of particular types of biomass fuels.

The beneficiaries of waste disposal benefits can be categorized into two broad groups: biomass residue generators, and the public at large. Biomass residue generators benefit from biomass energy generation by having an environmentally preferred, useful application for their residues. The public benefits by having cleaner air, reduced loading of landfills, reduced emissions of greenhouse gases, and healthier and more productive forests and watersheds. Thus, there is a tension between the residue generators and the public over who should pay for environmental improvements in residue disposal practices. Private residue generators, such as farmers and wood products manufacturers, make valuable economic contributions to the state's economy, and often argue that increasing their costs of waste disposal would damage their competitive position. Other types of residues, such as urban wood wastes, and forest overgrowth in the national forest system, are generated by the public sector. The costs of environmental improvement with respect to managing these residues are inevitably the responsibility of the public. 
This report focuses on eight proposed biomass policy measures, which, individually and collectively, have the potential to ensure a long-term future role for biomass energy production in California. The measures are listed in Table 15. Two of the policies would apply to power generation from all sources of solid biomass fuels; the other six promote the use of particular types of biomass residues.

Table 15

Policy Measures for Biomass Energy Production

\begin{tabular}{|c|c|}
\hline Measures applicable to all biomass sources & $\begin{array}{l}\text { Provide of production credits or tax credits for } \\
\text { biomass energy production, for example by } \\
\text { extending of the California RTF program or } \\
\text { modifying of the federal biomass production tax } \\
\text { credit (IRS } \S 45 \text { ). } \\
\text { Create of a minimum purchase requirement or RPS } \\
\text { for electricity generated from biomass. }\end{array}$ \\
\hline $\begin{array}{l}\text { Measures applicable to biomass diverted from } \\
\text { landfill disposal }\end{array}$ & $\begin{array}{l}\text { Modify the rules of conformance with AB } 939 \text { to } \\
\text { give full diversion credit for fuel use of urban } \\
\text { biomass residues, and rigorously enforce year } 2000 \\
\text { compliance requirements. } \\
\text { Provide incentives (e.g. grants, low-interest loans, } \\
\text { tax credits) for purchases of grinding equipment and } \\
\text { other fuels-production equipment at landfills and } \\
\text { transfer stations. }\end{array}$ \\
\hline $\begin{array}{l}\text { Measures applicable to biomass diverted from open } \\
\text { burning for disposal }\end{array}$ & $\begin{array}{l}\text { - Create a California "Agricultural Fuels Tax Credit" } \\
\text { to divert agricultural residues from open burning to } \\
\text { fuel use. } \\
\text { Create open-burning permit fees for agricultural } \\
\text { residues, which will both contribute to a fund that } \\
\text { can be applied to the cost of diversion of residues } \\
\text { from open burning, and motivate such diversion. }\end{array}$ \\
\hline Measures applicable to in-forest biomass residues & $\begin{array}{l}\text { Allocate increased funds from state and federal } \\
\text { budgets for wildfire risk reduction treatments on } \\
\text { public lands, with emphasis on thinning operations } \\
\text { rather than prescribed burning wherever applicable. } \\
\text { Impose a surcharge on water sales revenues to be } \\
\text { used to underwrite the cost of watershed } \\
\text { improvement operations, including biomass } \\
\text { thinning in key watersheds. }\end{array}$ \\
\hline
\end{tabular}

The long-term viability of biomass energy production in California depends on providing some kind of broad-based support for the biomass energy industry as a whole. A properly designed comprehensive program that allows biomass generators full flexibility with respect to biomass fuel procurement would produce the maximum amount of benefit 
for any given level of program cost, while preserving the overall biomass generating infrastructure. The analysis presented in this report shows that the value of the benefits that are preserved by enacting policy support measures for biomass energy production are clearly worth far more than the cost of the measures. The magnitude of the benefits overwhelms any consideration of the uncertainties inherent in the analysis. This is true for every category of biomass fuel used in California. The RTF created by AB 1890 and SB 90 supports the entire biomass energy industry, without regard to the source. A comprehensive support program can be supplemented by targeted measures aimed at promoting the use of particular residue types to address specific environmental issues.

Two key factors should be considered in judging the efficacy of any proposed policy measure for biomass energy production:

- Efficiency - how much benefit is provided per dollar of program cost

- Equity—who pays and who benefits

This analysis demonstrates that the quantifiable ancillary benefits alone provided by biomass energy production are worth about $6.0-20.0 \mathrm{c} / \mathrm{kWh}$; the costs of providing enough incentives to preserve the enterprise are about $1.5-3.0 \mathrm{k} / \mathrm{kWh}$. This demonstrates the overall societal efficiency of providing public policy support for biomass energy production. The economic efficiency of proposed measures must also be considered. A variety of means are available for maximizing the cost effectiveness of public policy interventions, many of which attempt to mimic competitive market processes. The equity aspects of proposed cost-shifting measures are addressed by ensuring that those who bear the cost of the policies also enjoy the benefits.

\section{Broad-Based Policies for Biomass}

Two of the proposed costshifting measures would apply to all categories of biomass fuels used in California: credits for producing electricity from biomass fuels, which can be production payments or tax credits, and establishing a minimum purchase requirement for electricity generated from biomass fuels. A minimum purchase requirement for renewables was included in the restructuring program that was being developed by the CPUC before AB 1890 was passed. The legislature eschewed this approach, and instead instituted a production credit program for use during the transition period to full competition to provide support to renewables during this crucial period. Each type of program can be implemented in a variety of ways.

\section{Credits for Biomass Energy Production}

Production credits for biomass energy generation can be established at either the state or federal level, and can be funded by a variety of mechanisms, including surcharges on electricity bills, draws on general funds, or tax credits that could be claimed by biomass fuel producers or biomass energy generators. The amount of a production credit can be set programmatically, or via the mechanism of a bid procedure. This section discusses 
two production credit programs for biomass energy generation that were used during the 1990s: the renewables transition fund program that was created as a part of electric restructuring in California, and the federal renewable energy tax credit. A variety of other credit-based programs could be designed to support biomass energy production.

California's electricity restructuring program created an approximately $\$ 500$ million RTF, to be collected as a surcharge on electricity sales over the designated 4-year transition period to full market competition. The RTF funds were to support renewable energy production during the transition period. AB 1890 does not provide for any longterm, ongoing support program for renewables. In fact, the original legislation envisions the renewables industries using the program to make themselves competitive in the posttransition marketplace. Because this goal has often not been accomplished, and may not be accomplishable, the California state legislature is expected to consider initiatives to extend the renewables incentives programs beyond the end of the transition period.

The RTF was divided into three accounts, one for current facilities, one for new facilities, and one for emerging technologies. The funds for current facilities were further suballocated among the various categories of renewables, with $\$ 135$ million designated for a group that includes biomass energy generators and solar-thermal power generators (Davis et al. 1997). All biomass generators selling power to the grid at SRAC rates are eligible to receive the credit, which originally was set at the lower of $1.5 \notin / \mathrm{kWh}$, or the amount of funds available in any given period divided by the eligible $\mathrm{kWh}$ produced during that period. On January 1, 2000, the maximum cap on the payment decreased to $1.0 \mathrm{c} / \mathrm{kWh}$. Based on the operating record of the California biomass energy industry over the past couple of years, the $1.5 \phi / \mathrm{kWh}$ payment level was a sufficient incentive to keep the state's operating facilities operating at high levels, even during off-peak hours.

The Energy Policy Act of 1992 created a category of tax credits for "Electricity Produced From Certain Renewable Resources," which is incorporated as Section 45 of the IRS code. According to the original legislation, new wind and biomass generating facilities that were put into operation between 1993 and 1999 and that sell their power output to unrelated third parties are eligible to claim the $\S 45$ tax credit, which currently is worth $1.7 \phi / \mathrm{kWh}$. The credit was extended in its current form for 5 more years in 1999.

For biomass systems, eligibility for the $\S 45$ tax credit is limited by a provision that the biomass fuel used for power production must be derived from "closed loop" sources. This means that the biomass must be grown as a crop specifically for use as a fuel. No biomass power plant in the United States today derives its fuel supply from closed-loop sources of fuel. As a result, the $\S 45$ tax credit has not been claimed by any solid-fuel biomass energy facility, and it is unlikely that, in its present form, it ever will be.

As discussed earlier, the greatest share of the environmental and social benefits of biomass energy production is provided by avoiding conventional waste disposal of biomass residues. The use of closed loop biomass fuels does not provide these types of ancillary environmental services. These fuels are also more expensive to produce than 
most residue fuel sources currently in use. The fact that the credit has never been used for a solid fuel biomass generating facility is de-facto proof that the amount of the credit is insufficient to provide for the cost-shifting requirements of generation using closedloop sources of biomass fuel. On the other hand, experience with the renewables transition program in California demonstrates that a credit in the amount offered by the $\S 45$ tax credit is at least sufficient to support energy production at current biomass generating facilities. Modifying the tax credit to include waste and residue sources of biomass fuels used at all generating facilities, regardless of their in-service date, can be justified on economic, as well as environmental grounds.

The $\S 45$ tax credit, as currently constituted, provides support oriented to offsetting the capital portion of the cost of wind and biomass energy generation. The credit is available only to new facilities (those placed into service after the credit was enacted), and only for the initial 10 years of the operation of an eligible facility, which is typically when most of the project's debt is repaid. Seventy-five percent or more of the cost of wind power generation is represented by capital cost, so capital cost support for wind is very appropriate. However, capital cost accounts for less than $40 \%$ of the cost of biomass energy generation. Biomass energy generation is burdened mainly by high O\&M costs, which result largely from logistical considerations for acquiring and handling waste and residue fuels.

The special public benefits of biomass energy production, like the high operating costs, are directly associated with the disposal of wastes and residues in an environmentally superior manner. These waste disposal services are provided in direct proportion to the operation of a biomass facility. Thus, the most appropriate form of support for biomass energy production, which is linked directly to the public benefits provided, is an ongoing operating credit that is not related to the age of the installation.

To allow the $\S 45$ tax credit to provide support that is usable by the biomass energy industry, four significant modifications to the tax code are necessary:

(1) Drop the closed-loop restriction on biomass sources that is currently in the code, making waste and residue fuel sources fully eligible for the credit.

(2) Remove the sunset date on the application of the credit, allowing it to be claimed as long as the facilities operate and provide waste disposal services.

(3) Allow all current and future biomass facilities to claim the credit, linked directly to their disposal of biomass residues.

(4) Make all biomass energy facilities eligible for the credit, regardless of whether they obtained tax-exempt financing for construction.

Both the RTF program for biomass facilities, and an appropriately modified $\S 45$ tax credit, offer biomass producers a fixed, administratively set credit level, one a production credit, the other a tax credit. The usefulness of a tax credit incentive for an industry that 
is experiencing economic difficulties, and often not producing taxable profits, is limited. Marginal producers, who should be the first priority of the policy, are most likely to lack tax liabilities sufficient to take advantage of a tax credit. Production credits that are paid monthly to producers without regard to their tax status, are greater incentives for the production of biomass energy than are tax credits of the same amount.

An alternative mechanism for providing credits is via use of a competitive bid mechanism, allowing the market to determine the true economic value of the credits. California policymakers have experienced difficulties in conducting efficient public auctions for renewables, so any credit program that uses bidding will have to carefully consider the proposed market structure. The RTF in effect uses an implicit bid mechanism in its formula to calculate production credit payments in cases where the amount of funds available in a given payment period exceeds the claims made during that period based on the ceiling price for the credit, which currently is $1.0 \notin / \mathrm{kWh}$. So far, funds have provided for claims at the ceiling rates. Their value has not been "bid-down" by overproduction as measured against allocated funds.

\section{$\underline{\text { Minimum purchase requirement }}$}

An alternative approach to supporting biomass energy production within the context of deregulated electricity markets is to create a market niche for power generated from biomass and/or renewable sources. This can be accomplished by establishing a minimum requirement for biomass or renewables as a percentage of the overall supply mix. All competing energy services providers must satisfy the minimum requirement. This type of program is the RPS. The effect of an RPS is to segment the overall market for generating sources into two markets, one for conventional power, and the other for environmentally preferred power. Market efficiency can be enhanced by allowing production credits to be traded among energy services providers, to allow for the most economical mix of biomass and renewables to be deployed statewide.

The California biomass energy industry pioneered the concept of creating a mandated minimum purchase requirement for electricity generated from biomass fuels. A minimum purchase requirement for biomass energy of $1.5 \%$ of the energy supply mix was proposed for legislative consideration in 1994, and passed in the California Assembly in 1996 as AB 1202. A broader RPS of 10\% for all renewable sources was being incorporated into the CPUC restructuring program during the same period (Morris et al. 1996). However, the legislative conference committee that crafted comprehensive restructuring legislation at the end of the 1996 session decided against including a minimum renewables purchase requirement, and it is not part of the current electricity restructuring program.

Although rejected in California, an RPS is being actively considered as a part of federal restructuring legislation, currently under consideration in the U.S. Congress. In addition, several states have incorporated RPS into their restructuring programs. Including of an 
RPS in a restructuring program creates a parallel competitive market for renewable electricity, which can be further differentiated by resource type. The renewables segment of the market presumably would carry a higher price than the market for conventional power, thus providing the incentive necessary to cover the above-market costs of renewables. The advantage of the minimum purchase requirement approach is that it creates a fully competitive market for renewables, or specifically for biomass, providing the same advantages of competition to this segment of the market that deregulation provides to the overall electricity market. Moreover, the program can be fine tuned by adjusting the level of the minimum purchase requirement, rather than having to make administrative decisions about price levels for production credits.

In lieu of a full RPS for California, a more modest program to support biomass energy generation might entail creating a minimum purchase requirement for biomass-generated power on the part of state facilities and energy users. The State of California is a significant consumer of electricity, so imposing a minimum biomass purchase requirement on state electricity purchases could create a market niche for biomass energy production, although its extent would be limited because of the aggregate amount of electricity use by state facilities. Biomass-generated power that is sold under standardoffer contracts with the utilities probably would not be eligible for this program, as the energy would be supplied into the newly created power pool (PX) on an undifferentiated basis. This type of program would be particularly applicable to the biomass generating facilities that have accepted buyouts of their utility power-purchase contracts and are operating as merchant facilities.

\section{Targeted Biomass Policies}

A number of policies have been proposed that would decrease the cost of supplying specific types of biomass fuels for conversion to energy products. Several years ago, California biomass energy producers argued for policies that would provide free fuel to power generators. Their rationale was that the waste disposal benefits they provided were directly related to their use of fuel, and that fuel-cost relief would provide the amount of support they needed to stay in business. Costshifting measures are proposed that target for urban waste wood, agricultural residues, and in-forest residue sources of biomass fuels. No targeted measures are needed to support the use of sawmill residue fuels, which are the lowestcost source of biomass fuels, with costs that are below the market price (see Table 10).

\section{Measures Applicable to Urban Biomass Fuels}

Biomass wastes that can be segregated and converted into power plant fuels make up $15 \%-20 \%$ of the material traditionally landfilled. California counties and waste districts are under a mandate (AB 939) to achieve a waste diversion rate of $50 \%$ by the end of 2000 , as measured against the baseline year of 1990, when approximately 50 million tons of solid waste were landfilled in California (CIWMB 1998). Two policies are proposed 
for supporting the conversion of landfill biomass wastes into biomass fuels. One would broaden the amount of diversion credit that can be earned for fuel production. The other would provide funds for grants or other incentives for installing biomass fuel production equipment at landfills and transfer stations.

\section{Amendment and Enforcement of AB 939}

The most important cost-shifting measure for supporting the use of urban and municipal biomass fuels in California is already in place in the form of AB 939. These types of biomass fuels have been increasing their market share in California over the past several years to the extent that they have caught up to sawmill fuels in terms of their contribution to the state's biomass fuels supply. Moreover, although the amount of urban sources of fuels used has been increasing, the cost has been stable or decreasing. This can be interpreted to indicate that solid waste authorities are absorbing some of the cost of compliance with AB 939 by sending more fuel to the power sector. However, the overall compliance level is now estimated by the CIWMB at only about $37 \%$, with $50 \%$ compliance mandated by the end of this year.

Many of California's counties will likely not be in compliance with AB 939 on December 31,2000 . Requirements have induced many counties over the past several years to position themselves for compliance to absorb some of the cost of biomass providing fuels. Presumably, sending more wood to the fuel market is among the lowest cost alternatives that have been used by waste managers to increase their overall diversion rates. As the appointed compliance date is just a few months away, and many counties are far from achieving compliance in their jurisdictions, there will inevitably be pressure to ease compliance requirements. The strongest possible enforcement of AB 939 is the most important cost-shifting policy that can be pursued with regard to urban and municipal sources of biomass fuels. Compliance requirements could be achieved more easily with the implementation of two policies discussed here.

AB 939 requires all counties in California to reduce the amount of waste disposed of in landfills by $50 \%$ by the end of 2000 . Each affected jurisdiction must calculate the baseline amount of waste generated during 1990 and compare it to the amount of waste diverted during 2000. As currently constituted, the law limits the proportion of the total amount of diversion that may be credited to biomass fuel use to $20 \%$ of the total diversion credit, or $10 \%$ of the total amount of waste. If biomass fuel demand can absorb more than $10 \%$ of the total amount of waste in a particular jurisdiction, the amount over $10 \%$ cannot be counted toward compliance with the diversion requirement under the current language of the law. In typical California urban solid waste, $15 \%-20 \%$ of the total amount of material destined for disposal is suitable for conversion into biomass power plant fuel, which is more than the amount of diversion credit that can be claimed.

This proposal is to remove the $10 \%$ limit on the counting of fuel use toward a jurisdiction's diversion credit, to allow each jurisdiction to produce as much biomass fuel as market conditions allow, while receiving full credit for this diversion from landfill 
disposal. Lifting the restriction on recycling credits that can be attributed to biomass fuel production will not require the input of public funds, nor will there be any direct cost to the counties or to the waste disposal industry. In fact, granting full diversion credit for biomass fuels production should have a positive effect on the overall cost of compliance with $\mathrm{AB} 939$ by extending the range of the options that jurisdictions have available to them for achieving compliance.

\section{$\underline{\text { Grants and Loans for Grinding and Other Fuel Production Equipment }}$}

To facilitate compliance with $\mathrm{AB} 939$ requirements for landfill diversion by the end of 2000, public sector funds could be used to provide grants or low-interest loans to landfills and transfer stations for installing biomass fuel production equipment. Biomass fuel production requires a significant investment in capital equipment, the cost of which can be a barrier to its installation. Grinders and screeners can enable landfills to divert $15 \%$ $20 \%$ of the waste they receive to a productive use.

A grant or low-interest loan program for fuel production equipment can be designed as a limited program with substantial results. The goal would be to assist counties in their efforts to comply with AB 939, rather than specifically in the production of biomass fuels. In addition to fuel -production equipment, other recycling equipment might be made eligible to allow the diversion alternatives to compete, thus allowing counties to determine the most effective mix of diversion mechanisms that will allow them to comply with AB 939.

\section{Measures Applicable to Agricultural Biomass Fuels}

Burning in California's major agricultural regions is a major source of air pollution in these airsheds, many of which are out of compliance with state and federal ambient air quality standards for some criteria air pollutants, particularly $\mathrm{NO}_{\mathrm{x}}$ and particulates. Open burning is a free right to farmers, widely practiced as the least-cost option for the disposal of agricultural residues, including vast quantities of woody materials such as orchard and vineyard prunings. The only restriction on open burning of agricultural residues is that it must be conducted on approved burn days, which CARB declares based on weather factors and ambient air quality considerations.

Two mechanisms are proposed to offset the difference in cost between biomass fuel production and open burning of agricultural residues. One would provide a direct incentive to producers or users of qualified agricultural fuels, such as a tax credit or production credit. The second would impose a permit and fee program on open agricultural burning. Regulation of open agricultural burning is a major and contentious issue in the state's agricultural valleys, which are under pressure from EPA to formulate compliance plans with federal ambient air quality standards. Fuel production or tax credits would cover the above-market cost of sending residue fuels to the power plants. A permit and fee program would provide incentives for farmers to divert more of their residues to fuels applications. 


\section{$\underline{\text { Agricultural Fuels Credits }}$}

One approach to providing cost-shifting support for the use of agricultural residues as biomass fuels is to provide a production or tax credit for qualified fuel production activities. This would be done most appropriately at the state level. California has long offered its taxpayers a variety of tax credits to provide incentives for various environmental and social purposes. For example, a tax credit is currently available for diverting rice straw from open burning to beneficial uses. An agricultural fuels credit could be structured in a variety of ways to target its support to applications where it can provide the greatest pollution reduction benefits. The production or tax credit approach spreads the cost of the program across all state taxpayers who collectively benefit from improved air quality.

One version of an agricultural fuels tax credit was introduced in the state legislature in 1997 as AB 1513. It would have provided for a maximum tax credit of \$30/green ton ( $\$ 45 /$ bdt equivalent) for agricultural prunings that are converted to biomass fuels. AB 1513 passed the California Assembly during 1997, and passed in the Senate during 1998. However, it died in conference committee before the 2-year legislative session was completed in 1998. The AB 1513 tax credit would have been restricted to fuels made from agricultural prunings, which currently make only a very small contribution to the agricultural biomass fuels market in California. It would not have applied to the use of fuels made from orchard removals, which make up the bulk of the agricultural fuels market.

Most of California's agricultural fuels are provided by orchard removals, a relatively inexpensive source of fuel to produce. However, orchard prunings, which are produced in much greater quantities than orchard removals, are expensive to convert to fuel. In current practice, the biomass power plants are consuming less than $7.5 \%$ of the state's orchard prunings. Almost all the rest are open burned, and are major contributors to air pollution problems. A tax credit for prunings converted to biomass fuel, payable to farmers, would offset the cost of fuel production from eligible materials and improve their competitive position in the biomass fuel market.

In February 2000, Governor Gray Davis held a Central Valley Economic Summit in San Joaquin Valley. A variety of policies were proposed during this event, including the enactment of measures to support the conversion of orchard prunings to biomass fuel to improve air quality. The policies proposed during the summit continue to be worked on. Present expectations are that a three-year program will be enacted to support the conversion of orchard prunings to fuel. As currently conceived, the program will offer incentives of ten million dollars per year for a three-year period. The first year will be funded with grants, while the second and third years will be supported with tax credits. Other details of the program remain under discussion, including whether and how to cap the amount of the credits on a per-ton basis. 


\section{Open Burning Permits and Fees}

Open burning of agricultural residues is a major source of air pollution in California's major agricultural regions. Nevertheless, the practice of agricultural burning is unregulated and only slightly restricted, with burning limited to approved burn days. Serious programs to restrict agricultural burning have long been debated, but the political will to enact them has not yet been garnered.

CARB is working on a program to address the air pollution problems associated with open burning by revising regulations covering agricultural burning, Title 17 of the state code. CARB proposes the enactment of guidelines that would direct each air pollution control district (APCD) to devise allocation programs for open burning. Instead of the present system, in which CARB declares only burn days and non-burn days, a third classification will be introduced, which will be partial burn days. During partial burn days APCDs will allocate burn permits within their air basins based on a variety of predetermined criteria, with the goal of limiting the exposures of sensitive populations to smoke. Any program that increases restrictions on open burning provides an incentive for farmers to pursue alternatives, such as converting their residues to fuel. In fact, burners who develop alternatives for some of their residues may be given higher priorities for receiving burning permits for their remaining residues.

In addition to imposing a permit program for open burning, possibly with incentives for diversion, a special fee could be assessed for burning that would create a fund for proving fuel production credits from prunings. In this approach growers would be able to bid into the fund collected from the fees to receive support payments for diverting residues from open burning to fuel production. A farmer would benefit in two ways by converting his residues to fuel. First, he would be able to collect a fee per ton of material diverted, the amount of which would be regulated by a bid mechanism. Second, the material that is diverted would not be subject to the payment of the burn permit fee.

The production credit or tax credit approach imposes the cost of the environmental improvement on the public, with the rationale that the entire public benefits from the improved air quality resulting from the reduction in open burning. The permit and fee approach imposes the costs on the farming community, who generate and burn the residues.

\section{Measures Applicable to In-Forest Biomass Fuels}

The long-term buildup of forest biomass in California and the western United States to levels much higher than in undisturbed, native forest ecosystems has become a major environmental concern. Periodic moderate fires are normal in western forests, and reduce undergrowth and downed fuel on the forest floor. However, the excess biomass loading in the forests is causing a measurable increase in the incidence, extent, and severity of high-intensity, destructive wildfires, which cannot be considered natural components of the ecosystems. These fires are causing extensive losses of environmental quality, 
devaluating property, and are increasingly threatening homes and neighborhoods. In addition, it is now widely believed that the overstocking of biomass forests interferes with ecosystem functioning in many forested watersheds, reducing the amount of water available for downstream environmental and consumptive purposes.

Forest treatment operations, such as mechanical thinning followed by prescription burning, are expensive activities that are commonly not performed, even on tracts of forest that would clearly benefit. At the peak of the California biomass fuels market during the early 1990 s, when biomass power plants were paying $\$ 40 /$ bdt or more for fuel, the price of biomass fuels was high enough to offset most or all of the costs of the treatments. Approximately 250,000 acres of standing, overstocked forests were improved during this period. As fuel prices have subsequently fallen, sales of biomass fuels no longer cover all the costs of forest thinning. To have their stands treated in conjunction with fuel production, landowners have to absorb part of the cost of thinning and fuel production. This represents a form of cost shifting that has occurred in the absence of any public policy measures. However, the result has been a significant drop in the amount of thinning being carried out, which is opposite to the trend that forest managers would like to see occur.

\section{$\underline{\text { Wildfire Prevention Credits }}$}

Preventing wildfires in California's forests is a high priority for both the California CDFFP and the U.S. Forest Service, as well as for most private owners of forest lands. California's Fire Plan (CDC 1996) emphasizes thinning and clearing operations as costeffective ways to reduce the risks of catastrophic wildfires, by removing excess biomass from forests before they start. The U.S. Forest Service is also interested in increasing the use of fire prevention treatments on Forest Service lands. Such treatments, however, are expensive.

The traditional method for reducing the forest fuel overloading in California is prescribed burning of biomass. The U.S. Forest Service recently announced increased fund allocations for prescribed burns. However, prescribed burning of overgrown forests in their present condition is risky, can lead to significant losses of the desirable growing stock, produce large quantities of air pollutants, and entail a risk of offsite, uncontrolled wildfires. Most prescribed forest burning is in lower density brushlands and settlement forest interface regions. Very little is being performed in densely overstocked forests.

Mechanical thinning operations, although more expensive than prescribed burns alone, offer a superior alternative for fuels reduction. In some cases mechanical thinning can provide the desired fire risk reduction service, in other cases prescribed burns will be conducted after thinning operations to finish the job. Thinnings carried out before prescribed burns, in which ladder fuels and the bulk of the other materials are removed, significantly reduce the risk that the subsequent burn will kill the growing stock that is supposed to be enhanced, and will reduce the risk of initiating larger, uncontrolled fires. It also significantly reduces the amount of pollution produced by the burn, by reducing 
the amount of material consumed. The exact optional treatment for any given tract of land is always site specific.

Wildfire prevention credits could be funded by a variety of mechanisms. More than half the forest lands in California that would benefit from thinning treatments are publicly owned. Moreover, publicly owned forests tend to be in worse overgrowth conditions than most privately owned forestlands. The U.S. Forest Service and the CDFFP have large budgets for fighting fires. If the same agencies were provided with an annual budget for performing fire-prevention treatments, the overall cost of prevention and fire suppression would decrease significantly in the long run (Morris 1998b). It might also prove desirable, from a public policy perspective, to grant tax credits or other incentives to private landowners who thin their own forest holdings.

\section{Water Production Credits}

A broad scientific consensus supports the concept that forest thinning and other watershed improvement operations could increase the production of environmental and usable water supplies from major forested watersheds (Cal/EPA 1997). This is because overstocked forest stands have an evapotranspiration rate that is elevated significantly compared with that of undisturbed native ecosystems. Increased evapotranspiration leads to decreased storage and release of water from watershed soils, especially during the summer, when such water is particularly valuable. Although the concept of increased water production from forest thinning is gaining acceptance, the science of correlating the quantitive impact is lagging, which creates a serious information deficiency in this area for making public policy.

As in the case of allocating funds for fire prevention to perform thinnings and prescribed burns in overgrown forests, it would be in the state's and the nation's interests to expend funds for watershed improvement operations to increase water production in key watersheds. Funds for these activities could be provided from a surcharge on commercial water sales, particularly if the marginal cost of increasing water supplies by this method were lower than that of developing new, conventional supplies. Making such a determination will benefit from advancing our understanding of correlating thinning operations and other watershed management practices with increased water production. In the meantime, it would be useful for water agencies to experiment with performing thinning operations to enhance water quality and supply.

\section{The Costs and Benefits of Policy Support for Biomass Energy Production}

Estimates of the above-market support required to make biomass energy generation viable in California were presented earlier in Table 12. Support requirements are shown as functions of biomass residue type. The support requirements are based on the current level of biomass energy production, for facilities with efficient energy generating equipment, selling energy at current market rates, and capacity under long-term, levelized 
contract rates. That will be the status for approximately two-thirds of the fleet of operating biomass facilities at the beginning of 2002, when the transition to full market restructuring will be completed. Many operable, idle facilities would face higher support requirements to resume operations, as most will not receive fixed-capacity payments if they are brought back into operation.

Facilities that now operate and receive market rates for energy sales are eligible to receive payments as high as $1.0 \notin / \mathrm{kWh}$ from the RTF, less than the amount of support calculated in Table 16. The facilities in this category can operate with a positive cash flow and contribute to capital recovery with the $1.0 \mathrm{k} / \mathrm{kWh}$ transition payment offered, although capital recovery may be below the level that would be typical for comparable kinds of investments. However, the RTF payments are scheduled to expire by the end of 2001; no other program is currently on the books to take their place.

As shown in Table 16, with biomass fuels priced at current market levels, and in the absence of any source of support, biomass energy generation in California needs to be compensated for its ancillary benefits at about $1.2-2.4 \phi / \mathrm{kWh}$ to operate profitably in a deregulated marketplace. Based on maintaining current levels of biomass energy production into the post-transition period, this would translate into an annual statewide need for providing approximately $\$ 50$ million of support. Table 16 shows the amount of the support needed for biomass fuel type used, based on current levels of use (1999 data), and current market rates for purchases of QF power. Based on industry performance over the past couple of years, support in the amount of $1.5 \mathrm{c} / \mathrm{kWh}$ appears to be sufficient to motivate most facilities to remain in full operation after completing their fixed-price period for energy sales.

Table 16

Magnitude of Support Needed in California

$\begin{array}{lcccc} & \begin{array}{c}\text { Wood } \\ \text { Processing } \\ \text { Residues }\end{array} & \begin{array}{c}\text { In-Forest } \\ \text { Residues }\end{array} & \begin{array}{c}\text { Agricultural } \\ \text { Residues }\end{array} & \begin{array}{c}\text { Urban } \\ \text { Wood } \\ \text { Residues }\end{array} \\ \text { Unit Cost Shifting Requirement }(\phi / \mathrm{kWh}) & 1.6 & 2.4 & 1.5 & 1.2 \\ \text { Amount of Fuel Applied To (mbdt/yr) } & 910 & 666 & 721 & 1183 \\ \text { Ele. Produced by Fuel (mil. kWh/yr) } & 852 & 623 & 675 & 1107 \\ \text { Total Cost (mil. \$/yr) } & 13.2 & 15.1 & 10.0 & 13.7 \\ \text { Total Support needed } & & & & \end{array}$


The amounts calculated to be necessary to allow biomass energy generation to operate profitably in California are based on current levels of biomass energy production, and current market prices for biomass fuels. As noted earlier, more than $25 \%$ of the biomass generating capacity that operated during the industry's peak has shut down in response to utility contract buyouts, and many have cut back on operations. The waste disposal services provided by the industry are directly proportional to the amount of fuel used, not to the amount of capacity in operation. Cutbacks in operations are likely to increase as PX prices are substituted for SRAC and the RTF program expires.

Because biomass residue disposal in power plants is environmentally superiority to open burning, landfill burial, and accumulation of excess biomass in forests, it would benefit the state to not only preserve the amount of biomass power currently being generated, but to increase it through one of two possible mechanisms:

- Stimulate operating facilities to increase generation during off-peak hours.

- Stimulate idle facilities to resume operations.

Increasing the amount of biomass energy generation in California by enacting support measures may be expensive, for several reasons:

- Because of market supply and demand effects, increasing biomass fuels consumption increases the average cost of the biomass fuel, and thus the total amount of support needed beyond the proportional increase in fuel use (see Figure 17, the California biomass fuel supply curve).

- For operating facilities, the potential to increase biomass fuel use falls mainly during off-peak periods, when electricity revenues are at a minimum, and capacity revenues are not paid. This will increase in significance as the California PX price replaces SRAC as the basis of payments on standard-offer PPAs. PX prices tend to be higher during peak periods, and lower during off-peak periods, in comparison with SRAC rates.

- Most of the utility contract buyouts that led to the closing of biomass facilities in California permanently eliminated the long-term capacity provisions of their standard-offer contracts, which means that these facilities, were they to restart, would receive lower total revenues than those operating under standard-offer contracts that receive firm capacity payments in addition to market rates for power sales. The green power market, should it develop vigorously, might close the gap between the revenues available to facilities operating under standard offer PPAs, and those lacking long-term capacity contracts. However, more than 2 years after the beginning of consumer choice, the green power market has not yet made a significant impact. 
- Increasing the amount of biomass energy generation beyond the fleet of biomass generating facilities would require even higher amounts of support, because new facilities have higher capital cost requirements than current ones. Stimulating the development of new facilities will add more than $1 \phi / \mathrm{kWh}$ to the amount of support needed, as compared with that needed for operating facilities.

The first two biomass support measures considered in this paper, enacting a long-term biomass energy production or tax credit, and creating a minimum purchase requirement for biomass energy, could provide the backbone for a comprehensive cost-shifting program. The other six cost-shifting measures promote the use of individual biomass fuel types, but do not generally support biomass energy production. These targeted costshifting measures would lower the cost of providing the targeted fuel to the power plants, rather than increase the revenues available from the subsequent generation of electricity. Targeted support measures can promote the use of particular types of fuels within the context of a viable biomass energy industry, but they probably can not work without an overall support program.

Table 17 shows costs estimates of the support measures considered in this paper. All estimates are based on current levels of biomass energy generation in California. Modifying the federal tax credit to include current biomass energy generation, as discussed previously, would cost the federal treasury approximately $\$ 50$ million dollars annually for the biomass generators in California, assuming that all the state's biomass generators that sell power through the grid could benefit from the tax credit. Based on the calculated needs for cost shifting, the other comprehensive cost-shifting policies, a wiresfunded production credit, or an RPS program, would probably also have costs of about $\$ 50$ million.

The cost of modifying $\S 45$ of the IRS code to make generation with residue fuels eligible for the credit is considerable. However, as the preceding analysis demonstrates, a $1.5 \phi / \mathrm{kWh}$ tax credit makes the difference between a facility continuing to operate, or deciding to close down or significantly curtail operations. Idle facilities or capacity do not earn income or pay taxes. Thus, for facilities that remain in operation as a result of the tax credit, or operate at a higher capacity factor, any taxes they pay for such operations are higher than if they were to shut down or curtail. In addition, these operations are important economic and environmental assets to rural communities in need of jobs, a local tax base, and enhanced environmental quality. 


\section{Table 17 \\ Cost of Biomass Policy Measures}

\section{Modification of IRS § 45 Tax Credit}

Cost: $\quad$ At current level of generation: $\sim \$ 50$ million/year for California generators

Control: $\quad$ Becomes part of IRS code, would require federal legislation to modify

Applicability: All biomass power production

Discussion: Cost to treasury proportional to kWh generated from biomass fuel

\section{Minimum Purchase Requirement}
Cost:
Probable range of $\$ 15-\$ 50$ million/year for California generators
Control: Cost can be controlled by the setting of percentage requirement and cap
Applicability:
All biomass power production
Discussion:
Under consideration for federal legislation, could be imposed on state energy purchases

\section{Modification of AB 939 Diversion Credit Rules}

Cost: $\quad$ No cost, probable net reduction in solid waste disposal costs

Control:

Applicability: Urban wood waste fuels that would otherwise be buried in a landfill

Discussion:

4. Grants for Landfill Grinders
Cost: $\quad$ Probable range of $\$ 1.0-\$ 5.0$ million/year
Control: $\quad$ Cost is set annually by allocation of state budget funds
Applicability: Urban wood waste fuels that would otherwise be buried in a landfill
Discussion: This would probably be a relatively small program

5. Agricultural Fuels Tax Credit

Cost: $\quad$ Probable range of \$2.0-\$20 million/year

Control: $\quad$ Rate of credit set in state tax code, proportional to amount of eligible fuel use

Applicability: Defined agricultural residue fuels

Discussion: Cost dependent on how rules are set

6. Open Burning Permit Fee

Cost: $\quad$ Probable range of $\$ 1.0-\$ 5.0$ million/year

Control: $\quad$ Fee level and rules of applicability would be set administratively, probably at the state level

Applicability: Defined agricultural residue fuels

Discussion: Cost dependent on how rules are set

7. Wildfire Prevention Treatment Funds

Cost: $\quad$ Probable range of $\$ 10-\$ 50$ million/year

Control: $\quad$ Cost is set annually by allocation of state and federal budget funds

Applicability: Forest residue fuels

Discussion: Cost dependent on how rules are set, need for treatment is vast

8. Watershed Management Fees Charged to Water Users

Cost: $\quad$ Probable range of $\$ 2.5-\$ 10$ million/year

Control: $\quad$ Cost is set by administrative agencies

Applicability: Forest residue fuels

Discussion: This may well be the lowest cost option available for expanding state water supplies 
Most of the other policy measures considered in this study would have administratively set and/or administratively adjustable costs. In three cases, grants to landfills for fuel production equipment, credits for the use of agricultural residue fuels, and direct funding for forest wildfire prevention activities, the costs are set administratively by direct allocations of public funds. In two cases, open burning permit fees and fees for water consumption dedicated to watershed management treatments, the costs would be determined by the assessment of fees on activities not directly related to the level of biomass energy production. The final cost-shifting mechanism considered in this report, modifying AB 939 to allow full diversion credit for the use of landfill wood waste as fuel, would have no net cost, and may lead to a decrease in the overall cost of compliance with state-mandated solid waste diversion requirements.

Any of the programs discussed earlier that apply broadly to biomass energy generation, including modifying of the federal renewable energy tax credit, extending the assessment of public-purpose funds to support biomass energy production, or creating a biomass RPS, would provide the foundation support needed to allow the biomass energy industry to continue to operate. Increasing the use of particular kinds of biomass fuel beyond current levels will require targeted cost-shifting measures. No targeted cost shifting is needed to promote the conversion of sawmill residues to energy.

The magnitude of the cost shifting needed to increase the use of urban wood residue fuels in California is modest, given that AB 939 is a driving force behind finding diversion applications for solid wastes. In fact, the main support strategy recommended for urban biomass fuels in this report is rigorous enforcement of AB 939. A small grant program, perhaps on the order of $\$ 1$ million/year, to help landfills and transfer stations install fuel production equipment would help counties meet their compliance obligations. Also ensuring that all material used as biomass fuel be given full diversion credit, a policy that will decrease compliance costs for jurisdictions that receive large amounts of recoverable wood waste, by giving them increased flexibility to achieve their compliance obligations, is essential.

Two types of biomass residues, orchard prunings and overgrowth in-forest biomass, are particularly worthy of consideration for targeted policy support. Increased use of both fuel sources would provide valuable environmental benefits to the state, but are more expensive to produce than those that are more heavily used by the biomass energy generators. Increased use of prunings would decrease the amount of material that is open-burned agricultural regions, providing major air quality benefits. Increased use of in-forest overgrowth material would provide for major improvements in the condition of the forests, and improvements in water supplies.

Assuming an overall biomass support program is instituted, the number of targeted incentives that would be necessary to substantially increase the use of agricultural prunings and in-forest residues would be modest. The above-market costs of agricultural residue fuels derived from prunings will require targeted support in the amount of approximately $\$ 5-\$ 10 /$ bdt to be competitive with other biomass fuel sources. For 
example, an appropriation of \$2.5 million annually for converting orchard prunings to fuel, against the background of a comprehensive cost-shifting program for biomass energy production, would promote the use of an additional 500,000 tons of agricultural residue fuels, which would significantly reduce the amount of agricultural burning in California.

The need for improved forest management is widely recognized, but funds to carry out meaningful programs are difficult to come by. Assuming a comprehensive cost-shifting program, in-forest residues will require targeted cost shifting of approximately $\$ 10$ $\$ 15 /$ bdt to be competitive with other biomass sources. Appropriation of $\$ 10$ million annually for thinning overstocked forestlands would promote the use of an additional 1.3 million tons of in-forest residue fuels. This would represent the treatment of an additional 75,000-100,000 acres/year of forestland that is not currently being treated for wildfire hazard reduction and watershed improvement. 


\section{Conclusion}

The biomass energy industry in California reached its peak level of production during the early 1990s, and has since declined by more than one-third. This decline has a variety of causes, but the underlying reality is that biomass energy is expensive to produce compared with the lowest cost alternatives available on the grid. The high cost of biomass energy production, an inevitable result of the small facilities and the high cost of collecting and transporting low-density residue materials, is a considerable liability in a marketplace that is being deregulated and that increasingly emphasizes cost. As a result, unless biomass energy generators are compensated for the environmental benefits they provide, the viability of the enterprise is in serious doubt.

Any further decline in biomass energy production in California, whether caused by facility closures or cutbacks, leads directly to a loss in the environmental and social benefits provided by the industry. As this report demonstrates, based on a conservative set of assumptions the value for the quantifiable benefits of biomass energy production is $10.7 \phi / \mathrm{kWh}$ of electricity produced from biomass. The social benefits not included in the computation are also significant, and add to the total societal value. These are very impressive numbers, much higher than the current market value of the energy, which is currently in the neighborhood of $3 \phi-4 \phi / \mathrm{kWh}$ for bulk power through the California Power Exchange. Even using minimal values for all quantifiable impacts, and ignoring the nonquantifiable ones, the benefits of biomass energy production $(5.8 \mathrm{c} / \mathrm{kWh})$ are higher than the level of support necessary to preserve the enterprise. The expected societal return on support for biomass energy production is a multiplicative factor of more than 7 .

Three scenarios are presented in this report for the future of biomass energy production in California, based on the future level of public policy support provided. The business as usual scenario assumes support roughly equivalent to the level provided by the RTF program over the past couple of years. The strong incentive scenario assumes support sufficient to allow currently mothballed facilities to restart and operate. The no incentive scenario assumes that the RTF program expires at the end of 2001, and no new biomass energy policy is enacted. Figure 13 shows projections of biomass energy production in California based on the three scenarios.

Loss of a significant fraction of the present level of biomass energy production in California would present serious social and environmental consequences. Almost 3 million tons/year of residues currently used as fuel would be added to the burden of material entering sanitary landfills, making compliance with AB 939 virtually impossible for many counties. Moreover, burying this material will burden the country with future greenhouse gas emissions that will not be avoidable when the Kyoto greenhouse gas emissions reductions must be achieved in 2012. 
Figure 13

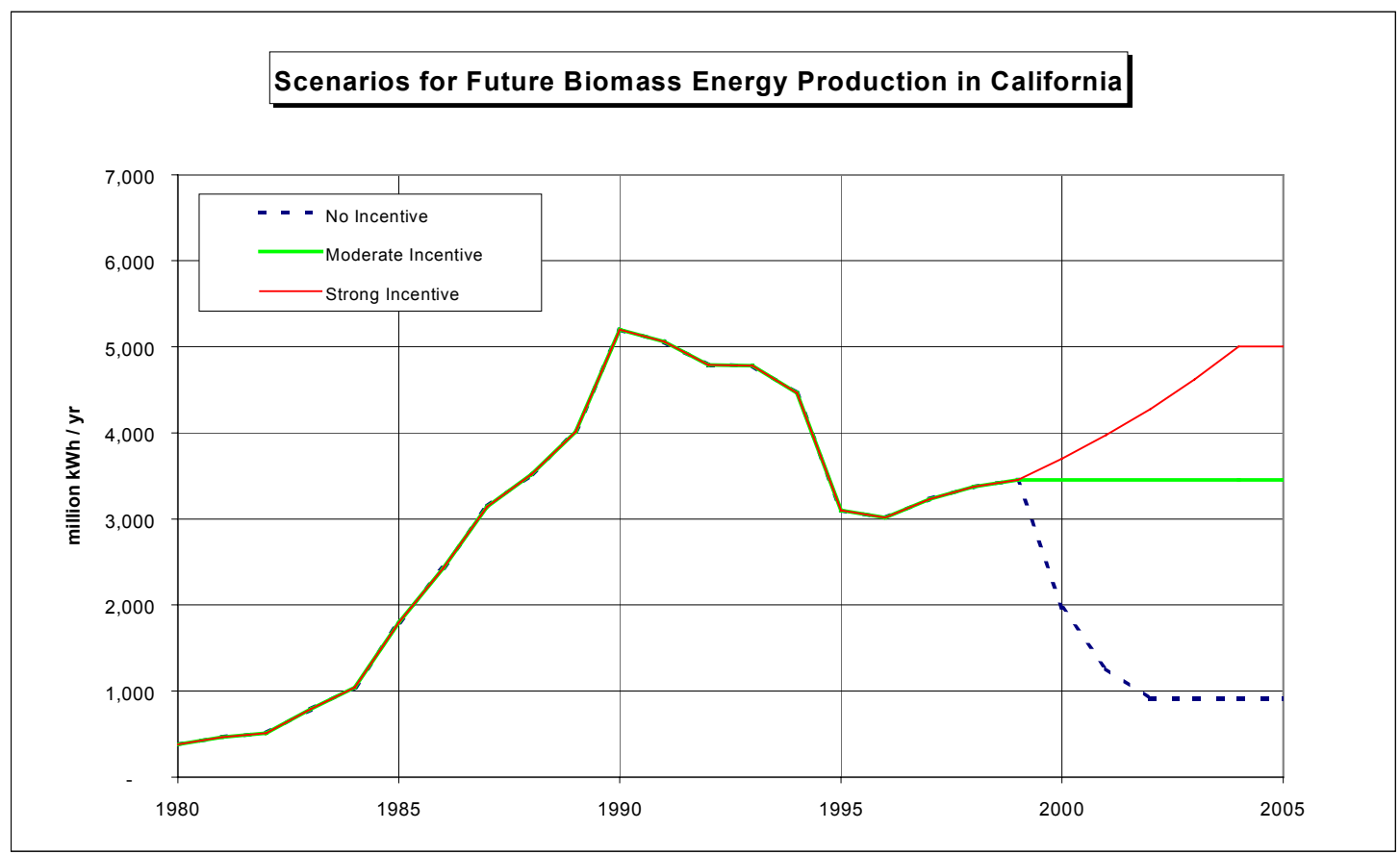

Disappearance of the industry would mean that more than 1.75 million tons of residues currently being used as fuels will return to open burning piles, where they will add measurably to the air pollution problems in agricultural and forested regions, many of which are already out of compliance with state and federal air-quality standards. Moreover, an additional 500,000 tons/year of residues will be allowed to accumulate in overstocked or otherwise unhealthy forests and watersheds. These residues will exacerbate the risks of destructive wildfires and ecosystem degradation that plague California's forests, and depress the productivity of many key watersheds.

The loss of the biomass energy industry would represent a loss of almost 3,000 rural employment positions, with serious negative impacts. Many rural communities would also lose their largest source of property taxes, and would suffer other economic multiplier effects as well. Energy diversity and security values would be lost.

The loss of the California biomass energy industry would exacerbate a number of important environmental problems, and leave affected rural regions with virtually irreplaceable losses of quality employment opportunities and tax base. In fact, increasing the capacity utilization of the infrastructure and encouraging the development of new biomass installations using ever-advancing technology, should be important goals of state and federal policy. The ancillary benefits of biomass energy production are worth far more than the above-market costs of operations. A modest level of compensation for these benefits will achieve a several-fold return in social and environmental benefits. The 
California experience with providing of biomass production credits $1.5 \phi / \mathrm{kWh}$ demonstrates that this level of support can stabilize and increased the use of facilities. A higher level of support would be needed to encourage idle facilities to reopen, or the development of new biomass energy production capacity.

The California biomass energy industry provides a valuable, environmentally preferred waste disposal service for more than 6.4 million tons of the annual solid-waste stream. These services have been provided without compensation, as the electricity market was able to underwrite them fully. They will be lost to competitive electric market unless means are developed to compensate generators for their environmental services. This is the focus of the proposed biomass support policies discussed in this report.

The study identifies a need for compensating biomass energy generators approximately $1.2 \phi-2.4 \phi / \mathrm{kWh}$ for their environmental services, to allow them to thrive in the competitive power market. This roughly corresponds to the fuel cost contribution of power generation from biomass, and is much less than the value of the environmental services that are retained. The special environmental benefits of biomass energy generation are directly related to the use of the fuel, so the rationale for providing public policy support for biomass energy production commensurate with its provision of waste disposal services is sound and reasonable.

Eight policy measures are analyzed in this study. Two of the proposed measures, creation of a production or tax credit for biomass energy generation, and establishment of a minimum purchase requirement for electricity generated from biomass, would apply to all forms of biomass energy generation, and would provide the foundation for preserving the industry. A production or tax credit could be provided at either the federal level, by modifying $\S 45$ of the IRS code to make it applicable to all power generated from biomass fuels, or at the state level, by extending the public purpose charges used to fund the RTF program. Efforts are under way to achieve both objectives.

The remaining cost-shifting measures promote the use of particular types of biomass fuels to reach specific environmental objectives. Two low-cost measures promote the diversion of urban waste wood to fuel applications, to promote year 2000 compliance with the diversion requirements of AB 939, the state's solid waste diversion law. Other targeted measures are aimed at increasing the use of agricultural prunings and in-forest biomass as fuels. Open burning of agricultural residues is a major source of air pollution in agricultural basins, and overstocking of forest biomass is a major threat to the health and wildfire susceptibility of forests. Increasing the use of these residues as biomass fuel, however, will be fairly expensive, although a great deal cheaper than the environmental losses currently being incurred.

The total cost of support to maintain biomass energy production in California at its present level of activity is approximately $\$ 50$ million/year, based on conditions that are expected at the beginning of 2002, the end of the transition period to full competition and the end of the RTF program. Most of the required amount could be provided by 
modifying the federal renewable energy tax credit, or extending public purpose funding for renewables in California beyond the end of the transition period. The remainder could be provided by targeted policy measures, such as appropriations of funds for wildfire risk reduction activities on state and federal forestlands, and for diverting agricultural prunings from open burning to energy production. Expanding the use of particular forms of residues through targeted policy measures will be well worth the cost in terms of the value of the benefits produced. 
Biomass Energy Production in California: The Case for a Biomass Policy Initiative

\section{References}

California Air Resources Board, A Procedure to Implement the Provisions of Health and Safety Code Section 41605.5 (AB 1223, 1983) Relating to the Determination of Agricultural/Forestry Emission Offset Credits, Report of the Stationary Source Division, Sacramento, CA, June 21, 1984.

California Biomass Energy Alliance (CBEA), Biomass Energy in California: Valuation of External Benefits, Report prepared for the California Environmental Protection Agency, December 2, 1996.

California Department of Forestry, California Fire Plan: A Framework for Minimizing Costs and Losses from Wildland Fires, Sacramento, CA, March 1996.

California Environmental Protection Agency, Report on AB 1890, Cost Shifting Strategies for the Benefits Attributable to the Solid Fuel Biomass Industry, Agency Report Submitted to the Legislature, Sacramento, CA, April 1997.

California Environmental Protection Agency, Air Resources Board, Proposed Amendments to California's Agricultural Burning Guidelines, Staff Report, Billington, J., and Ommering, L., Principal Authors, Sacramento, CA, February 2000.

California Integrated Waste Management Board, data available on the Internet at URL: http://www.ciwmb.ca.gov/EconForecast/, 1998.

California Integrated Waste Management Board, data available on the Internet at URL: http://www.ciwmb.ca.gov/Landfills/LFData.htm, 2000.

California Public Utilities Commission, Proposed Policy Decision Adopting a Preferred Industry Structure, Order Instituting Rulemaking/Order Instituting Investigation on the Commission's Proposed Policies Governing Restructuring California's Electric Services Industry and Reforming Regulation, OIR.94-04-031 / OII.94-04-032, San Francisco, CA, April 20, 1994 (the "Blue Book" Proposal).

Darley, E., Hydrocarbon Characterization of Agricultural Waste Burning, Cal/ARB Project A7-068-30, University of California, Riverside, April 1979.

Davis, C.; Huffaker, B.; and Tutt, T., Policy Report on AB 1890 Renewables Funding, Report to the Legislature, California Energy Commission Report no. P500-97-002, March 1977.

Greenhouse Gas Emissions from Management of Selected Materials in Municipal Solid Waste, U.S.EPA Report No. EPA530-R-38-013, September, 1998. 
Biomass Energy Production in California: The Case for a Biomass Policy Initiative

Jolley, S. and Carlson, W., Prescribed Fire Alone vs. Mechanized Pre-Fire Treatments: A Case for Considering All the Tools, Report by Wheelabrator Environmental Systems, Spring, 1999.

Intergovernmental Panel on Climate Change (IPCC), Climate Change 1995, Houghton et al., eds. Cambridge University Press, 1996.

Micales, J. \& Skog, K. The Decomposition of Forest Products in Landfills, International Biodeterioration and Biodegradation, V. 39, no. 2-3, 1996.

Morris, G., Fuel Use and Other Characteristics of Biomass Power Plants in the U.S. and Canada, FRA report to Hydro-Québec Ltd., December 1994.

Morris, G.; Wiser, R.; and Pickle, S. eds, Renewables Working Group Report to the CPUC, Published by the California Energy Commission, Report No. 500-96-008, August 1996.

Morris, G. The Environmental Costs and Benefits of Biomass Energy Use in California, NREL Report No. NREL/SR-430-22765, National Renewable Energy Laboratory, Golden Colorado, May 1997.

Morris, G. The Implications of Deregulation for Biomass and Renewable Energy in California, NREL report No. NREL/SR-570-24851, Golden Colorado, revised, August 1998 a.

Morris, Gregory, White Paper: The Economic Implications of Energy Production from Forest Residuals, Report of the Green Power Institute/Pacific Institute for Studies in Development, Environment, and Security, October 1998 b.

News of the Week, "Global Warming: Draft Report Affirms Human Influence", Science Magazine, vol. 288, page 589-590, April 28, 2000.

SCS Engineers, in conjunction with Donald Augenstein, Institute for Environmental Management, Comparison of Models for Predicting Landfill Methane Recovery, Report to the Solid Waste Association of North America, File No. 0295028, March 1997.

U.S. Environmental Protection Agency, Compilation of Air Pollutant Emissions Factors, Fifth Edition, Volume I: Stationary Point and Area Sources, EPA Report No. AP-42, Washington, D.C., 1995, plus updated supplements. 


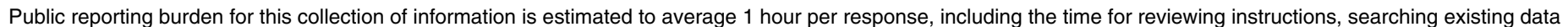

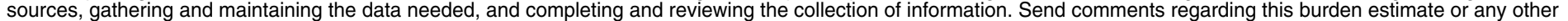

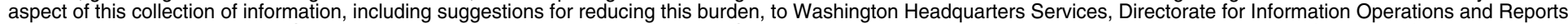

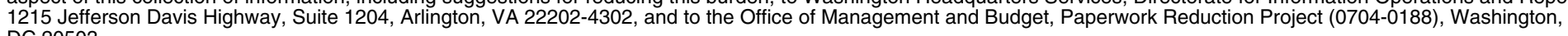
DC 20503

\begin{tabular}{l|l|l} 
1. AGENCY USE ONLY (Leave blank) & $\begin{array}{l}\text { 2. REPORT DATE } \\
\text { November } 2000\end{array}$ & $\begin{array}{l}\text { 3. REPORT TYPE AND DATES COVERED } \\
\text { Subcontract Report }\end{array}$ \\
\hline
\end{tabular}

\section{TITLE AND SUBTITLE}

Boimass Energy Production in California: The Case for a Biomass Policy Initiative

5. FUNDING NUMBERS
T: BP011010
C: AXE-9-18132

6. AUTHOR(S)

G. Morris

7. PERFORMING ORGANIZATION NAME(S) AND ADDRESS(ES)

Green Power Institute

2039 Shattuck Ave., Suite 402

Berkeley, CA 94704

(510) 644-2700

9. SPONSORING/MONITORING AGENCY NAME(S) AND ADDRESS(ES)

10. SPONSORING/MONITORING AGENCY REPORT NUMBER

National Renewable Energy Laboratory

1617 Cole Boulevard

Golden, CO 80401-3393

8. PERFORMING ORGANIZATION REPORT NUMBER

\section{SUPPLEMENTARY NOTES}

NREL Technical Monitor: Richard Bain

12a. DISTRIBUTION/AVAILABILITY STATEMENT

12b. DISTRIBUTION CODE

National Technical Information Service

U.S. Department of Commerce

5285 Port Royal Road

Springfield, VA 22161

13. ABSTRACT (Maximum 200 words) During the 1980s California developed the largest and most divers biomass energy industry in the world. Biomass energy production has become an important component of the state's environmental infrastructure, diverting solid wastes from open burning and disposal in landfills to a beneficial use application.

14. SUBJECT TERMS

15. NUMBER OF PAGES

biomass, biomass energy, biomass policy, California, open burning, landfills, electricity

16. PRICE CODE

17. SECURITY CLASSIFICATION
OF REPORT
UL

18. SECURITY CLASSIFICATION
OF THIS PAGE
UL
UL

19. SECURITY CLASSIFICATION
OF ABSTRACT
UL

20. LIMITATION OF ABSTRACT

Unclassified 